\title{
IMPERIAL
}

\section{MTELEGRAPHIC COMMUNICATION}
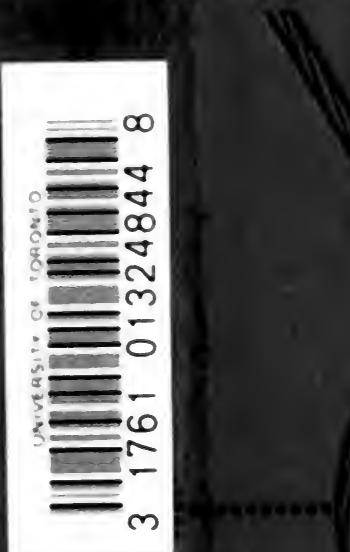

\section{CHARLES BRIGHT}

$$
F \cdot R \cdot S \cdot E
$$



Digitized by the Internet Archive in 2007 with funding from Microsoft Corporation 



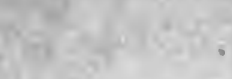

(a)

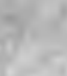

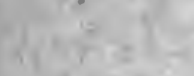

$3(x+20$

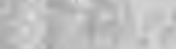

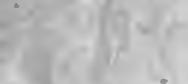

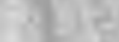

$44^{2}$

$\frac{17}{1}=$

(12) 18

4.

$-3+\frac{1}{4}+3$

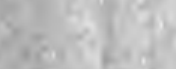

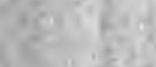

$x^{-2}+2=2$

$x^{n}+2+2$

$\frac{1}{8}$

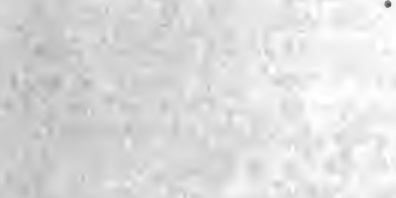

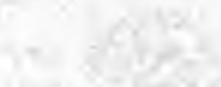

$x^{2}+(x+2=0$

(97)

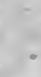



One Volame, Swper-royal octavo, mearly 800 fages, wabh atous joo Illustrations, Mafs, and Disgrams, (3 3s. mes.

\section{Submarine Telegraphs}

\section{Their History, Construction and Working}

\section{Together with an Appendix on "Wireless" Telegraphy}

Compiled from Authorities and Exciusive Sources

BY

\section{CHARLES BRIGHT, F.R.S.E.,}

M.I*st.C.E., M.I.Mrсu.E., M.L.E.E.

\section{EXTRACTS FROM NOTICES OF THE PRESS.}

"Upon bis task Mr. Brigbt bas bestowed untiring pains. Witb an inborn love of tho subject be has recorded every minutest detail of information connected with the design, construction, laying and fallure of the fint Channel and Atlantic Cables, and has throughout the work traced with rare impartiality the impress of Wheatstooc. Morse, Siemens, Lord Kelvin, Sir Charles Bright, and the bost of great minds, upon the $\mathrm{s}$ al evolution of modern telegraphy." - The Times.

" Mr. Bright bas a good right to deal with this subject. . He bas recorded the

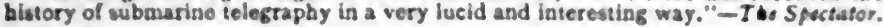

"The autbor deals witb bis subject from all polnts of view-political and strategieal as well as scientific. The work will be of interest, not only to men of selence, but to tbe general public. Wo can strongly recommend it." - The Athenarw.

"This book is full of information. It makes a book of reference which should be In every engineer's library. Mr. Bright has exceuted bis task in an impartial and disinterested way, and he has marsballed bis facts with much clearness." - Viafure.

"There are few, if any, persons more ftted to writo a treasise on submarine telegraphy than Mr. Charles Bright. The author has done his work admirably, and has written in a way which will appeal as much to the layman as to the engineer. - This admirable volume must, for many years to come, hold tbe position of tbe Finglish classie on submarise telegraply. It is crowded witb uscful information." The Engineer.

"Mr. Bright's interestingly written and admirably llustrated book will meet with a welcome reception from cable men." - The Elaclribian. I

\section{LONDON: CROSBY LOCKWOOD \& SON,}

\section{STATIONERS' HALL COURT, LUDGATE HILL.}




\section{Science and Engineering During the Victorian Era}

\section{CHARLES BRIGHT, F.R.S.E., M.INST.C.E.}

"This interesting little pamphlet is a reprint of an introduction which Mr. Bright wrote for the Victorian Era Exhibition last year."Nature.

"Mr. Bright has written an admirable pamphlet... He has managed to put into the compass of twenty-four pages a very clear conspectus of the features of scientific engineering progress during the Victorian Era."-Newcastle Chronicle.

- This very interesting lecture by Mr. Charles Bright summarises results which he believes to be as characteristic of the Victorian Era as the burst of learning and literature was of the Elizabethan." Yorkshire Pos?.

- Mr. Bright takes a rapid survey of the ground which has been covered in the region of scientific discovery and invention during the Victorian Era. His reminders on the subject though brief are very suggestive." - Sydncy Evcning Ncr's.

- Une brochure fort in téressante, et très pleine de faits . . . cette histoire est tres nourrie, et il est bon de la parcourir pour se rendre un compte exact des conquetes industrielles qu'a faites notre époque." La Revue Scientifigue.

LONDON: CONSTABLE AND COMPANY, LID. to Orange Street, W.C. 


\section{The Story of the Atlantic Cable}

DY

\section{CHARLES BRIGHT, F.R.S.E.,}

SL.I $=5$. C.R. M.I.E.E.

\section{OPINIONS OF THE PRESS.}

"The aubor is well known not only as tho bistorlan of submartse telegrapby. bot also as one of the leading authorities who have belped to make the bletory wblch be co luetdly records." - The Times.

"Tbo book is good reading throughout, the enormous diffecultics alterdans on tbe work in early days tetng graphically describod." - Morning Pous.

"Mr. Cbarles Bright, P.R.S.K. In itis brightly-writieg fitule volume, re-telle the thrilting sory which sbows what cas bo dove by enterprising routb. "-Datiy Tolograph.

"X romance of selence iruly; and nope can be better qualtied to tell it thas the aetbor of tbis fascinating book." - The Sfandard.

"The story was worth re-telling and Mr. Charles Brigbt was the tran 10 re-tell it. as bo is bimielf an electrician who bas spectalised in tbe laying of subenarise cables." - Dasiy Graphic.

- Mr. Cbarles Brighe bas treated bis oubject in a populas and attractive roannet, avolding technical Languago as far as possible." - Daiby Lavl.

"The author, wbo is commonly regarded as the historlan of submarine telegraphy. bas bere given the narrative of a great achievement in a strikingly interesting manser. The man wbo ultimately achleved the laying of the cable was the late Sis Charles Tilston Brigbt-latber to the autbor-at the age of tweaty.six, whereupon be became the roungest knigbt on record." - Daily Chromisle.

" I t is a useful memento of the ditticulties attending a great enterprisc and of the faltb and perseverance wbich eventually surmounted them after a series of beart. breaking lailures. A truly wonderful story."-Pall Nall Gaselse.

"The story is well told, and Dot mercly to people of seientise pursults will tbis record of momentous acbicversents appeal. Afl who admire cournge, perseverabee, patience and fertility of resource will be entbralled. No romance could escite the cunotions or call up more entbusiasm than the book before us. "-Si. James's Gaseste.

- Mr. Bright tells the story in a manner that brings bome to us the beroism of the projecton of a piotseer work. The account of this unrivalled enterprive is worthily represented in ibls listle book and sbould inspire wany a young wind 10 overeome obrucles in the way of dolag things." - The Spectater.

"The suory of the laying of the early Atlantic cables is one of veritable romance. It is told bere with skill and sympatby." - Safurday Roviow.

- Mr. Charles Bright ls by bereditary right and scientife sttainuneat an escellent autbority on the story of the Atlantic cable, so we welcome bis tinte book, wbicb tella well tbe wooderful persistence and enterprise which led to an fauportast tactor in world-connections."-Tha Athonawn.

"This litile work is erammed with information most clearly set our, and bas in parts all tho entbralment of a rotnance. "- The A rademy.

"The uory is extremoly well told by Charles Brigbi and reads like romasce." The World.

- This is a well-written and popular account of a great work $n$ bich provides all the elements of real romance-the sirugple in the face of unending ditheulties and disappoistments, tho failures when within an ineb of success, tbe dramatic tricuspb is sbe end."-Truth.

"Tbis little volume is excellens in every respect."-ilature.

"For the manner in which the thousand and one difsculties in this sreat uxder. taking were surmounted, we warnily commend our readers to Mr. Brigbt's toteresting and accurate pages."- Emginecrimg.

"The narrative is one of inrense interest, and is moulded into an agreeable form. It is well wortby of perusal by those who wish to pass a few bocrs is readisg of the beroic deeds of our corerunners "-Elestrical Roviotw. 


\section{The Life Story of \\ Sir Charles Tilston Bright}

\section{SOME PRESS NOTICES OF THE ORIGINAL EDITION.}

" Will be generally welcomed as a worthy and needed memorial of one of the foremost figures of a superlatively great period of enginecring progress. "- The Times.

"Prescnts the carcer of a famous Englishman witb all the charm of simplicity and cntbusiasm." -Morwing Post.

"These volumes, whilst dealing with some of the most notable of Viotorian performances in science, will serve to keep alive the memory of a truly distinguished man." - The Globe.

"Not only of interest to the general reader, but of value to the profession of which Sir Charles Bright was one of the chief pioneers." - Westminster Gasette.

"Sir Charles Bright's life, though not long, was so full of great achievements and interesting adventure that it well deserved a careful-cven minute-record." Manchester Guardian.

"These two volumes are the story writ large, but not too large."-The Spectator.

" Though dying at the early age of fifty.six, be really 'fulfilled a long time, if we reckon by the amount of his professional and scientific work of world-wide importance." - Saturday Review.

"The book is a monumental tribute to the memory of a man who must have inspired his companions with strong aftection and admiration. The book is fully illustrated, and maps, plans, sections, portraits, and otber illustrations greatly enbance its value." - The Athenaum.

"Sir Charles Bright was truly a wonderful man, and it is well that the facts of his carecr sbould be published. It makes us proud of our race to read again the story of bis carly life."-Enginering.

" Sir Charles, with his extremely keen, alert, and agile mind, full of expedient'and resource, his thorough workmanship in every detail and his restless energy, was marked out for a telegraph engineer, though he might equally bave distinguished bimself in any other line." -The Engineer.

"A futting uncmorial of one of the earlicst, most popular and most eminent of electrical pioncers." - The Electrician.

"The book is a very buman document. It is at once a book of travel and'adven. ture, a record of active and earnest achievement, a history of the youth of a mighty scientific industry, and a mine of information on the technical features of early elcetrical enginecring. Every electrical enginect who has difficultics to overcome hitmself will find encouragement and suggestion in reading how Bright overcatne his. The book is illustrated with illustrations that really illustrate-sketches of cable operations, machinery, etc. - while every telegraph man will find bere a record of both the human and the scicntific sides of land and telegraphy that will do his heart and his brain good to read. "- Electric World and Engineer (Neto York).

LONDON: CONSTABLE AND COMPANY, LID. to Orange Street, W.C. 


\title{
The Locomotion Problem
}

DY

\author{
CHARLES BRIGHT, F.R.S.E., \\ M.Iพระ.C.K., M.1.R.E. \\ Author of "Swbmarine Tolographs." "The Life of \\ Sir Charles Bright," "The Story of the Allandte \\ Cabse." "Science and Enginesring during \\ the Vistorian Era," and "Ionferial \\ Proferential Policy.
}

\section{PRESS OPINIONS.}

"This litsle book coneains a great deal of information, and the whole forms a very interesting discussion of one of the most importans of present day subjects."The Times.

" Mir. Charles Bright's litelo volume may profirably bo read by any one interestod in this topiomand who nowadays is not?"-Duiby Telegraph.

"Mr. Bright has conviderable acquaintance with the subject in lis various aspects. and the reader will find most of its reore important questions fully and ably dwo cussed." - Norwing Past.

"Mr. Charles Bright. F.R.S.E., consider in an Ioteresting brochwre. 'The Loco. morlon Problem. the new cireurnstances that have arisen from the krowing vorue of the petroleum and electrieally propelled vebicle and their probable econoanic etects." - The Siandarid.

- Here we have an examination extremely interesting at the present time wea the congested inase of London is the subject of many theories and many reanedien, and Mr. Bright considers the questlons involved wilh the knowledge of an expert rather thas a thoorist." - Datly Masl.

"Though the Motor Car Act bas since been in active operation, and tbough progress has alnoe been made in the practical realieation of public automobiles and tube rallways. there is no change in tbe general situation such as vould render tbese lectures out of date at the present time." - The Observer.

- Mr. Charles Bright, F.R.S.E. is peculiarly qualised by iraining, knowledge of atairs and patural bent, to review the locomotion question in the broad light of the country at large, and this little volume will be found pregnaut witb ldeas and eminently practical." - Sunday Times.

"Mr. Bright surveys the whole feld and shows bimself superior to projudice: but at the same time the does not strink from advocacy of what be believes in best, and also likeliest, to occur. As a sportsman-being a member of the Leander Club, stull keeping wicket for the SI.C.C., and formerly a metriber of the Commitree of the All England Lawn Tennls Club-be can clairn to look at sucb things as the motor question in a sporting spirit, and, therefore, with consideration for his fellow-beling. and for dumb animala. - The Sportsman.

- Nr. Bright deals in a judiclal and unblasend spirts with all the main argursers recandlag the motor question, und also relative to motor buses $t$. tratswars, as well as largely in relation to tubes, whilst treating bis subject in a retnarkably luels manner." - Sporting Life.

"Mr. Bright bas glven us here a seasonable little volume condsting of lecture: delivered belore the Motor Car Act came into operation. "-The Spectabor.

"There are directness and force in all Str. Bright's lecturet-whether tbey be an telegraphs, or on suct a question as is contalibed in tbe volume before as-retieb renders them especially valuable." -Safwrilay Roview.

[Ser Over.]

\section{P. S. KING \& SON, ORCHARD HOUSE, WESTMINSTER.}




\section{PRESS OPINIONS-(continued).}

"The locomotion problem is the subject of Mrr Bright's latest work. The subject is treated in his usual lucid manner, and those interested in this much.vexed question could not do better than consult its pages if they wish to arrive at a fair viers." - The Onilook.

"Mr. Charles Bright's republished lectures contain much useful information regarding the subject they ireat of." - Trwth.

"A thoroughly able, impartial. and comprehensive study of one of the most important questions of the day will be found in these throe excellent lectures by the distinguished engineer, Mr. Charles Bright."-The W'orld.

"This little book, by Mr. Charies Bright, is one which overy one interested in the great traftic question should read. It deals with the subject clearly, concisely, and exhaustively, and is the most valuable contribution to the motor-car controversy we bave set had."-The Field.

"This is a most timely publication from the pen of Mr. Charles Bright, F.R.S.E. Whencerer Mr. Brigbt touches a subject that comes within bis province-and we should be loth to attempt to assign a limit to his province-be leaves but little of importance for any one else to say. Without being tedious, he gives a multipliclty of detall, and yet all the time keeps the broad features of his topic well in view. The writer wbo ean do this is in a fair way for being wortby of the diploma absolute of autborship: and we lmagine it would be hard to find any one who has this skill in greater fulness than Mr. Charles Bright." -The Referce.

"Mr. Charies Bright bere discusses the menace of the motor in a fair and temperate spirit which should give satisfaction to both sides in the controversy." - The Scotsman.

"The writer is an expert in the subject and we have here many shrewd and sensible comments." - Birmingham Daily Post.

"Mr. Charles Bright has many good things to say on the motor and all the questions that surround it." - Western Mail.

"No one who takes an intercst in the all-inportant question of road traction can aftord to lose the advantage of reading anything that an expert like Mr. Bright has to say on such a subject." - Liverpool Journal of Commerce.

"In dealing with tramways, Mr. Bright enters a useful protest against the piecemeal method which municipal pottering bas imposed upon inter-urban tramway develop. ment. There are many other matters-such as railway and tramway competition and the relation between iraffic facilities and the bousing problem-with which Mr. Bright deals in a very suggestive way. Any one in search of a useful and simple survey of a complicated problem will find this little volume appropriate to his purpose." - Electrical Industries.

"Mr. Bright maintains that rapid locomotion, though excellent in its way as a temporary palilative for present diffculties, tends as much towards centralization as towards decentralization. He is of opinion that the real solution will be found in industrial redistribution and in the establishment of garden citles." - Railway News.

"A most useful and interesting book is constituted by Mr. Charles Bright's reprinted lectures on the question of road locomotion." - The Car.

"The lectures are admirably written and contain much information relative to the traffic problem." - Motoring Ilustrated.

"Mr. Bright points out that a large proportion of the ill-feeling towards motorists is engendered by men who have never owned or driven a horse themselves, or who entragt the driving of their cars to persons who bave had no experience of imftic. Anotber matter on which Mr. Bright touches is the increasing inepticude of looul authoritles which, instead of dealing with subjects under purview in a reasonable way, are degenerating into societles for the Perpetual Discussion of Trites." - Motor Car Journal.

"There is bere-as might bo expected in view of the authorship-an admixture of humour and solid sense that renders Mr. Bright's lectures decidediy attractive reading. "-A wtomobile Club Journal.

\section{P. S. KING \& SON,}

\section{ORCHARD HOUSE, WESTMINSTER.}




\section{King's Publications on Topics of To-day.}

\section{OAPTURE IN WAR ON LAND AND SEA.}

By Dr. Haxs Wrubrza, of the University of Bonn. Translated from the German into English. With a Preface by Јонм M. Ronzrson, M.P. Demy 8vo. Cloch. 5s, net. (Inland Postagl 3d.)

Mr. Robertion. In his Prelace, speclally deals with the Dochuration of London and Naval Prize Blll.

Coxrzxrs,-Introduction-Historleal Review: Pirct Principles of Lav and Prize on Sea and Land-National Property-Rallweys, etc.-Private Property-Time and Place of Selsure-Object of Selzure-Biringles 10 end Seareb-Reasoas for Retention of the Law-Reacoas for Abolition of the Law-Indirvet Rffects of the Law upon Neutral-Direct Rfeets of the Law upon Neuirale-England and the Law of Prlze at Sea, particularly is Cocr. parison with Germany-Sucgeatlons for Reform-Bibllogrepby-Indea.

\section{BRITISH RIGHTS AT BEA UNDER}

\section{THE DECLARATION OF LONDON.}

By F. E. Bray. Crown 8vo. 1s. net. (Inland Postage sd.)

Coxrzxrs. - Preface-The Origin of the Declaration-Some Principlen of Criticism-Blockade-Coneraband of Was-Unneutral Service-Destruc. tion of Neutral Prizes-Transfer of a Neutral Flak-Enomy CbaraciezConvoy-Resistance to Search-Compencutlon-Parllamentary and Final Provisons-Appondix.

Times: . . very timely and careful staterzent of the case for the Doclaration. . . Mr. Bray has done much to render it easy of comprebea. sioa. ... We are not concerned to endorie all bls arkutrents, but we are bound to say thas they deserve and should receive attentive and dispasaionate consideration..." be 18," be says, "actuated largely by tbe fear leve a question which should essentlally be viewed from a non.party polas of view stoould bo used througb any misapprebenston as a political weapon by the party 10 which bo beloags."

\section{THE ASSURANCE COMPANIES ACT, 1908.}

With the Rules and Orders made thereunder by the Board of Trade. With Notes, and an Addenda containing the Companies (Converted Societies) Act, :9:0). By Macricz Hawtrzy Truz. Lovr, of the Inaer Temple, Barrister-at.Law. Demy 8v0. 5s. net. (Inland Postage 4 d.)

\section{UNEMPLOYMENT INSURANCE.}

A Study of Schemes of Assisted Insurance. A Record of Research in the Department of Sociology in the University of London. By I. G. Gibson. With a Preface by L. T. Hовнотse. Dermy 8ro. Cloth. 6s. net. (Inland Postage 4d.)

\section{HISTORY OF FACTORY LEGISLATION.}

By B. L. Hotchins and A. Harrison (Mrs. F. H. Spencer). D.Sc. (Econ.). With a Preface by Sıdney Wers, LL.B. Second, Revised Edition, with a New Chapter. Derny 8vo. Clotb. 6s. net. (Inland Postage 4 d.)

$$
\text { P. S. KING \& SON, }
$$
ORCHARD HOUSE, WESTMINSTER. 


\section{King's Publications on Topics of To-day.}

\section{THE NEW SOCIAL DEMOCRACY.}

A Study for the Times. By J. H. HARLEY, M.A., Late Scholar of Mansfield College. Oxford. Vice.President of the National Union of Journalists. Demy 8vo. Cloth. 6s. net. (Inland Postage $4 d$.)

Conrzwrs. - The Question stated-Can Socicty bo Transformed?-A Forecast in 1908 - The Situation in 1910 - Anatole France as a SocialistProudhon and the Labour Movement-The Collapse of Collectivism-Tbe Rights of Reason-Review and Conclusion.

\section{THE CRISIS OF LIBERALISM:}

\section{NEW ISSUES OF DEMOCRACY.}

By J. A. HoBsos, author of "The Evolution of Modern Capitalism," "The Industrial System," \&c. This volume contains a LIBERAL plea for the REFERENDCM. Demy 8vo. Cloth. 6s. net. (Inlard Postage $4 d$.)

\section{THE PROVINCE OF THE STATE.}

By Sir Roland K. Wilson, Bart., Author of " A Short History of Modern English Law," etc. Demy Svo, Cloth. 7s. 6d. net. (Inland Postage 4d.) (In the Press.)

\section{LEGAL POSITION OF TRADE UNIONS.}

By Henry Herman Schlorsser, of the Inner Temple, Barrister. at-Law; Lecturer on Public Administration at the London School of Economics; and W. Smith Clark, M.A., LL.B., of the Inner Temple. Barrister-at-Law. Demy 8vo. Cloth. 7s. 6d. net. (Inland Postage 4 d.) (In the Press.)

\section{PROBLEMS OF LOCAL GOVERNMENT.}

By G. Moniagu Harris, M.A., Barrister-at.Law; Secretary to the County Councils' Association of England and Wales. Demy 8vo. Cloth. 10s. 6d. net. (Inland Postage 5d.)

\section{THE ALIEN PROBLEM AND ITS REMEDY.}

By M. J. Lasda. Crown 8vo. Cloth. 5s. net. (Inland Postage 4d.) (In the Press.)

P. S. KING \& SON, ORCHARD HOUSE, WESTMINSTER. 
IMPERIAL TELEGRAPHIC COMMUNICATION 



\section{IL TELEgRAPHIC}

\section{CommunicATION}

B.

CHARLES BRIGHT, F.R.S.E. ni

M.IssT.C.E., M.I.E.E.

ALTHOR OP "SLENARIXE TELEORAPMS: THE? HSTOMY, COYIRtCTION AND WORKIKO," ETC., ETC.

\section{P. S. KING \& SON}

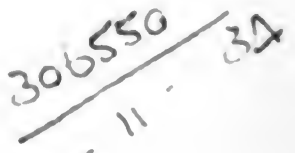

ORCHARD HOUSE, WESTMINSTER 

to

ase taife 



\section{PREFACE.}

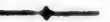

THE following pages are, in the main, constituted by reproductions of certain papers, addresses, and articles contributed, at different periods, to the British Association for the Advancement of Science, the London Chamber of Commerce, the Quarterly Review, the Fortnightly Review, the Monthly Review, and the Westminster Review, together with my paper only lately read to the Royal Colonial Institute. These various contributions may, perhaps, be said to form something like a history of the movement for extended and cheaper Imperial Telegraphy, whilst also revealing how little has been really done towards the realisation of reforms which have for a considerable time been under official consideration. Bearing in mind recent agitations, these pages also bring to light how projects and suggestions of a bygone period come to be perpetuated as something novel in years to come. 'My proposal of an all-round Imperial 
rate of IS. or under-in fact, the lowest figure that is found possible-and the reduction of rates for deferred (non-urgent) messages are notable examples. In this connection-as well as on other accountsthe reader is asked to observe the date of each essay.

Seeing that all footnotes in these pages are those made at the time of original publication, it may be well to add here certain remarks by way of putting the reader in possession of important applicable circumstances of subsequent date.

Firstly, in the article on "An All-British or Anglo-American Pacific Cable" reference is made (on p. I4) to the fact that the United States was actively considering the question of a trans-Pacific cable. Things move more quickly in that country than they do here. Hence-in a modified form to the Philippines-the said line was duly laid at the instance of the Commercial Pacific Cable Company in I902-3, almost simultaneously with the long-talked-of "AllBritish" cable.

Secondly, the Inter-Colonial Railway referred to (on p. 37) in my London Chamber of Commerce address is now the entire property of the Canadian Government.

Thirdly, the land line now serving the Pacific cable system does not pass through the State of Maine, as stated on the same page. 
Fourthly, the invention of the cable relay to which $I$ alluded in my London Chamber of Commerce address (p. 59) as being likely to be of considerable value for strategic (or other) lines, has lately been brought to a thoroughly practical stage, as indicated on p. 158 .

Fifthly, the British West African cable rates, though still high, have been substantially lowered since the delivery of the lastnamed address (Addendum, p. 74).

The existing state of things in cable tariffs generally is shown in the Appendix at the end of this volume. I had, at one time, thought of devoting a separate column to the distance by cable corresponding to each rate, with a view to serving as an approximate guide when comparing the tariff to different points. I came to the conclusion, however, that this might lead to misunderstanding, or its relevance be over-estimated - though cable distance (not, of course, distance overground) should, as things stand at present, be the main factor in determining a proper rate to a given spot.

Finally, the total length of cable at present operating at the sea bottom is some 260,000 nautical miles, rather than the figure given (p. 67) in the aforesaid address.

In view of the forthcoming Imperial Conference the republication of these addresses and papers in book form may, perhaps, T.C. 
serve a useful purpose-in conjunction with the Introduction summarising the present position, and the Telegraph Map at the end of the volume. The latter shews all the cables of the world, and the main land line connections, up to date. It also indicates, in red, certain proposed lines having a definite Imperial object.

I trust, in conclusion, that there is not more repetition in regard to the especially important points in these pages than can scarcely fail to be associated with a number of contributions, at disjointed intervals, on the same subject.

\section{CHARLES BRIGHT.}

Caxton House,

WESTMINSTER, S.W.,

May, I9I1. 


\section{CONTENTS.}

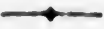

$\cos$

1. THE PACIFIC CABLE PROJECT . . . I

11. AN ALL-BRITISH OR ANGLO-AMERICAN PACIFIC CABLE

III. THE PACIFIC CABLE . . . . . 18

IV. IMPERIAL TELEGRAPHIC COMSUNICATION AND THE "ALL-BRITISH" PACIPIC CABLE • . . . . . 29

V. IMPERIAL TELEGRAPHS . . . 76

V. IMPERIAL CONSOLIDATION BY TELEGRAPHY 96 VII. IMPEKIAL TELEGRAPHY AT A POPULAR TARIFF . . . . . . 103

VIII. COMMUNICATION BY CABLE . . . I32

IX. IMPERIAL TELEGRAPHS . . . . I50

APPENDIX. EXISTING CABLE RATES * . . I95

INDEX . . . . . . . 209 



\section{INTRODUCTION.}

It may be safely averred that railways, steamships, and telegraphs are combinedly our most powerful weapon in the cause of Inter-Imperial Commerce. It has, however, yet to be realised how much can be done towards Imperial unity and fostering trade betwixt the scattered units of the Empire by direct, efficient and cheap telegraphic communication.

What has so far been achieved has been almost entirely due to private enterprise. The service is admittedly. good, but costly and, imperially speaking, incomplete. It is incomplete for want of various additional lines-mainly for strategic purposes-on fresh routes. The latter lines are such as commercial concerns are indisposed to undertake. The high tariffs are undoubtedly, to a great extent, due to the costly character of a cable. Apart from this, private companies naturally fix the charges for messages from a shareholders' point of view, rather than from the public standpoint. 
Whilst there is much to be said against the State encroaching on the recognised scope of private enterprise, no Government should be precluded from interfering with private enterprise where desirable in public interests, in contradistinction to the interests of shareholders. These interests are liable to be at variance where-owing to the magnitude of the undertaking or to other conditions of the enterprise-the public is deprived of the important safeguard of unrestricted competition. Indeed, where companies secure large subsidies they should surely not protest against Government control or even to the Government subsidising other systems, especially in cases where the said. companies are indisposed themselves to undertake the establishment of communication to a given point, whether desired for Imperial or strategic reasons.

So far, however, very few conditions have been made by the Government on behalf of the public when paying subsidies: the granting of landing rights has practically never been made an occasion for stipulations in the public interest. Quite recently the Western Union Telegraph Company of America applied for landing rights for two new Atlantic cables, one of which had already been laid in anticipation. It might well be thought that these rights would only have been granted under suitable restrictions 
in the interests of our country as a wholeespecially as the Board of 'Trade appear to have taken some five months to consider the matter. As an actual fact, however, no such conditions have been imposed.'

With the establishment of deferred rates (a reform which is still under consideration at the moment of writing), we shall have partially met the anomaly of there being nothing to choose between the mail to and from Australia-occupying altogether the best part of three months-and a cablegram at 35 . a word. This is the only recommendation of the Cable Communications Committee of I90I which has so far been in any sense acted upon.

Besides instigating the employment of the cable by those who have so far never used it, reduced rates would also effect wonders in the wider diffusement of Imperial news in a not too restricted form.

Whilst there can be little doubt that international cables are best left completely in the hands of private enterprise, and whilst the taking over of other existing cables by the State is only to be recommended in special (All-British) cases, there can be no gainsaying that the establishment of strategic lines

- The main section was completely laid on August 15th, 1910, and that between Newfoundland and New York on September 23rd, 1910, but on the above account the line was not open for public working till February 17 th, 1911 . 
comes within legitimate Government scope. They should, indeed, be but on the same footing with our navy and army-as necessities of the age such as should not be regarded from a commercial aspect at all. It is, indeed, as essential for us to be able to rely upon talking freely, yet secretly, with the rest of the Empire, as it is for us to be, in the matter of armaments, abundantly prepared for war. These two provisions combinedly serve as the best ensurance for peace; yet either provision alone is of comparatively little value. This subject the writer has dealt with more fully elsewhere ${ }^{1}$ but by the death of Sir Charles Dilke the nation has lost a valued authority who, in his time, contributed as much as anyone thereto.

Inter-Imperial telegraphic communication should not, I maintain, be regarded from the financial standpoint-i.e., as to whether it will be directly profitable in each instance. The Inland Telegraph system of the United Kingdom is (unlike the Postal service) conducted at a loss. This is solely warranted by the advantages accruing to the public. There is, however, far less ground here than obtains in the case of telegraphic communication between the

1 Lecture to the Royal United Service Institution, April 17th, 1907; also two lectures to the Royal Naval War College, Portsmouth, February, Igog. 
different branches of the Empire. In the first instance, public utility only applies in an individual sense - a large proportion of the population of this country not desiring to use either the telegraph or the telephone. On the other hand, interImperial telegraphy serves a national, Imperial, and strategic end, whilst serving as a powerful incentive to inter-Imperial, trade.

The amalgamations which seem highly likely to take place between the American Telephone and Telegraph Company, the Western Union Telegraph Company, the Anglo-American Telegraph Company and the Direct United States Cable Company point to the possibility of our trans-Atlantic cable system becoming a huge American trust. Thereby, apart from other objections, the rates would be more likely to be raised than lowered-possibly even with a view to checking trade between Great Britain and Canada. The cables owned by these com. panies are in any case all "pooled" together as regards profits and tariffs, whilst the five other existing cables are the property of the Commercial Cable Company-another American organisation, though (at present, at any rate) outside the aforesaid pool.

The "All-British" Pacific cable works at a distinct disadvantage in that it has no office in London, having, in fact, to entirely 
rely on the Atlantic Cable Companies for the transmission of messages between the Mother Country and Canada. Hence, it will be seen-from what has been said generally-that inter-Imperial news to or from the United Kingdom is at present subject to the control of American interests and party politics. Indeed, at the moment -thanks to the All-British Pacific cableCanada is better supplied with Australasian news than it is with tidings from the Mother Country, notwithstanding the admittedly large number of Atlantic cables. Thus the desirability of an independent, absolutely "All-British" line between the United Kingdom and Canada has, for the various reasons above indicated, become more than ever accentuated. In connection with the Pacific cable project it was always recognised that this link must in due course follow, together with an independent land line taken throughout at some distance from the United States border. ${ }^{1}$

Quite recently the proposed connecting link with the Pacific cable has been brought forward more especially on a commercial rather than on the high state "All-British" basis. The route suggested, ${ }^{2}$ i.e., by Orkney,

1 Blue Book, Cd. 46, of 1900, pp. 25 and 30. For some time this connection was made partly through the State of Maine.

2 The Times, November 26 th and 30 th. 
Shetland, the Faröe Islands, Iceland, Greenland, and Hamilton Inlet (Labrador), is the same as was proposed (in 1860) in connection with early Atlantic cable ventures. It has also much in common with recommen. dations the present writer has made from time to time, for communication by wire. less telegraphy at a series of short ranges. These comparatively short stretches render possible a comparatively inexpensive type of cable in conjunction with the interpolation of automatic retransmitting relays at each landing-place. It is doubtful, however, whether Hamilton Inlet would prove a suitable terminus for the cable. Neither is it certain whether the departure from the "All-British" idea is sufficiently warranted by this particular route. It is conceivable, indeed, that the technical advantages (speed of working and economy in cable type) could be achieved by means of relay stations at what would, Imperially and commercially speaking, be more favourable points; and, in the course of a recent report, the writer has had occasion to indicate the advantages of a combined Gul of St. Lawrence and Hudson Bay route (for wireless telegraphy as well as cables), whilst also calling attention to the desirability of the line following a projected "All-Red" Steamship route-or at any rate, making its starting point from the headquarters thereof. 
At all the landing-places suggested the cable would be under adequate naval protection, and some of the climatic objections, in so far as they apply, can be more favourably met in the route here indicated.

It is not unlikely that our present comparative lack of direct, speedy and cheap steamship and telegraphic communication with Canada has much to do with the gradual growth of trade relations between Canada and her neighbour the United States; and that if these communicating links had been more nearly and satisfactorily achieved we should never have heard of a reciprocity agreement between these countries.

At present, telegraphic communciation with the Cape is conducted by means of cables landing on foreign territory at more than one point, besides being subject to ready interruption at the hands of the French or other foreign fleets in the event of a European war.

This serious strategic defect could be improved on by laying a second cable-on a different, and unrecorded, route-from our shores to Gibraltar and thence on to Bathurst or Sierra Leone.

A further "All-British" communicating link with the Cape would be provided if cable connection were effected between Sierra Leone (or Bathurst) and a certain (British) portion of the West Indian cable system, whence it would be brought into touch with 
the proposed independent Atlantic cable on routes here indicated.

In this way, the suggested "All-British" Atlantic cable would be serving as a second (and superior strategic) route to the Cape in addition to forming a satisfactory connection with the Imperial cable to Australia; and any project for bringing the Mother Country, Canada, the British West Indies and South Africa into direct, "All-British," communication with one another should surely be worthy of serious consideration at the present moment when it is so desirable to develop trade betwixt all of them.

One of the first requirements, however, is to put our telegraphic facilities in the British West Indies into proper order. The tariff is high (to British Guiana it still stands at 75 . a word!), whilst the traffic is correspondingly low ; and, for a variety of reasons, there is serious need for unification of the rival systems in the field. Full particulars regarding the unsatisfactory position of cable telegraphy in the West Indies may be found in the recently published Report of the Royal Commission on Trade Relations between Canada and the West Indies. ${ }^{2}$ The Report favours Government expropriation. In the words of the Commission (of which Lord Balfour of Burleigh was chairman), "We think it may fairly be deduced that if the property of the

i Blue Book, Cd. 5369. 
Companies were obtained for anything near the price suggested, the Government could, at a cost little, if at all, exceeding the amount of the subsidies now paid by the Imperial and West Indian Governments, give to the West Indies an incomparably better telegraphic equipment, and probably at the same time considerably reduce rates."

Should this counsel be followed, and should the proposed independent Atlantic cable (connecting up with the Pacific cable) also be a State affair, it would then be a question whether the British West Indian cables and the All-British cables (some of which have still to be achieved) should not come under single control along with the Atlantic and Pacific lines and the required land line connecting the two.

The further strengthening of our telegraphic bonds to Egypt and India will undoubtedly become desirable before long; but these could not be relied upon as satisfactory strategic lines owing to the route they necessarily pursue. Wireless telegraphy should, in due course, have a field here if only to meet emergencies.

Whilst recognising that in the development of our Imperial telegraphic communications there is great scope for wireless telegraphy on an auxiliary basis, ${ }^{1}$ it is to be

1 For instance, much of the necessary telegraph work betwixt the West Indian Islands should be accomplished by " wireless" means. 
fervently hoped that the Government of the day is not (as has sometimes been hinted) going to evade-ay, excuse itself forfollowing up the Imperial cable project further on the plea of waiting for the development of wireless telegraphy. That would, indeed, be an undesirable development of the "wait and see" line of action. Occasion may, however, be taken to again call attention to the various recommendations of the Igor Inter-Departmental Com. mittee, scarcely any of which have so far been pursued, though various further inquiries have been talked of from time to time.

Nowadays the general policy of Governments in this country-i.e. what to do and take up-is, unfortunately, somewhat intimately associated with the question of votes; and it is feared that the genuine concern amongst the electorate as a whole regarding Imperial matters does not in reality amount to much. Be that as it may, what sort of inquiries are made of the Colonies as to the effect of further Imperial communicating links? On the contrary, do not the Colonies have to do all the pressing; and is it not, as a rule, rather a cold ear that is given to them by the Home Government ?

The department most concerned-the Colonial Office-has but little say in the matter, being overruled by the department 
with the purse-strings on the one hand; and, on the other, by a technical department which has practically nothing to do with our oversea dominions or with the technique or administration of ocean telegraphy. Thus, the latter department (the Post Office) is not represented on the Pacific Cable Board, notwithstanding the fact that it is referred to by all the Government departments regarding everything in any way connected with telegraphy or cables.

There is great need for centralisation here, and centralisation of those intimately associated with the subject in all its bearings. This could be suitably brought into being by a Board of Control, or Authority, with every department properly concerned represented thereon-not forgetting the other branches of the Empire. 


\section{IMPERIAL TELEGRAPHIC COMMUNICATION.}

\section{THE PACIFIC CABLE PROJECT.}

How soon the biggest gap in the world's cable system, namely, that across the Pacific Ocean, will be spanned it would be out of place to predict. If, however, the present long peace between the great powers of the world is not broken, there is no reason in the nature of things why this important enterprise should be much longer delayed. It is difficult to foresee any insurmountable engineering difficulties in its way, albeit the ground has been only partially sounded over at present. Along one or two of the proposed routes it is true that depths have been found which exceed, by some 700 fathoms, those in which any cable has hitherto been laid. This, of course, would necessitate the construction of a well-adapted

2 Extract from Chapter IV. of "Submarine Telegraphs: their History, Construction, and Working," published by Messrs. Crosby Lockwood \& Son, in 1898-three years before the Imperial Pacific Cable became an accomplisbed fact.

T.C. 
type of cable, as well as of suitable machinery for paying out and-in view of what must be called the usual eventualities-for picking up the same. But such matters will certainly not daunt any telegraph engineer or contractor worth his salt. The more doubtful question is whether the line could be made a commercial success; whether, in fact-even within the next quarter of a centurysuch an expensive enterprise could be made to pay. It is upon these commercial, as well as what may be called quasi-political (inter-Imperial) considerations, that its fate depends, rather than upon any advances in the art of submarine telegraph engineering.

The proposed tariff rate from Europe to Australia, via the projected Pacific cable, is 35 . a word. In view, however, of the losses said to have resulted from the recent reduction of tariff on the existing system, some authorities have expressed doubts whether such a comparatively low tariff could be rendered profitable. This consideration raises the whole question whether the existing service ${ }^{1}$ viâ

"By this service, provided by the "Eastern" and its allied companies, Australia and New Zealand, as well as India, are placed in communication with North America, not only via Europe, but (if necessary) vid the Cape, West Africa, and South America. The further extensions of the great Eastern trunk-line also connect all these countries telegraphically with China and Japan. In fact, it will be seen, by referring to the Telegraph Map, that China, Japan, and our East Indian and Australasian Colonies and depen. dencies, possess already - apart from duplications-at least three alternative lines of communication with the United States and Canada. These are (I) The Eastern, Eastern 
India does not meet present requirements. This service, passing as it does, over cables entirely duplicated, and in part triplicated, cannot be considered liable to interruption by any of the ordinary " accidents of cable life."

There is, however, one contingency-and a very serious one-in which this extremely undesirable eventuality might occur. In the event of a great war between this country and another naval Power, or Powers, it is quite conceivable that more than one of our Mediterranean cables (if no others) might be ruthlessly cut by the enemy, and our communications with Egypt, India, and other Eastern, as well as Australasian, stations entirely broken off.

Extension, \&ce., cables to India and Europe (to England vid Continental land lines, or vid Gibraltar, \&c.) and the Atlantics thence to America; (2) the Great Northern cables and land lines from China to Europe, vid Siberia and Russia, in connection with the Atlantic cables, as above; (3) the above-mentioned Cape route from India, vid West Africa and South America. 


\section{AN ALL-BRITISH, OR ANGLO-AMERI- CAN, PACIFIC CABLE. 1}

VARIOUS schemes for telegraphically spanning the Pacific Ocean have been considered and discussed by many able authorities for a long time. Thus it is now twenty-eight years since a devious sort of trans-Pacific cable was first proposed by the late Mr. Cyrus Field and other American capitalists, who endeavoured to negotiate financial arrangements for the purpose. Their plan was to connect California with China, via Alaska and Japan, but it had to be abandoned.

Since then the Pacific idea has been further developed in this country, and from a national rather than a private commercial point of view; and the route which has so far found most favour in the English mind is naturally that which, in the first place, provides for communication between British Columbia and Australia. Her Majesty's Government and the Colonial Governments most concerned have been urged, from time to time, to consider the matter in its naval and strategic aspects. Two Colonial conferences (in 1887 and and I894) were largely occupied with this subject, as may be gathered from the bulky Blue Books

1 Fortnightly Review, September, 1898. 
All-British, or Anglo-American, Pacific Cable. 5

which record their proceedings. The Dominion Government took the matter up quite strenuously in 1893-4, and invited the various contracting firms to send in estimates for construction and laying, under condition of forming a company for working and maintaining the cable. Subsequently Lord Jersey in the course of a long report on returning from the Ottawa conference, strongly recommended the Home Government to take further steps. Finally, in $1896, \mathrm{Mr}$. Chamberlain called together a conference at the Colonial Office to thoroughly go into the question. Over this the Under-Secretary of State (Lord Selborne) presided. A number of experts were called to give evidence, and a report on the whole in favour of the AllBritish Pacific Line was ultimately arrived at, the entire affair occupying nearly six months.

Yet no steps towards realisation have yet been taken-and why? The answer is because the Admiralty reported against it, thus affording the Treasury a loophole. The Admiralty appear to have acted thus in view of the tempting bait offered them at that moment by the allied telegraph companies (opposed to the Pacific scheme) of connecting up two important naval stations in the course of another proposed "All-British" line. Having in mind the improbability of the Treasury approving both schemes, the Admiralty was of opinion-perhaps, naturally, from their immediate standpoint - that the preference should be given to the route via Gibraltar, Ascension, and St. Helena. 
In the present article it is contended, however, that an obvious moral is to be gleaned from the Hispano-American war, such as has an important bearing on the question of spanning the Pacific Ocean. ${ }^{1}$ We have here a striking suggestion of what we may expect as regards telegraphic interruption in the event of war with another European Power. The International Telegraph Convention of $\mathrm{I} 884$ recognises, it is true, the principle of protection by Government; but the effect of responsibility is practically annulled in certain circumstances by the following clause: "It is understood that the stipulations of the present Convention do not in any way restrict the freedom of belligerents." Thus, the argument that cables are as safe in times of war as in times of peace obviously falls to the ground. Surely, then, a consideration of the prospects reveals the urgency of a system of telegraphically uniting the entire Empire without touching on foreign soil. It is a matter of greater moment than perhaps the ordinary commercial mind is able to appreciate.

The present lines to India and Australia are as follows:-

\section{(a.) Lisbon, Gibraltar, Malta, Egypt, and the Red Sea.}

(b.) France, Italy, Greece, Egypt, and Red Sea.

1 The cables between Florida and Cuba were not actually cut only because it suited the Americans better to control the cable and exercise censorship, i.e., to stop messages in any way obnoxious to their interests. 
All-British, or Anglo-American, Pacific Cable. 7

(c.) Germany, Austria, Turkey, Russia, and the Pacific Coast.

(d.) Lisbon, or Cadiz, and the West and East Coasts of Africa, via the Cape.

Again, our Colonies have been known (comparatively recently) to be dependent on the Russian-Siberian land lines for communication with the Mother Country; and Lord Wolseley once remarked in regard to this matter, "To depend on lines so placed is not only unwise, but suicidal."

Still, most of these cables being entirely dupli. cated, and in part triplicated, cannot be considered liable to interruption in the ordinary way. On the other hand, if we became engaged in war with another country, all these routes touching at foreign countries would probably be at once interrupted in the Mediterranean or elsewhere. A Russian journal, the Novoe Vremya, recently said: "In case of an armed conflict between this country and England, our first task would be to block England's communications with India and Australia." Furthermore, when war with Russia was imminent some years ago, the Russian authorities are known to have had a ship at once equipped with the necessary cable-hooking apparatus.

The only possible answer to this is that a manof-war of our own nationality would always be at the right spot to keep guard, or intervene, at the proper moment. 
It is scarcely necessary here to go into the question as to how such interruptions can be effected. It suffices to say that means have already been found-during the Franco-Prussian war, during the Chilano-Peruvian war, as well as on other occasions - to effect this end, not only on and close to the shore, but also at sea. A cable deposited in depths under three hundred fathoms is peculiarly prone to interruptions of the above character, apart from the rough bottom so frequently met with in comparatively shallow water. Not only can a cable be cut in shallow water by a small steamer with purchase gear that will raise an anchor, but lengths can be removed in a manner that would tax the resources of a repairing vessel, or man-of-war, to replace-even if on the spot at the right instant.

There are also several ways in which a cable can be readily (and, at first sight, innocently) interrupted at and near the water's edge-to wit, by bonfires on the beach, by fishermen, \&c., supposed to be employed on their ordinary avocations. Several cables have been interrupted by bonfires, some for that set purpose, others accidentally. During the "Jameson Raid" of 1896 , the African telegraph system, by the east and west coasts respectively, were each in turn subjected to interruption. Had the "sanitary authorities" at one place burnt their rubbish a few days earlier the breakdowns would have been simultaneous, and our means of communication with South 
Africa would, at this critical moment, have been entirely cut off-just as it is at the time of writing.

The most obvious risk, perhaps, to a nation like Great Britain, whose Colonies and possessions - with the naval and military forces for their protection-are distributed over every quarter of the globe, is that of a carefully pre-arranged surprise war, declared against us by another naval power, or of a well-prepared revolution in one of our Colonies or dependencies. Here the inconvenience of suddenly interrupted cables might conceivably take the home authorities unawares-not to mention the temporary stoppage of telegraphic communication between two or more important parts of our Empire by an enemy effecting a successful coup de main upon a station (or cable end) in the line of communication.

Any scheme, then, for further, and independently, reducing the chances of a total breakdown of telegraphic communication with our Colonies can scarcely fail, in the interests of the Empire, to commend itself to British subjects-no matter what the efficiency of the existing system may be, which, however, as a pioneer system, should certainly receive every consideration.

Though it is true the cables to the East are laid on the trade routes, protected by British war-ships, there would surely be a greater sense of security attached to a cable laid in the open, broad ocean, far away from other European Powers, 
at a four-mile depth, whose course need not be known, and which would have but few ends, all of which could be kept strictly under Government surveillance.

The proposed All-British Pacific Cable may be regarded as one of the first and most important lines to meet these conditions. In introducing comparatively few landing places, it would be, relatively speaking, free from the sources of danger here alluded to. It would, indeed, for obvious reasons, be less at the mercy of the enemy than any previous cable system. Thus, if the ordinary line of communication between England and Alexandria were broken-through the Mediterranean and Cape cables being interrupted-we should still be able to speak to the East, provided the Atlantico-Pacifico-Indian route round the globe remained intact. And, except in the deplorable, and not very likely, event of a war with our American cousins, the chances of that route being also interrupted are not particularly serious.

With the immense commercial field of China about to be thrown open, it may be fairly surmised that if we do not span the Pacific soon, in one direction or another, some other Power will, and possibly obtain a naval supremacy there; thus no time should be lost in carrying the project through.

The French have actually laid what they term "the first link of the chain destined to connect 
Australasia with North America." Their Austra. lasian landing is the French convict settlement of New Caledonia; and, it is said, they do not care on what American territory they land. Let us devoutly hope that the Pacific line will not be allowed to be under the control of the French in combination with our American cousins, as seems possible from recent information. Two things are quite certain, however. One is that a Pacific cable will eventually be laid by some hand or other, and probably at no distant date. The second is, if we see to this speedily, it will tend to check foreign enterprise in the above direction.

We will now pass on to a scheme that appears to have been suggested by the Eastern Extension Telegraph Company as an alternative for the Pacific line-i.e., their proposal to lay a system of All-British cables to the Cape and Australia via Gibraltar and other important naval stations. It is understood that the majority of the Australian Colonies have now decided not to support this scheme, in anticipation of a trans-Pacific cable. ${ }^{1}$

1 An exception is to be found in Sonth Australia, which supports the "Eastern" scheme and opposes the Pacific line. This policy is apparently because, owing to the extremely inefficient land line across Australia-a cause of constant telegraphic delays- the Government fears that the Pacific cable would deprive it of the traffic on which it now makes a profit at the expense of the other Colonies. Thus, by a singular coincidence, this shaky unreliable land line, which renders the Pacific cable more than ever necessary to the Australian Colonies, is one of the main stumbling. blocks to its construction. 
An admirable line in its way-if only as a superior duplication of existing systems-the Cape and Australia proposed cable can scarcely be regarded as a substitute for the Pacific project. It does not meet the case from an Imperial and strategic standpoint, because it does not include in its scope the largest and most populous of all our Colonies-the Dominion of Canada. Again, it would pass through foreign waters; moreover, in landing on the wrong side of Australia, it must be largely dependent on the good behaviour of Australian land lines.

Still, it is but human of shareholders to look at things from a different standpoint ; and if the proposed Pacific line, in destroying the monopoly of the existing systems, is destined to seriously affect their profits, it is a question whether provision would not require to be made to guarantee investors proper compensation.

Subjoined are some of the main reasons in favour of a system of All-British lines-and especially the Pacific cable-being laid without further delay:-

(a.) As an extra and independent string to our bow, if only for strategic, diplomatic, and political purposes.

(b.) Owing to the greater sense of security in a line laid in the open, broad ocean-away from other naval powers.

(c.) As involving few stations, easily defended 
All-British, or Anglo-American, Pacimc Cablz. 13

and comparatively inaccessible from other European Powers in time of war.

(d.) As an important item in realising and maintaining a naval supremacy in the Pacific Ocean.

(e.) As furthering an Imperial Customs Union which would render us independent of the good offices of the rest of the world. Such a consummation is furthered more than anything else by connecting the Mother Country with the Colonies.

(f.) Because we should thereby be no longer putting all our telegraphic eggs into one oceanic basket.

(g.) When the West wishes to communicate with the East, or the East with the West, the message has at present to be sent backwards round two hemispheres. Surely this is a state of things which in these days should be remedied.

(h.) Because of the resolution recently passed by the Colonial Premiers of Australia :- "That if Great Britain and Canada each contributed one-third of the cost of the Pacific cable, New South Wales, Victoria, Queensland and Tasmania would be in favour of contributing the remaining third."

It is perhaps scarcely necessary to add that there are no technical (engineering or electrical) difficulties involved by the scheme, such as are not well within the range of practice. 
The weak point in the "All-British" line, as considered by the Colonial Office in 1896 , is undoubtedly the land lines through Canada.

But there is an alternative which, in view of recent ideas, will probably commend itself to many a broad-minded Imperialist, and certainly to all who interest themselves in the idea of a PanAnglican Federation. If, in fact, a permanent and reliable understanding could be arrived at with our American cousins-with whom we are naturally united by the common bond of the English tongue -any serious difficulties in the realisation of the All-British Pacific Cable scheme might be effectively overcome; still more if, for certain purposes, that coming nation, Japan, were included in such alliance.

It is known that the Americans are actively considering a project for a Pacific cable to Japan via Honolulu and various islands. By means of a comparatively short branch, the All-British interests could be combined with the Anglo-AmericanJapano (if the above-mentioned treaty were brought about), and thus two Pacific cable schemes could be practically realised by one Pacific cable. Moreover, not only would the share of the cost to each country be enormously reduced, but the actual total cost would be materially less than in the case of the All-British route, owing to the long section therein (such as entails an extra large conductor and insulating sheath) being avoided. 
All-British, or Anglo-American, Pacific Cíple. is

Combination of this character would do much? towards more firmly binding together the two countries-aye, and all English-speaking countries - under the banner of a common tongue.

In any case, the standpoint from which the immediate necessity of laying a trans-Pacific cable is likely to be determined is the National, inter-Colonial, and Anglo-American one, rather than the purely commercial. For their mutual benefit, the great English-speaking and Englishgoverned countries-that Pan-Britannic "Oceana," living here under the "Union Jack," there under the "Stars and Stripes"-may decide sooner than either the telegraphic or the financial world could hope or anticipate, that they must and will have their Pacific cable.

Let us now survey the effect of telegraphic communication with our Colonies and the United States, so far as it has gone at present.

There is at least one political result of this great development of the world's system of electric nerves, which Englishmen may safely regard with unmixed satisfaction and pleasure. This is the much closer relations which have thereby been rendered possible-nay, are on their way towards being fully established - between the mothercountries of the United Kingdom and the daughternations, English-speaking, English-modelled, as to their institutions, and, in the main, of British and Irish stock, which have sprung up in the 
most distant quarters of the world. The "Little England" idea, so fondly cherished by the old Manchester school of economists and politicians (who would gladly have seen all our young and vigorous Anglo-Celtic brood chased, as young birds from the parent nest, almost before they could fly), is practically as dead as a door-nail. In its place we hear, on all sides, of Imperial Federation and Inter-Colonial Federation schemes, of a PanBritannic Zollverein, or Customs Union between the United Kingdom, its self-governing Colonies, and India, and-grander, if less practicable, than all these-we now hear of negotiations for the establishment of a permanent arbitration tribunal for settling peacefully all future differences between the two main divisions of the English-speaking world. These movements may end in some form of British Imperial Federation, accompanied with a permanent modus vivendi with the United States. They may even lead, beyond this, to the constitution of a new nation, on a grander scale than any which the world has yet seen - a true PanAnglican Federation-embracing all the "free" communities in different parts of the world which, albeit of diverse races and even colours, are naturally united by the common bonds of the English language. In a subject like this, which concerns the rising generation in all these countries, -from the United Kingdom and its great "emancipated daughter," the United States, down to the smallest African and West Indian communities- 
All-British, or Anglo.American, Pacific Cablz. 17

speaking and reading our modern lingua franca, it is but natural that we should consider such questions, especially as the extension of submarine telegraphy is doing more, perhaps, than any other single movement to render their eventual realisation possible.

Concluding with things as we find them to-day, viewed as the mouth-piece of the public, the unanimity of the Press on the subject of the Pacific cable is, indeed, remarkable ; and especially when we consider the all-powerful influences opposed to such a project. Here we have, in fact, an excellent example of the independence of the press in this country. 


\section{THE PACIFIC CABLE. ${ }^{1}$}

AN endeavour will be made in this paper to emphasise the fact that, notwithstanding the opinions that have been advanced in certain quarters, there are no engineering or electrical difficulties standing in the way of realisation.

Let us consider the subject under its different heads, with a view to dealing with the various objections that have been raised from time to time, according to circumstances. First of all, it should be clearly understood that cables have been previously laid and repaired in depths over 3,000 fathoms. The deepest water in which the cable on the most favoured route might possibly require to be submerged is 3,300 to 3,400 fathoms, near Fiji Island. There are indications of some 5,000 fathom depths in these latitudes, but well clear of the suggested cable line. These particulars are brought to the fore in view of the extraordinary statements that have gained currency that the cable could never be laid, much less repaired, if only on account of the depths being so much greater than anything hitherto experienced.

1 Paper read before the British Association for the Advancement of Science, at Bristol, September, 
Survey.-A sufficient knowledge of the nature and depths to be met with are already at hand to decide in favour of the undertaking and for the determination of the types of cable to be employed. The portion of the route which more particularly requires a further and more detailed survey, is that between the Fiji Islands and Australia on the one hand, and New Zealand on the other. I venture to think the series of soundings here involved could well be made, on the return journey by the ship dispatched to land the shoreends at the further points, immediately previous to laying the main sections. Though many dark hints have been thrown out as to the unfavourable composition of the bottom-by those who, perhaps naturally, do not want a Pacific cable-the statements are not supported by facts, so far as the actual route is concerned.

Type of Cable.-In designing a cable for the greatest depth to be met with, special care would, of course, require to be observed to adopt a type which would combine the requirements of safe laying from the contractor's point of vies, with those of durability looked at from the aspect of the proprietor. The latter include the necessity of the cable readily accommodating itself to any irregularities at the bottom, and, at the same time, being a good subject for recovery, not only when new but also a number of years after submersion. These interests sometimes conflict. Naturally the most important point is to select a type which, if 
carefully and properly laid, will permit of being picked up several times over, and several years hence. The cable must be of a character which lends itself well to paying out with a sufficiency of slack to meet all subsequent cable operations. Again, its specific gravity must be limited by considerations of recovery. When the difficulties of raising a cable to the surface in deep water first presented themselves in connection with Atlantic telegraphy, a low specific gravity cable was adopted with the special object of meeting these difficulties. ${ }^{1}$ This type consisted of each iron wire being enveloped in manilla hemp. Such a cable is now, however, entirely ruled out of court as lacking in durability, and the result of experience all goes to show that for types of this character a close-sheathed cable, with the iron wires more or less firmly butting against one another, is practically a sine qua non. Each wire would be separately coated with preservative compound and covered with a thin cotton tape. A cable of this class combines durability with the minimum of rigidity, which renders it well adapted to the general requirements of laying and repairing operations. For the purposes of securing a given actual strength, the wires-which would, of

1 At that time this type of cable was also in much favour, from a laying point of view, owing to its low specific gravity tending to materially simplify the require. ments in the way of holding-back gear and brake power, the efficient working of which, in controlling the cable's egress, was, for the lack of experience, in some doubt. 
course, be galvanised-must be made of homogeneous iron of the greatest possible breaking strain. Having regard to pliability, there is a limit to the size of each wire, neither must it be below a certain gauge with a view to durability after submergence. The outside covering of the cable should be composed of compounded hemp cords or of jute (or hemp) yarns-in preference to canvas tape-on account of having greater durability and as binding the whole cable together more firmly and permanently. For recovery purposes, from a skin-friction standpoint, the outside circumference of the cable should not be greater than is absolutely necessary to meet other qualifications; and, in some respects, the same remark holds good from an efficient laying point of view. Finally, a smooth outside surface is of more importance here than might, at first sight, be supposed.

Laying.-For paying out the cable efficiently in the deepest water special attention would have to be observed to the character of the brake apparatus, and if the ordinary friction brakes now in vogue can be supplanted by something more free from the chances of undue heating an advance will have been made. Such an innovation would be especially valuable in this connection on account of the length of one of the sections-that between Vancouver and Fanning Island-being substantially greater than anything previously dealt with. This section, with a proper allowance for slack, \&c., 
would run into something like 3,500 nautical miles, as against 3,174 nautical miles for the recently laid French Atlantic cable between Brest and Cape Cod. The brakes and holding-back gear must, again, be of a character that will allow of rapid changes in the retarding force. They must also be of ample strength to prevent what would be a comparatively heavy cable from running away in the deep water and coiling itself at the bottom so as to form kinks when afterwards being lifted.

Repairing.-It has been argued by some that if a cable were ever laid on the suggested route it could not be subsequently recovered. In reply to this contention it may be pointed out that cables have already been picked up and repaired in depths of over 3,000 fathoms in the open sea; this not, of course, on a single bight, but by first cutting it at the bottom and then, having thus taken a great part of the strain off, lifting the cable elsewhere. Such a system is, of course, capable of extension ad libitum by buoying the line in festoons at different points and in gradually increasing heights from the bottom until the strain at another position is sufficiently reduced to permit of the bight being raised to the surface.

Again, objections have been raised as to the length of time taken in the recovery of a cable in such depths. It must, however, be borne in mind that cables are now frequently picked up and repaired in upwards of 2,000 fathoms in the course of a few days. 
Electrical Working.-It has been asserted that if the Pacific line were laid it would not work satisfactorily. This suggestion is not, however, in agreement with facts, though it is true that the maximum speed obtainable on the long sectionsay 3,470 nautical miles-with a large core would be low as compared with that attained on the Atlantic cables, which are, at business hours, kept heavily burdened with traffic. Nevertheless, with a core of the same proportions as that adopted in the Anglo-American Telegraph Company's last cable-650 lb. copper to $400 \mathrm{lb}$. gutta-perchaunder ordinary conditions a speed (in five-letter words) could be secured well up to the minimum required by the Canadian Government in $1894^{\circ}$ The foregoing would be by ordinary manual transmission, whereas all the latest improvements in machine transmission, with curbing arrangements as well as condensers, would naturally be applied, with something like a 35 per cent. increase in the speed, whilst the adoption of Muirhead's duplex system would nearly double the working capacity of the cable.

As a first venture the above cable would probably be sufficient to meet the ends in view. It is conceivable that a larger core would be out of the question on the ground of cost. Moreover,

1 It should, however, be remembered that though seven letters is still often taken as the equivalent of a cable word, it nowadays more usually averages up to nine letters. Such discrepancies go to prove the futility of expressing a required speed in words only. 
increases in the dimensions made beyond this would have the effect of still further increasing the mechanical difficulties as regards a suitable type of sheathing. Experiments have, in fact, already been made on two Atlantic cables with lower electrical values looped together to test the possibility of working through a considerably greater length than that to be dealt with here, the results being perfectly satisfactory.

In the construction of the first cable to India (via the Persian Gulf) Messrs. Bright and Clark, as engineers to the Indian Government, adopted a conductor in which four ordinary wires were drawn down so as to form the four quadrants of a true circle, with a ring outside to embrace the whole. By this means, with a given weight of copper, the electrostatic (inductive) capacity of the core was reduced without increasing the conductor resistance, the result being a very material increase in the attainable speed of signalling, whilst sufficiently maintaining the mechanical requirements as regards pliability, \&c. Messrs. Siemens Bros. have since, to a great extent, achieved a similar end in their compromise between the single solid wire and the strand conductor, and this has proved a great success on a number of Atlantic cables. It would seem as though a plan of drawing the wires down to a smaller total area might, in this undertaking, be advantageously adopted. In the case of the Persian Gulf cable an economical method of securing any particular speed was not 
of the same vital importance. Moreover, in that instance, the length not being of an abnormal character, the extra cost of that type of conductor was probably scarcely made good by increased working value. Here, however, the author is of opinion that this plan would be found to more than repay the increase in initial cost, especially as it would also materially reduce the quantity of gutta-percha required to obtain the same minimum thickness throughout for fulfilling the mechanical as well as electrical qualifications, the said material being the béte noire in the cost of an ocean cable.

General Remarks.-Viewing the proposed line as a necessity to meet the political requirements of the age, attention may be drawn to the circum. stance that in the great depth and length in the open sea lies a source of security for the cable from a strategic standpoint. In a depth of over 3,000 fathoms a man-of-war, with all the implements ordinarily at her disposal, would experience considerable difficulty in interrupting such a line. On the other hand, a cable submerged in shallow water is seriously open to interruption of this character. In introducing comparatively few landing-places, the route under consideration would be, relatively speaking, free from malicious interference at the hands of the foreignerespecially as the proposed landing-places are on British soil, far removed from foreign waters. 
With reference to the effect of the Pacific line on the cost of telegraphic communication, it may be observed that at present if anyone in Victoria, say, wishes to communicate with Canada, his message traverses about I2,000 miles, and costs him 6s. a word. By direct Pacific cable, this tariff would be reduced to about $2 s$. $6 d$., the length of line being little more than half. It may be added that the message would reach its destination within an hour, instead of taking sometimes nearly twenty. four hours to find the hands of the individual to whom it is addressed.

In conclusion, with regard to the various schemes for a Pacific cable, it should be remembered that forty years ago the feasibility of Atlantic telegraphy was the subject of incredulity - partly in Section A of the British Association meeting of 1855-at the hands of many of the greatest authorities until the cable was actually laid and worked in 1858 . In that instance there were practically no data to go upon; whereas the proposed Pacific line may be regarded as but a further extension of what has already been done, though certainly involving special arrangements and precautions.

In this paper the author has, in the main, only dealt with the technical side of submarine telegraphy in its present state of practice. If, however, some of the shining lights of Section A could get their ideas into shape-or, on the basis of actual experiment, furnish us with new material 
-the whole difficulty, in a financial sense, might be at once solved.

By way of improving the present means of signalling upon cables, Mr. Oliver Heaviside, F.R.S.-who treated the subject mathematically in the Philosophical Magazine in 1879-has advocated the introduction of both "leak" circuits and self-induction into cable lines. To put this suggestion into practice, electrical engineers have devised new forms for the insulated conductor, accompanied by devices which to a certain extent realise the said theoretical advantages. But the only conclusion arrived at in regard to the application of these ideas to the ordinary cable circuits of to-day is that, when suitably disposed along the line, in obviating the choking effect of retardation they secure increased definition for the signals, yet not sufficiently to permit of any substantial increase in the working speed, even with the battery power raised within reason.

A number of other proposals have been made; but so far as concerns any further substantial increase in the speed attainable for submarine telegraphy under given conditions, it seems probable that if this is to be effected it will be by an entire revolution in the form of conductor, dielectric, and completed cable, rather than in the signalling apparatus. The latter has probably reached its limit of sensitiveness. Any further increased sensibility of the instruments is likely 
28 Imperial Telegraphic Communication.

to be at the expense of steadiness, and would tend to bring them within the range of influence of other surrounding forces. It is even now quite beyond that required or justified by the cable itself under present conditions. 
IMPERIAL TELEGRAPHIC COMMUNI. CATION AND THE "ALL-BRITISH" PACIFIC CABLE.'

A SPECIAL meeting of members of the London Chamber of Commerce was held at the Cannon Strect Hotel, on Thursday, December $4^{\text {th, }}$ 1902, when Mr. Charles Bright, F.R.S.E., delivered an address on the above subject. The Right Hon. Lord Brassey, K.C.B. (President of the Chamber), took the chair.

Lord Brassey, in opening the proceedings, said it was quite unnecessary to dwell at length on the importance of efficient telegraphic communication, not only in those interests of trade with which the London Chamber of Commerce was chiefly concerned, but also in those political aspects which were by necessity so much in his view during his years of service as an Australian Governor. Those telegrams received day by day and hour by hour from the Motherland, keeping them constantly informed of every event of Imperial concern at the moment of its occurrence, were a binding force, the influence of which could hardly be over-stated. This influence of telegraphic communication as a

' London Chamber of Commerce, Pamphlet No. 40. 
great Imperial binding force was singularly illustrated when the great strain and stress of the conflict in South Africa came upon them. It was the instant communication of tidings from the front which gave them the contingents. Men stood together in the streets; they scanned the telegrams of disaster posted up at the offices of the newspapers; then asked each other, "Shall we stand here and do nothing?" They said to one another, "No, indeed, this must not be," and they came to our assistance. Lord Brassey had pleasure in introducing - if an introduction were necessary-Mr. Charles Bright, who was a high authority on all matters connected with telegraphy. $\mathrm{He}$ had made it, in all its aspects, peculiarly his own subject, and had been engaged as engineer and electrician in the construction, testing, laying down and repairing of many thousand miles of submarine cable in various quarters of the globe. Mr. Bright was the author of the standard work on submarine telegraphy, besides having largely contributed to the literature of the subject in other ways - including valuable evidence to the Cable Communications Committee, following on his report on the Pacific cable to the Colonial Office. Mr. Bright, moreover, had a strong hereditary connection with the subject. His father, the late Sir Charles Tilston Bright, the eminent engineer, was knighted when but twenty-six years old, for the laying of the first Atlantic cable. 
Mr. Charles Bright then delivered the following address :-

"Lord Brassey and Gentlemen,-The share which telegraphy performs in uniting the British Empire was, on October 31st, 1902, advanced a very important stage with the actual completion of the All-British Pacific Cable and telegraphic girdle. That will ever be a memorable period in the history of the Empire, and on Monday next, December 8 th, 1902, the new line will be open for public traffic. This, together with the recently published report of the Inter-Departmental Cable Communications Committee, seems to suggest the present as a suitable moment for taking a survey of our position in regard to Imperial telegraphic facilities. Let me at once explain that, within the confines of my address, I can only hope to touch on the fringe of some of the more important features of the subject. There are present those whom I cannot profess to inform; but if there is anything suggestive, or of interest, in these remarks, my main object will be attained. Whilst this address is, of course, largely an expression of opinion from a single individual, it is, at the same time, the result of a considerable study of the subject from all points of view without being encumbered with a brief for any particular interest :-

"I do not propose to dwell at length on the gradual-very gradual-development of the Pacific 
cable scheme. That has already been fairly, fully and accurately recorded in the columns of The Times. The story is one of much talk and tremendous obstruction, occupying some fifteen years or more, as against one and a half year's work; but, as we know, words are cheaper than cables. The plan was first talked of in the 'seventies, and was discussed at the Colonial Conference of 1887 ; but it obtained its first real footing at the Ottawa Conference in 1894 .

"There has certainly been no lack of zeal and ingenuity on the part of those who have, for their own reasons, opposed the scheme openly and otherwise. First of all it was asserted that the cable could never be laid, much less repaired, on account of the abnormal depth, which was put down at fourteen miles in places, the maximum depth on the route being in reality 3,200 fathoms -roughly about $3 \frac{1}{2}$ miles-a good strategic depth, and, practically speaking, no greater than that at which cables have previously been laid. Then, the bed of the Pacific Ocean was said to be covered with coral patches such as would make short work of the line even if laid. In the course of a paper read at the British Association I endeavoured to explode these suggestions, which were, indeed, based on misrepresentations of fact, as is now proved; but, gentlemen, the depth is the same, the bottom is the same, and the engineering and electrical methods are the same. They have not altered in the interval, and it is certainly a matter 
of congratulation that certain parties will now be better informed than they were. It, however, behoves the Government and the public to remember in future that, in these matters, the views of interested parties should not be implicitly relied upon; neither should any argument be taken much account of from those who give vent to the following statements in the same breath: (I.) The cable is not wanted; (2.) it could not be laid, repaired, or successfully worked; (3.) if insisted on, we are the people to do it.

"A historical and technical record regarding the construction, laying, and working of the Pacific cable forms no part of my theme. The science of submarine telegraphy has been worked out for many years, and the Pacific cable may be regarded as but an extension of what had already been done, though certainly involving special arrangements and precautions. The difficulties that were raised, however, remind one somewhat of the incredulity in the first Atlantic cable, but with this difference, that in the latter there were practically no applicable data to go upon.

"This afternoon we could not possibly have a more suitable chairman. His father (the late Mr. Thomas Brassey) was one of those who had sufficient belief in the Atlantic cable to stand as guarantor for $£ 10,000$ in connection therewith. Moreover, he (Mr. Brassey) was one of the first ten directors of the same firm of contractors who have so expeditiously carried out the manufacture 
and laying of the Pacific cable in some weeks less than the contract time.

"As a matter of fact, the cable might have been laid in a considerably shorter interval after a decision was arrived at had the contract of this important national work been divided amongst the three or four large firms who tendered, at least one of whom (the Silvertown Company) ${ }^{1}$ had-like Sir Sandford Fleming and others-laboured so hard in the cause. A more favourable moment might also have been taken for seeking tenders or giving out the contract from the cost of materials standpoint. As it was, the order was placed with a firm who were at the time busily engaged for their immediate clients over one of the very lines with which the Pacific cable is to compete. In the ordinary course of business every mile of the former was made and laid before the laying of the latter was commenced, the result being that the Pacific cable is well forestalled as regards traffic. But while some of us may hold the opinion that the project should have been carried out in a different way, we must all agree that the Telegraph Construction and Maintenance Company have done their work in an altogether admirable fashion.

"The importance of the Pacific cable from a sentimental point of view is surely not unworthy of consideration. It can, indeed, scarcely be

1 At the Canadian Conference of 1894 , this Company put in by far the lowest tender that has ever been given for the work. 
doubted that direct and unbroken Imperial telegraphy is an all-powerful weapon for develop. ing trade between the Mother Country and her Colonies, and for bringing about something in the nature of Imperial Federation or a PanBritannic Customs Union-tending to render us independent of the good offices of the rest of the world.

"It has been estimated that our expenditure in ' cabling ' to Australia previously stood at over $£ 1,000$ per day; and one of the immediate effects of the Pacific cable in the matter of future interColonial trade is that a message will now take inside an hour instead of nearly a day to reach its destination. Another effect of the Pacific cable-which, indeed, took place immediately the scheme became 'dangerous'-is that the rates from this country to Australasia now stand at 35 . instead of $4 s$. $9 d$. and formerly $9 s$. $4 d$. on the average. The new telegraph will also serve to attract increased attention to the 'CanadianPacific' route as an alternative to globe-trotters.

"What constitutes a weak spot in the Pacific cable is, of course, the long section on the route eventually decided upon between Vancouver and Fanning Island-running into $3,45^{8}$ nautical miles. The result is a slow working system, and this in competition with a complete system of high-speed cables. Thus, if the traffic is to be remunerative, it is bound to become congested at 
certain hours of the day, in view also of the difference of time. Hence, if only on this account, and to meet interruptions and possible lengthy repairs, the line must be duplicated sooner or later. This duplication might, however, well take the form of a link with the American Pacific cable system-as, indeed, I pointed out some while back.

"On the other hand-by way of avoiding a duplication of the All-British Pacific Cable-there has been some talk already of an arrangement with the company controlling the rival lines to Australia; and I note that a prominent shareholder of the Eastern Extension Telegraph Company thinks that 'if the Pacific cable breaks down those controlling it would be disposed to enter into an arrangement with the rival line, and that in that case they-the "Extension" Company-would be able to get back to higher rates.' The experience of joint purses, however, in the case of the Indian traffic is not very happy from the public standpoint. Moreover, anything like a partnership between a Government and a company is objectionable in principle, seeing that the Government should be concerned with looking after the interests of the public.

"Though the duplicating system of the 'AllBritish' Pacific cable may well be Anglo-American in character, the original system itself should be strictly 'All-British' to and from headquarters. So far this is not the case between England and 
the nearest end of the cable at Vancouver. In other words, the new Pacific line constitutes a private wire between Canada and Australasia, but not so between the Admiralty here and the admiral in command of the Australasian station. The situation is somewhat peculiar. On the one hand our cablegrams can pass through any of the -Anglo-American' or 'Direct United States' Company's Atlantic cables which are British with All-British landings on the eastern sea-board of Canada. The telegraphic connection of these systems with Vancouver is, however, as far as Montreal, by means of the American-owned wires of the Inter-Colonial Railway. On the other hand, if we entrust our messages to the Commercial Cable Company to go by any of their cables, it must be remembered that, though this system lands on Canadian territory, it is an American company; moreover, these cables pass n shoal water somewhat closely to St. Pierre de Miquelon-a French Colony-south of Newfoundland, where two of the French Atlantic cables land. Again, its immediate connection with the Canadian Pacific land lines involves a journey of 270 miles through the State of Maine; and beyond this the 'Canadian Pacific' Telegraph could, in the event of our being at war with the United States (as also in the case of the InterColonial line) be interrupted at many points with comparative ease. It may be added that the Commercial' Company has exclusive working 
agreements with the Canadian Pacific Company to the effect that all messages from the Pacific cable to this country must be handed over to the latter (Commercial Company) cable system.

"Surely all this points to the necessity of an independent (All-British) telegraphic link between the Mother Country and the Pacific cable at Vancouver, at a low tariff. A general statement from the Colonial Office in 1899 required that this should be furnished, 1 but nothing further has been done in the matter since then; and I would ask what is the use of going in for an expensive 'All-British' cable, if the land line connection is open to easy attack? In the case of a possible war with the United States, the Pacific cable would be of no use whatever, owing to the position of the existing Canadian land line connection-if for no other reason. As regards the rest of the route, any new 'All-British' Atlantic cable might suitably be taken at a respectful distance from St. Pierre, whilst avoiding shoal water off Newfoundland as much as possible. The objection to the Northern Gulf of St. Lawrence route on the score of ice is probably not insurmountable, and it would, of course, be the best route strategically. Short of this, St. John's, Newfoundland, should at any rate be again fortified and provided with a cruiser, cable depot, and repairing ship, to meet the

1 Blue Book, Cd. 46, p. 25. 
present condition of the undefended Atlantic cables along the route that connects up with our new Pacific line through Canada. At this end, any new Atlantic cable should, if possible, be landed nearer headquarters than any of the existing lines, and an underground connection provided with a view to avoiding the delays and interruptions to which our Atlantic and Eastern systems are prone on the overhead wires.

"When it is remembered that an Atlantic cable costs about half what a first-class battleship costs ; and that the latter is often of little use out of touch with headquarters, it will be seen that the sum involved for carrying out the 'All-British' con. nection with the Pacific cable is not altogether out of proportion with the degree of necessity. Seeing that 10,000 messages cross the Atlantic per day, surely it cannot be said that there is no room commercially for another Atlantic cable. Let us hope that the Pacific cable has broken the spell, and that a number of other lines of communication on a variety of routes will now be recognised as desirable for Imperial, strategic and commercial reasons.

"As I have previously remarked, the opinions of those concerned in existing systems should not be put at too high a value in considering future needs. Further, it is to be hoped that those anxious about the welfare of vested interests will also realise that a ' $\mathrm{dog}$ in the manger' policy is 
not essential. Healthy competition need not necessarily involve inconvenience to existing systems; for the more lines that are laid, the more familiar becomes the idea of a cablegram, and increased facilities always increase the demand, as we shall see shortly with the competition of wireless telegraphy. This latter fact should also serve as a solace for the reduction of tariff, which, with a similar effect, will no doubt follow.

"The general principle must be accepted that the more independent lines on entively different routes, the better for purposes of ensuring communication being maintained (in war, as in peace) between any two points of the Empire, seeing that we have experienced a number of quite serious and harassing telegraphic interruptions, which might, in certain instances, have led to fatal results.

"In some cases, however, it appears that duplications or triplications might safely take the form of land lines or a part land line and part cable system-it being remembered that, roughly speaking, a land line costs initially about onesixth what a cable does, besides possessing five times the efficiency of a cable, under given conditions, as regards, message-carrying capacity. These duplications or triplications could not, of course, as a rule, be 'All-British,' but would, at any rate, form an extra string to our bow in times of peace. Moreover, from a strategic point of view, it can certainly be said that a land line 
through a foreign territory is scarcely more liable to disturbance than a cable in quite shallow, foreign, water. It is sometimes stated that it would be unfair to the Cable Companies to compete against them at land-line rates; but if a cable system is worth its salt, and the rates not abnormally high, it should be able to stand its own against any land-line system, if only on account of the better service afforded by the former and by its greater reliability and permanence. If it cannot, that fact may be taken as a sign that it is an unnecessary expense, and had better 'go under.' On the other hand, it is absurd to expect the cable rate to be the same as a land-line rate between two given points as a matter of course; for in addition to the wide difference in initial cost, the risk of establishment and maintenance is vastly greater in the case of a cable.

"There are several features that tend to explain the present relationship between the Cable Companies and the Imperial and Colonial Governments (including the Government of India), and the small amount of control hitherto exercised by these Governments over the Cable Companies. The Governments concerned have scarcely ever taken the initiative in establishing telegraphic communication either by sea or land. The Atlantic cable, for instance, would probably not have been laid to this day, but for the individual exertions of English and American capitalists. On the other hand, Governments have granted 
very considerable subsidies ${ }^{1}$ and guarantees in response to those who have undertaken to establish communication to their countries; and in return until quite recently, our Government, at any rate, (unlike certain other European Governments) has, as a rule, only demanded priority, and reduced rates, for Government messages,${ }^{2}$ the control of the line ${ }^{8}$ and suppression of codes if required ; covering the inspection of all messages in time of war." In other words, the conditions insisted on by this Government have, so far, been almost entirely to the advantage of the Govermment itself, rather than on behalf of the telegraphic public. Under the various circumstances it is, perhaps, no great matter of surprise that the Governments concerned have not in the past found themselves in a position to dictate terms to the companies for the working of their lines. At any rate, they have not, as a rule, done so, except in regard to the conditions named.

1 A subsidies' statement is given in the Appendix to this address.

${ }^{2}$ Examples of the variability of rates will be found in the Appendix to this address.

${ }^{8}$ In the case of some of the West India and Panama Company's cables, Governinent messages were arranged to be sent free, and this Company also agreed to supply news free; but both are absurd conditions and should never have been accepted by concessionaires. Half rates for Government messages and quarter rates for Press is a fair logical proportion.

- This latter, though sometimes by a special clause, is usually covered by a clause that the cable is subject to the terms of the International Conventions. Until the latter were established in 1865 , all messages crossing a frontier were examined, even in times of peace. 
"Let us now turn to the other side of the question-that is, whether the Telegraph Companies have in the past failed to comply with reasonable requirements. It need scarcely be said that the primary object of such companies-as of other business undertakings-is to earn dividends for shareholders, and is, in no sense, philanthropic. Thus the enterprising investor has benefited by rich profits in return for his risk.

"Attention has been drawn to the supposed injustice of the rates to certain places being inconsistent with the rates to others. ${ }^{1}$ This, however, cannot altogether be considered a grievance against the companies, and is often entirely apart from any question of monopoly. When financiers endeavour to raise capital for a new line, they have to show pretty definitely the traffic that is likely to be derived, and, if working on this basis, the rates require to be adjusted largely in accordance with the probabilities of traffic volume. Thus in an obscure settlement the rate has often to be somewhat high, with a view to covering the working expenses of the station-perhaps an unhealthy one-even though the said spot is situated at a distance from the terminus, such as would in itself involve a comparatively small initial outlay in

- Up to the date of the Mauritius and Bermuda cables respectively, the only instance known of where the Govern. ment definitely exercised the right of controlling the public tariff is that of the first Atlantic cable. The particulars of this are given in a letter from the Treasury published in the "Life Story of Sir Charles Tilston Bright," 1st edition, vol. i., page 120 ; also 2 nd edition, page 43 
cable, and even though the traffic for this particular station would not demand a high-speed type of cable. All these considerations-as well as the subsidy (if any) obtained-need to be taken into account by those who risk capital in pursuit of an income out of submarine telegraphy. Seeing that - possibly for the reasons suggested-stipulations as to tariff have scarcely ever been made by the Governments granting concessions, the owners of submarine cables have, not unnaturally, charged the tariff they consider likely to be most remunerative.

"The tariffs prevailing in foreign countries may form a guide to a certain extent, in regard to the question as to what rates are 'fair and reasonable.' Those interested in pointing to the losses said to be incurred by what they consider (or state) to be too low a tariff to pay, illustrate their arguments by the fact that the Atlantic rate was lowered to $6 d$. for eighteen months on trial, and subsequently had to be brought back to a shilling. ${ }^{1}$ But this stands for very little, for it may be questioned whether the experiment was of sufficiently long duration. During the trial period the number of messages

1 As a matter of fact, what actually took place was as follows:-The "Commercial" Company started with Is. $8 d$. tariff in 1884 . In 1886 the "Pool" Companies lowered the rates to $6 d$. a word. The "Commercial" then reduced theirs to IS., and after eighteen months the "Pool" came down to the same figure-Is. a word. Largely owing to the moderate Atlantic rates by competition, we are able to telegraph to Vancouver at Is. $6 d$. a word, though the traffic cannot be great. 
conveyed was, however, more than doubled, and the proportion was steadily increasing. If the tariff is halved the number of messages sent must, of course, be materially more than doubled to make up for the increased cost in traffic; for, unlike letters, each telegram requires a separate messenger.' Still, in time, the corner might have been turned.

"Whether or no the 'Eastern' and Allied Companies have exercised foresight in charging in various instances comparatively high rates, ${ }^{2}$ creating considerable reserve funds, whilst declining to lay certain cables for which there was obviously a public demand, is another question. Seeing that they have taken full advantage of their opportunities, it is doubtful whether any claims for special consideration as financial pioneers-which the Associated Companies might otherwise reasonably make-would have great weight.

"It should, I think, be taken as an axiom that no reduction of rates will pay at first, matters improving only gradually as the public become aware of the advantage afforded them. This view is, however, evidently not shared by the Associated Companies, for in the year I886 the late Sir James

- In letters, an increased number does not (within limits) mean increase of staff.

- The effect of high rates on the Gold Coast is strikingly exemplified by a fact stated by Mr. Henniker Heaton, that a friend of his at Lagos, in order to avoid the high rates charged on the direct route to London, has been in the habit of sending his cablegrams largely by the French land. line route via Senegal and Paris. 
Anderson (managing director of the 'Eastern' Company), in the course of a paper to this Chamber remarked, "If they were to lower their tariff to $2 s$. to India and to $4 \mathrm{~s}$. to all other places beyond India the companies would lose more than half their present revenue.' (As we know, these reductions have, under stress, since been partially reached, without any signs of the said disaster.)

"It may be remarked incidentally that-in answer to recent public calls and partly due to a wiser handling - the companies referred to have of late shown signs of pursuing a more progressive and favourable policy; for, besides waiving the question of subsidies where before they were said to be vital, ${ }^{1}$ they have lowered some of the rates to a material degree. This, however, is no doubt largely owing to distinct suggestions of State or other competition, as well as to the various inquiries recently set afoot-at the instance of agitation and pressure. Besides the reduction of rates to Australia and other places resulting from the Pacific cable project, the separation of the British and foreign offices at Hong Kong and Shanghai, and the ultimate extension of the CapeAustralia cable to Adelaide, are cases of the

1 A somewhat large subsidy $-£ 37,400$ a year in all-was asked by the "Eastern Extension" Company for the new line to and from the Cape to Australia; but the laying of this was ultimately agreed upon without any subsidy whatever-before the Government had actually settled on the Pacific cable. A reduction of tariff was volunteered at the same time. 
suggestions of critics being eventually acted upon after being for a considerable time derided as unreasonable, unnecessary, unpractical, and, indeed, 'involving penury' to the companies. Then, again, the eventual solution of that mystery, the Indian rates, only came about through Sir Edward Sassoon's persevering inquiries. The 'Eastern' and 'Indo-European' Companies were 'most desirous of a reduction,' but Russia and Germany were said to object. Other similar proposals are being made now that evasion appears impossible, and no doubt some ingenious explanation of all these reforms is available; but we see the effect of agitation and how much is due to those who have agitated. The net result is at any rate satisfactory, but, without actual competition, it usually takes a long time to get what is wanted.

“ Yet, speaking generally, it needs very weighty arguments to justify any Government in entering into competition with private enterprise. ${ }^{1}$ The State should, on the other hand, exercise on behalf of the public taxpayer an effective control, rather than otherwise interfere with industrial undertakings. Looking to the future - and passing from the general to the particular-it appears

- Government intervention in regard to the Pacific cable only became necessary because the companies responsible for our cables to Australasia were not prepared to meet requirements. In such circumstances no company can reasonably expect to be protected against Government or otber competition. 
abundantly clear that the State is not only perfectly entitled morally, but that it is also its duty to watch over and protect the interests of the public by putting a limit on the rates to be charged by telegraph companies when the latter seek subsidies, or at any rate landing rights. ${ }^{1}$ A sliding scale tariff, dependent upon, say, a fixed standard revenue, ${ }^{2}$ might be found possible - on the gross receipts, not on the net profits, which cannot readily be checked. Or, again, the rates could be based somewhat on the average earnings for a given period. $^{3}$ Further, a guarantee of traffic-either on the laying of a cable or on a reduction of tariffwould, I imagine, be preferable to the payment of large subsidies.

1 Where subsidies are not sought, landing rights become the only fighting weapon, or lever, the Government have; yet even this might be turned to better account than has been the case hitherto. To place the existing rates on a proper footing at once-especially if there is any idea of encouraging competition rather than otherwise-a special Act of Parliament should, strictly speaking, be introduced for the purposes of their adjustment. It is, however, difficult to recognise the justice of such a course, under the particular conditions that have prevailed up to date; moreover, it is questionable whether a Bill with this end in view would ever pass.

2 Six per cent. suggests itself as a fair return for this class of undertaking.

3 A certain rate per mile is an obvious standard; but this, for the reason that the tariff has to be arranged on the basis of probable traffic volume, and that the shareholders' outlay has also to be considered, would not always be fair. Probably the best rough standard at present existing is the Atlantic tariff, for her competition-more or less severeis in force, and on the other hand, English Atlantic companies have had no actual subsidies. 
"Another useful reform would be that of the gencral adoption of a class of 'deferred messages ' at special and reduced rates, as already in use in India and other countries. At present only five per cent. of the messages sent are of a private or domestic character; but, if deferred rates came into vogue for employing the cables through the night, the number of such messages might be very largely increased. The principle of deferred rates certainly seems more reasonable than that of 'urgent' and 'ordinary'; for, unless otherwise stated, it would be natural that all ordinary telegrams should be urgent; moreover, the 'deferred' rates suggestion should suit the traffic better, bearing in mind, too, the difference in time that often exists. The proof that there is ample room for this proposed system rests in the fact that the companies say that, if it were adopted, nearly all messages would go on that basis. It is not unlikely that it would be accepted as feasible if sufficient pressure were brought to bear, though possibly the International Convention might again prove-or appear to be-a stumbling block! Whether deferred messages should be sent in code language is another question. Some consider that the Reuter system of 'packed' messages meets all requirements, but this is not altogether the same thing in practice. Latterly the companies have proposed to codify domestic or social messages for the public, and it is possible that this may meet

T.c. 
the same ends practically-though perhaps not so pleasantly.

"Legislation should be introduced, if necessary, to put a stop to what are known as 'blocking ' rates; that is to say, to prohibit a company from charging excessive rates for forwarding messages on behalf of another system - with a view to destroying competition.

"Then, again, the Government could suitably take occasion to bargain with companies for reduction of rates in one direction when granting landing rights in another.

"An indemnity might also be imposed for every day's interruption to communication above a certain number. This is better than applying anything of the sort to the duration of time occupied in actual repairs. It is a point, however, which should not be pressed, for a number of alternative-routed cables between given spots is more essential and would probably meet the requirements.

"In the public interest the Government ought also to guard against subsequent financial amalgamations, absorptions, ${ }^{1}$ or joint purses; besides providing for taking over any given cable (at an expert's valuation) at any time, if found desirable. ${ }^{2}$

1 These, though having certain advantages from an economic administrative point of view, are liable to lead to abuse of power-besides defeating wholesome competi. tion.

2 This has been recognised lately at the recent Conference between the Colonial Secretary and Premiers, when 
"Further, it is a question whether exclusive landing rights should be granted, unless on very definite and favourable conditions.'

"Speaking generally, wherever competition is excluded to the benefit of any particular interests; a corresponding advantage ought to be secured by the Government on behalf of the public. In any case, exclusive rights should be capable of being terminated if found desirable, and ought never, in future, to be made permanent. ${ }^{2}$

"The result of reduction of tariffs would probably, as a matter of fact, eventually tend to an increase of revenue instead of the reverse. Had the companies rather more adopted the

the following resolution was passed in favour of an expro. priation clause for future cables :-

"That it is desirable that in future agreements as to cable communications a clause should, wherever practic. able, be inserted reserving to the Government, or Govern. ments concerned, the right of purchasing on equitable terms, and after due notice, all or any of the cables to which the agreements relate."

- A somewhat striking instance of the impropriety of monopolies from the public standpoint exists in the case of Hong Kong, to which port a single company possesses sole rights of cable communication for twenty years from the date of its agreement with the Government, i.e., from October 8th, 1883 .

8 This is based on an approximate estimate of the life of a cable-a very ordinary period being twenty five years: sometimes it is only twenty years. But this has been exceeded in several instances; and in, at any rate, one instance, the period has been made indefinite, i.e., permanent-notable in that obtained by the "Eastern" Company from the Khedive for telegraphic communication with Egypt. Somewhat similar considerations appear to have been secured by the companies from Turkey and Persia. 
principle of opening up a country and its trade (in the same way that railways do without subsidies) and lowered rates with the direct object of creating a demand-allowing, in a word, that telegraphy tends to react on trade-they might have done even better than has actually been the case, and would not then have had practically all the chambers of commerce on their trail! It is possible that the reason the companies do not want to lower their rates is because if they did so they would require to increase their staff, ${ }^{1}$ and possibly the number of lines between given points. ${ }^{2}$ The latter reason is, as a matter of fact, a strong argument in favour of reduced rates from the strategic and taxpayer standpoint.

"At present, cablegrams are never sent by private individuals, except under great stress-indeed, the cable is hardly thought of by them ${ }^{3}$-and messages would be sent on a much larger scale by small business houses if the rates were materially lowered. This still more applies to the Pressmost important clients-who might, with cheaper rates, do so much to bring the Empire into closer touch, politically, commercially and socially.

1 At the present time, the "Eastern "group of companies employ a staff at home and abroad amounting to about 2,000 , exclusive of the 700 odd who are attached to their fleet of twelve cable repairing ships.

2 In other words, though they might in the end earn as much revenue by reduced rates, it would give them a great deal more trouble and expense to effect this.

B It is doubtful whether many know exactly what course to pursue when wishing to send a cablegram. 
"The popularizing of the cable could be effected partly by reducing the rates for above a certain number of words if further alternative lines be laid, the effect being an encouragement to business cablegrams covering more ground.

"But what we really want-and what perhaps we shall some day get-is a universal shilling or even $6 d$. rate for all cables throughout the Empire. Meantime, anything in the shape of lower rates and an increased number of cables on different routes to carry the increased traffic would be good commercially, politically, and strategically. If the Government would guarantee the companies, for a given period, against loss, the experiment might be agreed to, I imagine.

"Let us now turn more especially to the strategic aspect of alternative lines on different routes. This has often been misrepresented. For instance, those who have advocated the ordinary trade routes as the best routes strategically for cables have-by way of backing up their contention-laid stress on the fact of our men-of-war being on the spot. It should be remembered that in the event of a 'surprise war' our communications with the rest of the Empire vii the Mediterranean would probably be cut off before war was actually declared.' This would not be

- A power which is friendly to-day may be unfriendly to-morrow; in fact, with the present state of foreign politics there is no knowing who we may not have against us at any time. 
an easy matter for the enemy to accomplish, but it would be a sufficiently valuable achievement to be worth a good deal of trouble. For that very reason, it should be similarly worth our while to render such an achievement out of the question; and that is best accomplished by increasing the number of our telegraph routes, and of taking future cables further out of the reach of naval powers. As things stand at present, in practically every case, the enemy could only effect interruption to our traffic by more than one line being disturbed at the same time. This would probably always involve more than one European Power being against us, but it would be a possibility to be reckoned with in the event of a 'surprise war.' As a matter of fact, it could invariably be effected in the absence of one of our battleships being on the right spot at the right moment in both cases.

"If it happened that France and Russia were combined against us, Russia ${ }^{1}$ would at present be in a position to cut off our communications with India and Australia in the Mediterranean, ${ }^{2}$ besides interrupting the system of the Great Northern Telegraph Company on the one hand and the Indo-European Telegraph Company ${ }^{3}$ on the

1 It is known that Russia has for years had carefully prepared schemes for cutting off our communications to the East and Far East, and the same applies to France.

2 During the bombardment of Alexandria this actually did occur.

${ }^{3}$ This Company has, it is believed, recently had foreign clerks forced on them in Germany and Russia. 
other, whilst France paid her attention to the system via the African East and West Coasts respectively, as well as the European land lines and the cables in the English Channel.

"The mere fact that the Associated Companies are in the habit of setting aside a part of their reserve fund for war risks, clearly indicates that they do not really consider their cables safe in time of war. The companies, however, contend that strategic cables could be laid 'to order' as required. This undoubtedly might be practicable, though often difficult to accomplish; but if we recognise the likelihood of our communications being interrupted before war has been declared, we have to face the fact that to start laying down such lines after the outbreak of war would be too late; while in the case of an interruption of existing lines, it might be several weeks, if not months, before the missing link could be restored, during which time the effect would be disastrous. In this argument, too, those concerned appear to forget for the moment the oftreferred-to scarcity of gutta-percha at a critical moment.

"Then there are those who consider that a line which touches on foreign soil can readily be converted at short notice into an 'All-British' line by a change of route in the event of war. Of course such a thing might be done with a successful issue, but the risk is great, and the result is less likely to be satisfactory in any case than a 'ready-made' line. 
The suggestion that such 'All-British' lines should be made 'to order,' as required, seems to indicate an admission as to the utility of this class of line, though the suggestion comes from those who argue that cables are least liable to disturbance in time of war if landed on foreign territory of various nationalities. ${ }^{1}$

"It should be accepted as an axiom that lines laid for strategic reasons meet their requirements best if laid in deep water, with few landing-places, ${ }^{2}$ their route, except at the ends, ${ }^{3}$ being unrecorded. A knowledge by the enemy of the position of a cable in deep water ${ }^{4}$ is a far less serious matter than when laid in shallow water. A man-of-war can pick up and cut a cable in shallow water just as it is equally true she can probably more easily repair a cable here: but without long lengths of actual cable, grappling rope, and the necessary

1 It would not do to rely on all countries showing such consideration for neutral cables, even for international reasons, as the United States appear to have during the Spanish.American war. It must be remembered that control and censorship fairly covered their requirements, and that the water was deep.

2 Interruptions to cables by bonfires on the beach have already been effected more than once. Landings should be guarded.

8 Notice of the approach of cables within two or three miles from the shore is, of course, a necessary provision against damage by anchors; moreover, it would be impos. sible to maintain secrecy at such distances from the landing end, just as also any attempt at foul play could easily be detected and remedied here.

4 Throughout their war with Spain, the Americans were never able to cut all the Cuban cables landing at Santiago, owing to the deep water there. 
picking-up machinery, she cannot do much with a deep-water cable.'

"It is scarcely necessary to call attention to the importance, even under normal conditions, of telegraphic communication with all our naval fortified and garrisoned coal stations, besides all ' defended ports.' To effect this alone the ordinary trade routes must be departed from.

"One of the few points against 'All-British' cables is that of setting the backs of Europe as well as the United States against us. But this has been practically discounted by the fact that France and Germany, in addition to our American cousins, are now going in for similar precautions themselves, initially on account of the cables of the world being British owned.2

"A stock argument is sometimes brought up to show that 'All-British' cables are not necessary from the point of view of secrecy, because the purport of messages can be concealed by the cypher code. Surely, however, it would be a mistake to rely on the security of the cypher, or any code, when we know by experience that the most difficult cypher can be translated if a suffi. cient number of messages are available to work on, together with a knowledge of the correspon-

If the Navy had properly equipped telegraph ships with a staff of cable engineers and electricians, the matter would, of course, be different.

- France decided upon establishing communications with her possessions before "All-British" lines were seriously contemplated or talked of. 
dent's identity, and the probable nature of his communications. ${ }^{1}$ There are reasons for supposing that the cyphers of most of the European Foreign Offices have been translated by other interested Powers many a time, and if once a system of half code half plain language is indulged in the decipherment becomes a comparatively simple matter.

"Apart from this, the mere fact that messages passing through foreign territory are subject to serious and often intentional inaccuracies and delays is a sufficient' argument in favour of 'AllBritish' lines. Cables landing on foreign shores are, it should be remembered, largely worked by clerks of the country even in times of peace; and if trouble is in the wind messages are either stopped altogether or 'muddled' at an important point to 'make time.' Again, the seizure of the cable station previous to the declaration of war is a conceivable course of action, but that would not be likely to occur in the case of a cable landed on British territory, and certainly not if it were adequately guarded.

"The telegraph companies have very naturally paid their first attention to the trade routes as giving the best prospects of revenue; yet these are not good routes strategically wherever the cable passes through shallow water in the vicinity of

' A good example of how codes are read when desired, is the reading of the Spanish code by the Americans on the Havana-Key West Cable during the recent war. That cable was left intact for this express purpose. 
foreign territory. The class of cables whose object is mainly strategic have seldom been laid, if only for the reason that their prospects of revenue are poor. But we should recognise them as an essential of the age, and in particular as a necessary adjunct of Imperial policy. It is, indeed, just these lines that the State itself should consider the advisability of itself undertaking, if necessary.

"What is the use of an idea such as Imperial unity, or how can it be relied upon in practice, without Imperial mobility in a strategic sense? This latter can only be effected 'by 'All-British' cable communication under definite Government surveillance, either direct or through a subsidised company acting as their agent. Considering what we pay for our postal sea service, this view should be readily accepted, for, obviously, no country requires strategic cables so much as the British Empire, with its far-reaching possessions.

"If certain strategic cables were laid the traffic on the ordinary trade routes would be less likely to become disorganised in war time by the suppression of code messages.

"The typical strategic line, avoiding foreign soil, has been materially assisted by a recent invention. By its means long sections of expensive typed cable may be avoided whenever an island, however small, is found on the route, so that the apparatus can be inserted between the ends of the incoming and outgoing cable. This forms a system 
of retransmission which dispenses with the necessity of a large staff of operators for effecting the same manually.

"The case for 'All-British' cables in addition to international lines does not rest only on strategic grounds. We need them for consolidating the Empire-politically and socially-as well as for the assistance of Imperial trade. The companies have already provided a fairly adequate network of cables on trade routes; but direct 'All-British' lines are now required, if only to ensure speedy and uniform 'cabling' facilities throughout the whole of the Empire both in times of peace and war. If we could render the entire British Empire practically as one country, by means of telegraphy, a great result would, indeed, be achieved.

"For commercial, trade reasons, the more links on various routes the better to ensure communication in all directions at all times; and at least one of these routes should, for the various reasons enumerated, be 'All-British.' At the present moment the 'All-British' element in the now existing girdle is broken at two spots, Madeira and St. Vincent, both Portuguese territory; and though Portugal may be regarded more as an ally than as a possible enemy, it is also true that no belligerent would hesitate to consider so feeble a neutral Power, the fact being that the value of a cable landing on neutral territory all depends 
upon circumstances-that is to say, what the neutral Power is and the conditions of politics at the time.

"The complete 'All-British' chain might be completed by a cable from Ascension (or Sierra Leone) to Barbados or Jamaica, where it would fall in with a cable from Canada. Such a scheme would constitute the first truly 'All-British' line from this country to the Cape. Time does not permit me to go into the various cable routes that should be taken in hand; but I will only mention that - partly with a view to trade between Canada and the Cape-a useful 'All-British' line might be established between these countries either via the West Indies, as above, or by a more direct route-say to Bermuda-connecting up with the 'All-British' Atlantic cable that I have already spoken of as a link with the Imperial Pacific line. The map before you, besides bringing into prominence the Pacific line, is specially designed to show the telegraphic girdle in a complete, unbroken form; that is to say, going by the Western (Pacific) route to Australasia and returning by either of the Eastern routes, or vice versi. There are other lines even more urgent for purely strategic reasons which the Cable Communications Committee have taken note of.

"A difficulty in getting funds voted for purely strategic cables exists owing to the Treasury having so many calls for immediate indispensable -indeed, vital-needs; and purely strategic cables 
never appear under this head until too late! Experience is certainly a sure means of learning our requirements; but in things national it would be better to do so by forethought.

"A few words now regarding the broad question of State absorption of our cable system by special Act of Parliament. Whilst there can be no question that, from the public point of view, there is much to be said in its favour, it must be remembered that there are many unfavourable features about any step which tends to check private enterprise in a country, the secret of whose greatness may be said to be largely due to that very function. There are also political objections to State absorption. Hitherto, the companies have acted somewhat in the capacity of diplomats, hence, partly, perhaps, their objections to 'AllBritish' lines. On the other hand, it must be recognised that the State, in having no shareholders to consider, should have less difficulty in serving the public satisfactorily in certain particulars. Wholesome competition, however, usually meets that objection to private enterprise, with the additional advantage that, as a rule, business men-with a commercial training and the necessary special experience-manage such matters better than Government officials and Civil Service clerks, \&c., with their numerous and varied duties.

"As before stated, guarantees in some form, of traffic or revenue, might be found a convenient 
shape for Government encouragement to take with reference to any future lines. This would be a sort of compromise between granting a subsidy more or less large and giving no support whatever. The principle also seems better; and would, perhaps, avoid too close an examination into the question of fair profit by the companies. It is already in Government operation with the Indian railways.

"Though, mostly for diplomatic and political reasons, the balance of evidence and argument may be against immediate, or complete, State - absorption and monopoly, it would seem that in the absence of the existing telegraph companies meeting national needs-the Government would be entirely justified in encouraging competition, as they would also in setting afoot certain State lines-strategic or otherwise. The effect of this could be made to cover any desired reduction of tariff, it being assumed that the existing rates could scarcely be adjusted by Act of Parliament.

"From a strategic point of view, as well as from a general maritime standpoint, Great Britain and Ireland should be provided with a complete system of telegraphic communication round the entire coast, in communication with various inland centres and military stations. It is a piece of work which could best be dealt with by wireless telegraphy, in preference to overbead lines or coast cables, which latter fail owing to abrasion against 
64 Imperial Telegraphic Communication.

rocks, kinks, \&c. ${ }^{1}$ Government might well encourage progress here by establishing funds for further experiments such as would be likely to produce highly useful results.

"Some of you may, by the way, have been wondering why I talk of cables in view of the existence of wireless telegraphy. The answer is that-apart from low speed and lack of secrecywireless telegraphy can (at present) only be relied upon in such cases as the one I have just referred to, together with that of ships and lighthouse signalling; and the immediate question in connection with this new invention is how we can get it under control from a single centre.

"Lord Brassey and Gentlemen, before sitting down, let me thank you for your kind attention."

\section{Discussion.}

Mr. J. Innes Rogers (Chairman of the Council) said there was one point in Mr. Bright's very able address which struck him very much, and that was that he dealt with cable telegraphs as if they were specially intended for purposes of war. Now he (Mr. Rogers) recollected the starting of ocean telegraphy, which was then considered to be something like the inauguration of an era of peace. That, however, had not come to pass, as they all

1 This matter was gone into by the writer yery fully in The Engineer, of February I 7 th, March 3 rd, March Ioth, and March I7th, 1889 , in the course of a series of articles on "Coast Telegraphic Communication." 
knew; but he thought the first telegram sent by the Atlantic cable was from our late great Queen to President Buchanan of the United States, and consisted of the words, "Peace and good-will to men." They had heard a great deal from Mr. Bright of the strategic question connected with submarine telegraphy; and it would not be doubted that it was one of the most important subjects the Government should consider, if they had, as he feared they had not, proper Intelligence Offices attached to the Army and Navy. With regard to the advantages of cable telegraphy in time of peace, the enormous saving of stocks of goods which the cable enabled them to effect was very remarkable. For instance, there had been a great many complaints of late years of the want of prosperity of the docks of London. That was largely due to the existence of ocean telegraphs. The producers of goods no longer sent them on consignments to large centres like London, but kept them in the place of production until they were wanted, and then sent them to the competing country which paid the best prices for the goods. That effected an enormous saving in capital. Mr. Rogers gave other instances of the enormous advantages conferred upon commerce by ocean telegraphy, and concluded by expressing the hope that the Government would not lose sight of the important strategic aspect of the question.

Capt. Anthony S. Thomson, C.B., remarked that all would agree that the Pacific cable must T.c. 
sooner or later be duplicated by one or other of the methods suggested by the lecturer. With reference to the question as to the acquisition by the Government of this country of the control of the cables, he agreed with Mr. Bright that that should in any case only apply to those which were All-British, as it would not do for our Government to have control of or acquire cables that touched on foreign soil. He further wished to endorse all the lecturer had said as to the admirable manner in which the cable had been laid by the contractors.

Sir H. C. Mance, C.I.E., gathered from the address that had been given that the best thing they could do was to lay as many cables as they could, so that it would be hardly worth while for a foreign Power to attempt to cut them in time of war. It was not so easy as people thought to cut a cable. Even when the position was exactly known and in deep water, he did not consider any foreign Power would find it in time to escape some of our cruisers. As to wireless telegraphy, he was of opinion that it could never be considered as a rival to submarine cables of any length. Wireless telegraphy had come to stay, and had a very useful sphere of action in outlying places and in communication between ships, although the latter could not be relied on in time of war, owing to the ease with which it could be interrupted by another vessel.

Mr. Charles Bright, F.R.S.E., agreed with 
Mr. Rogers in his remarks regarding the peaceful effects of submarine telegraphy-indeed, he had drawn attention to that in his address-and there was no doubt that many a misunderstanding between Governments had been avoided which would have ended in war, but for this rapid means of communication. Still, it would not do to shut our eyes to the possibilities of war at any moment; and in his (Mr. Bright's) opinion it was essential for the Admiralty to be in constant and immediate, private wire, communication with the fleet of each naval station, besides the Home and Colonial Governments being in similar touch with one another.

On the motion of Lord Brassey, seconded by Mr. M. H. Gray, a hearty vote of thanks was accorded to Mr. Bright, and briefly acknowledged by him, the proceedings being brought to a con. clusion by a vote of thanks to the chairman.

\section{ADDENDUM.}

STATISTICS, TECHNICAL DA'TA, ETC.

\section{Total length and Capital Value of Cables so FAR LAID.}

THE total length of telegraph cable so far laid at the bottom of the sea, down to the present time, is over 200,000 nautical miles (N.M.), representing about fifty millions sterling. These last figures are the actual capital originally invested in the various Cable 
Companies. The present mariket value of their united capital greatly exceeds that figure, the shares of the "Eastern" Company, for instance (which owns by far the largest individual cable system), being worth 5 o per cent. more than their original value.

\section{Subsidies.}

The following are some of the more important subsidies paid by the Governments concerned :-

In I869, the West India and Panama Telegraph Company had certain subsidies for inter-insular cables from English and French Colonies in the West Indies for ten or twelve years.

Some years later subsidies amounting to $£ 32,400$ per annum for twenty years were obtained from the Australian Governments by the Eastern Extension Telegraph Company for telegraph communication with Australia. ${ }^{1}$ A little later a sum of $£ 4,000$ was voted for a cable from Australia to Tasmania.

In 1879 the Eastern and South African Telegraph Company was subsidised by Government to the extent of $£ 55,000$ per annum for twenty years for the cables on the east coast of Africa from Aden to the Capei.e., $£ 35,000$ from Great Britain, $£$ 1.5,000 from Cape of Good Hope, and $£ 5,000$ from Natal-about sufficient to pay for the cable, in fact. It may be remarked that the cable was very urgently needed at the time.

In 1885 the African Direct Telegraph Company (of the "Eastern" group) laid cables down the west coast of Africa to the Cape, subsidised annually for twenty years by $£ 19,000$ from Great Britain and $£ 6,000$ from Germany. In the same year the West African Telegraph Company (now absorbed with the "Eastern" group) obtained $£ 32,000$ from Portugal, and $£ 12,000$ from France for cables establishing communication with these

1 This sum was first paid in 1879 in ordor that the "Eastern Extension" Company should duplicate the Penang-Australia Cable, which had been frequently interrupted since it was first laid in 1870. 
countries' Colonies on the said coast. 'These were annual subsidies for twenty three years.

A few years later (1893) the "Eastern and South African" Company laid a cable from Zanzibar to Mauritius vid Seychelles, subsidised by the Home Government to the value of $\ell 28,000$ per annum for twenty years.

In 1859 it was agreed by the Home Government to pay $£ 8,500$ a year for twenty years to the Halifax. Bermuda Cable Company for a cable between those points.

In 1896, the Direct West India Cable Company entered into an agreement with the Home Government for $£ 9,000$ a year for twenty years in respect to a cable between Bermuda and Jamaica.

\section{Cable Construction and Shipping Output of Great Britain.}

About too N.M. per day.

\section{Cost or Construction.}

The cost of a submarine telegraph cable may nowadays be roughly estimated at $£ 150$ per N.M., but this figure varies a good deal with the working speed aimed at, as well as on the length of section and other considerations.

\section{Speed of Cable laying.}

About seven knots; but sometimes up to ten knots.

\section{Stacs.}

Five to 15 per cent.; average 7 per cent.

\section{Cost of LAYing.}

The cost of submersion may generally be roughly estimated at about one and a half times the cost of construction. 


\section{Life of a Cable.}

This can be almost anything from five to, say, twenty-five or even forty years, i.e., before it gets into such a poor state that it becomes cheaper to lay a new line than to risk the chance of protracted, and possibly unsuccessful, attempts at repair.' Nowadays, when the type is carefully selected subsequent to a complete survey-assuming that the cable is of good manufacture and carefully laid-there is no reason that it should not last the longer period named, provided that the bottom be ooze and that there is a complete absence of casual sources of detriment, such as earthquakes, ships' anchors, rocks, coral, sharks, sawand sword-fishes, teredoes, vegetation, plant life, obnoxious minerals or submarine springs-all found in shallow, rather than in deep water.

Two inches of good substantial mud or ooze, which may as a rule be found in deep water, are the best possible preservatives for a cable; and "the deeper the water, the better the bottom, the safer the cable," may safely be taken as an axiom.

Probably the record case of freedom from repairs is the "Brazilian Submarine " 2 Company's St. VincentPernambuco Cable, which lasted nine years after being laid before any sort of fault showed itself-even in the shallow water approaches.

\section{Cost of Maintenance: Duration and Cost OF REPAIRS.}

The maintenance of a cable is usually put down at something between $\ell^{6}$ and $\ell^{8}$ per N.M. per annum.

1 On the other hand by successive renewals as necessity arises, a cable might, perhaps, in certain instances, be kept going almost indefinitely-thereby saving a heavy expenditure all at once. Sometimes the more valuable gutta-percha insulated conductor is recovered and resheathed with new armour.

2 Now the Western Telegraph Company. 
There is, however, a great element of luck attached to this - to wit, the 295,000 entailed in repairing the 1874 Atlantic, occupying over a year. Luck, here, is almost entirely a question of weather and the condi. tion of the cable near the seat of repairs. To give another example more directly dependent on the weather : The Aden-Bombay section was once broken in 1,900 fathoms for 251 days. For 148 days opera. tions had to be entirely laid aside owing to a monsoon. Ultimately 1,76 miles of cable were required to effect the repair.

\section{Valee as an INVESTMENT.}

Although-at first sight, at any rate-a somewhat risky property, deep sea telegraphs have generally proved a very remunerative source of revenue. Depreciation, however, forms an important factor in the accounts of a cable-owning company. A large renewal fund is thereby rendered essential, especially as the first cable laid between two given points is never regarded in these days as sufficient for its owners to rely upon solely and permanently.

Thus the necessary sinews of war are considerable. Nevertheless, investors in cable stock obtain a good return for their money in the long run, and examples are not wanting of very quick and profitable returns. For instance, the original Malta-Alexandria Cable earned as much as $£ 3,000$ in a single week soon after it was laid, or at the rate of $E 117$ per N.M. per annum. Again, between 1864 and 1869 the Persian Gulf Cable was earning at the rate of $£ 100,000$ per annum.

\section{Number of Cablegrams conveyed Per Anivn.}

In land telegraphy the number of messages conveyed through the British postal telegraphs is at the rate of one and three quarter messages per head of the population per annum. Nothing like this rate can be found in the case of cablegrams. Roughly speaking, about six million messages pass over the entire network of the world's 
cables in the course of a year, which is equivalent to about $\$ 5,000$ for each day of twenty-four hours. Since the first lines were laid the number of messages have increased out of all proportion to the increased mileage of cable provided to convey them. Indeed, but for the code system, the existing cables or working staff could not possibly cope with the traffic as it is at present. About 90 per cent. of the messages sent over cables are in cipher or other code language.

\section{Rate of Cablegram Transits.}

The average time occupied in the transit of cablegrams has been enormously reduced for public traffic. Where formerly it took an average of five or ten hours to get a message through to its intended destination, from thirty to sixty minutes now suffice for extreme points, and between many stations the time is as low as from three to five minutes.

\section{Working Speed of Cables.}

Since the application of automatic (machine) transmission to submarine cables within recent years, the speed is, practically speaking, only limited by the type of conductor and insulator adopted-i.e., by considerations of initial cost. The last three Atlantic cables have sufficiently large conductors and insulators to enable automatic working up to nearly fifty words a minute (simplex). The speed of cables worked manually - provided the "core" (conductor and insulator) is of sufficient dimensions for the length-is only limited by the speed the clerk can work the transmitting key, say twenty-five to thirty words a minute (simplex). The working speed of any cable is dependent, inversely, on the product of the conductor resistance and the electrostatic inductive capacity of the cable, and varies, inversely, with the square of the length-i.e., if a cable of given type is doubled in length, the working speed becomes a fourth of what it was with the original length. 
Practically all cables-apart from duplicationsare duplexed nowadays. The result of this is to very nearly double the earning power of the cable by enabling messages to be sent in both directions at the same time, whilst scarcely reducing the effective speed in either.

\section{INDIARUBUER AS AN INSULATOR.}

Lest the scarcity of gutta-percha should be seriously considered, attention may be called to the fact that a very considerable length-some where about $2,500 \mathrm{~N}$.M. - of cable insulated with vulcanised indiarubber has been worked through for years and is doing good service. Indiarubber is even superior to gutta-percha for tropical waters, infested with teredoes, or swordand saw-fishes-such as abound in moderate depths.

\section{Engineering Statistics.}

Greatest known depth at sea bottom-4,656 fathoms -Off the Kurile Isles.?

Minimum temperature at sea bottom $=34^{\circ} \mathrm{F}$.

Greatest depth at which a cable has been laid = 3,200 fathoms, Pacific Cable (Vancouver-Fanning Section); also 3,113 fathoms, Bermuda.Turk's Island Cable.

Greatest depth at which a cable has been repaired - about 2,700 fathoms, between Lisbon and Madeira. N.B.-1, -0 o fathoms = one nautical mile (N.M.) = $6,087 \mathrm{ft}$.

Longest length of any cable section laid $=3,458 \mathrm{~N} . \mathrm{M}$. Vancouver-Fanning Island (All-British Pacific Cable); previously 3,174 N.M., Brest (France) Cape Cod (United States) Cable.

Greatest length of any cable worked $=3,700$ N.M. (two lengths of cable looped together).

In 1866 an experiment was made for working through the second and third Atlantic cables looped

- Slightly greater depths bave been spoken of, but in these cases the soundings have been unreliable. 
together. The battery consisted of a few drops of pure sulphuric acid in a silver thimble, with a fragment of zinc weighing a grain and a half. The instrument used was the Thomson mirror galvanometer, the signals obtained being excellent. 4,733 N.M. of cable have, it is believed, been worked through, for experimental purposes, more recently.

\section{TARIFF.}

A curious example of the variability of rates to spots about equidistant is provided in the instance of Shanghai or Hong Kong and Vladivostock; a telegram to both the former costs 5 s. $6 d$. a word, whereas to the latter it may be sent for Is. $3 d$. a word. ${ }^{1}$ Another instance: France can send a message to her West African Colony, Senegal (St. Louis), for 1s. $3 d$. and to Cutanu for is. $7 \frac{1}{2} d$. a word, while we have to pay 6s. 3d. a word to Accra, 7s. Id. to Lagos, and similar tariffs to other British possessions on the Gold Coast. ${ }^{2}$ Yet another case of cheap telegraphy enjoyed by Frenchmen has sometimes been referred to: that of Tunis or Algeria at $\frac{1}{2} d$., as compared with our rate to Egypt at Is. 9d., but the cables to Algiers and Tunis are really French Government cables. We have also the Atlantic cable tariffs, which-under the existing

1 The explanation of this former tariff rests, no doubt, in the fact that the Great Northern Telegraph Company holds a monopoly for telegraphic communication from Vladivostock to Shanghai and Hong Kong; and the explanation of the latter tariff is, probably, due to the Russian Government only having granted landing rights at Vladivostock on the company undertaking not to exceed that tariff for the public.

- The former low tariff is not unlikely to be partly due to the messages going overland from Senegal, besides which the line is said not to "pay," and the explanation of the high tariff to Accra, Lagos, \&c., is, no doubt, mainty on the basis of poor prospects of traffic.

The minimum tariff is that by Government cables to the Continent, i.e., 2d. a word. 
state of affairs of fifteen cables, and, at any rate, one company opposing a joint purse-are now, since 1888, fixed uniformly at 1s. per word, instead of a minimum of $£ 20$ for twenty words as at first. when a monopoly existed. ${ }^{2}$ As stated in the address, the Atlantic rates were lowered to $6 d$. for eighteen months on trial; they were afterwards brought back to 18.

The existing Atlantic cables represent a capital of about $\{20,000,000$. A knowlodge of the profits derived from each system is not readily to be arrived at, but, from a comparison of the traffic receipts or " money returns " of the oldest Atlantic Company at different periods, it may be said that the " takings" are, roughly" speaking, very much the same as they were twenty-five years ago, i.e., about $\{200,000$ per annum. This is explainable by the fact that, althougb the number of messages now passing is much greater, the reduction of the rate under the infuence of competition just about cancels this advantage $s 0$ far as the receipts are concerned. 


\section{IMPERIAL TELEGRAPHS. ${ }^{1}$}

THE hour of three o'clock on the morning of October 3Ist, I902, should be regarded as an important date in the history of the Empire; for then it was that the Puck of modern science carried out the promise which he gave three centuries ago:

"I'll put a girdle round about the earth In forty minutes"

and that by the completion of the last link in the Pacific telegraph the Australian Commonwealth was, at one stroke, brought, telegraphically speaking, ten thousand miles nearer to the Dominion of Canada than before.

The scheme from which the cable ultimately emerged was one formulated some twenty years ago. It has passed through many vicissitudes, and not a few disappointments. It had had to encounter and overcome many obstacles, both those inherent in the difficulties of the plan itself, and those raised by interested opponents. The late Sir Julius Vogel was perhaps the first to put the idea prominently forward; but the greatest credit is due to Sir Sandford Fleming for pressing the scheme with unremitting perseverance, as well

1 Quarterly Review, April, 1903 
as to the Silvertown Company, Mr. Alexander Siemens, Sir Charles Tupper, the late Sir John Macdonald, Sir Mackenzie Bowell, Sir Donald Smith (now Lord Strathcona), Mr. J. Henniker Heaton, the Hon. Harold Finch-Hatton, and others. In the latter stages of the project, the energy of Sir William Mulock, Mr. W. Pember Reeves, and Sir Horace Tozer was of great use in bringing things to a head.

The plan was first talked of in the early 'seventies. It was referred to in the official returns of the Canadian-Pacific Railway in 1880 , and was discussed at the Colonial Conference of 1887 ; but the first real footing it obtained was at the Conference at Ottawa in $r 894,{ }^{1}$ when the Canadian Government invited and received tenders from responsible contractors. Powerful interests, however, stood in its way; and there was much opposition, which, combined with misleading statements as to difficulties, had the effect of shelving the scheme for some years. On Mr. Chamberlain becoming Colonial Secretary things began to bear a different aspect. He immediately took the matter up and appointed a Royal Com. mission to consider the whole question. The Commission-composed of representatives of the

1 Blue Book, Cd. 7553. It was at this time that the importance of H.M. Government securing Neckar Island as a resting.place for the cable (with a view to reducing the length of the long section) was publicly urged, the only result being that we were forestalled by the American flag being promptly hoisted there. 
Treasury, the Colonial Office, and the Colonial Governments, with the Earl of Selborne as chairman-commenced its deliberations in June, 1896. It examined various expert witnesses on the whole subject, besides which the Colonial Office was furnished with a report from the present writer as to the practicability of the scheme. The Com. mission issued its report in favour of the project in January, I897. But the report was not made public until April, I899, after the lapse of two years and four months, during which various offers were made by the Associated Telegraph Companies to effect the same object and maintain control of the cable-system of the world. In the end, tenders were invited from various contractors ;

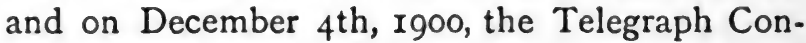
struction and Maintenance Company were entrusted with the manufacture and laying of the line.

In the following February a permanent Board of Control was established, representing the Home Government and the Colonial Governments concerned $^{1}$; and in August, I90I, the Pacific Cable Bill was passed. The Act provides for the construction and working of a submarine cable from

1 The composition of the Board was as follows: Sir Spencer Walpole (Chairman); Mr. G. E. Yorke Gleadowe, of the Treasury, and Mr. W. Hepworth Mercer, Crown Agent for the Colonies, representing his Majesty's Government; Lord Strathcona and Mount Royal and Mr. Alexander Lang, representing Canada; the Hon. Henry Copeland and the Hon. Sir Andrew Clarke, representing New South Wales, Victoria and Queensland; the Hon, W. Pember Reeves, representing New Zealand, 
the island of Vancouver, by way of Fanning and Fiji Islands, to Norfolk Island, and thence by two cables to New Zealand and Queensland respectively. For this purpose it authorises the raising by the Treasury of $£ 2,000,000$ at 3 per cent. out of the Consolidated Fund. The profits are to be divided in proportion to the disbursements of the contributory Governments. After a good deal of discussion it was agreed that the Home Government should join in the cost of construction and maintenance to the extent of five-eighteenths, the rest being met by the Colonies concerned. ${ }^{2}$ Provision is also made in the Act for the borrowing of money for the purposes of the cable.

The surveying of the route was completed on August 3oth, 1901. The bed of the Pacific Ocean in this quarter had been said, by those who opposed the scheme, to be largely composed of coral; but there was no evidence of this. On the

1 Commenting on the question of payment for the Pacific cable, and criticising an historical record of Sir Charles Tupper, a certain distinguished statesman wrote in The Times: "What I oppose are the demands made by the people of Canada on the pockets of the people at bome for large cash contributions, or guarantees, to carry out transmarine projects for the commercial advantages of the Dominion, while the United Kingdom, without any contribution or guarantee from Canada, has to bear the burden of protecting these transmariue under. takings in war. . . I am a real Imperialist, and decline to be a sham one."

Considering the large contribution made by Canada towards the cost of the line, and the fact that the com. mercial advantages referred to are by no means confined to Canada, too much weight should not be given to these remarks. 
contrary, it was ascertained that "globigerina" ooze-the best possible resting-place for a cablewas the main constituent feature. The construction of the cable was commenced in the autumn of I901, and on March I3th, 1902, the laying operations were begun. The entire work was completed on October 3Ist, 1902, several weeks ahead of contract time; and on December 8th the new line was opened for public traffic. Thus it took only about a year and a half to make the line which had been under discussion for some twenty years.

The various sections are as follows:-

\begin{tabular}{|c|c|c|}
\hline Portions of the Line. & $\begin{array}{l}\text { Distance } \\
\text { Overground } \\
\text { in Nautical } \\
\text { Miles. }\end{array}$ & $\begin{array}{l}\text { Length of } \\
\text { Cable in } \\
\text { Nautical } \\
\text { Miles. }\end{array}$ \\
\hline $\begin{array}{l}\text { Vancouver to Fanning Island } \\
\text { Fanning Island to Fiji } \\
\text { Fiji to Norfolk Island } \\
\text { Norfolk Island to Doubtless } \\
\text { (New Zay } \\
\text { Norfolk Island to Brisbane }\end{array}$ & $\begin{array}{r}3,22 \mathrm{I} \\
\mathrm{I}, 906 \\
883 \\
\\
48 \mathrm{I} \\
778\end{array}$ & $\begin{array}{r}3,45^{8} \\
2,043 \\
981 \\
\\
519 \\
835\end{array}$ \\
\hline Total & 7,269 & 7,836 \\
\hline
\end{tabular}

Thus it will be observed that the quantity of slack used cver the entire line was about 7.8 per cent. In the course of the preliminary survey, a steep submarine mountain was encountered about roo miles from Australia in the direct route between Australia and Norfolk Island, the depth 
changing suddenly from 2,500 to a little over 200 fathoms. This elevation was christened, after the surveying ship, the "Britannia Hills"; and a detour was made by the cable in order to avoid it. In this connection it may be noted that a distinguished civil engineer once spoke of the Pacific cable as having been "laid with what was called a swing from point to point." But the only sense in which the term "a swing from point to point " could be reasonably applied to the laying of a sub. marine cable would be in the event of actual suspension from point to point, and this is not the case with any section of the Pacific line. The greatest depth experienced on the route of the line

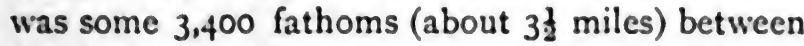
Vancouver and Fanning Island, being only 287 fathoms in excess of that on the cable between Bermuda and Turk's Island, though it had been stated by some that a depth of fonrteen miles would be encountered. ${ }^{1}$

The cable between Vancouver and Fanning Island is the longest hitherto laid in one piece, being 285 nautical miles longer than the French Atlantic line from Brest to Cape Cod. The great length of this section constitutes the weak point in the system, and even with a special core the working speed of the line is only roo letters per

- The German Atlantic cable goes into 3.300 fathoms between Fayal (Azores) and New York, as does also the Cocos.Perth section of the Cape-Australia line, and the Wake-Guam section of the American Pacific cable is in still deeper water.

T.C. 
minute by automatic curb (simplex) transmission, or about 170 letters per minute by duplex working. The conductor is of special design, due to Mr. Willoughby Smith, which combines the electrical advantages of a solid conductor with the mechanical advantages of a strand. ${ }^{1}$ No special novelties being introduced, it is not necessary to describe in detail the construction of the cable.

It may be doubted whether the Pacific cable would ever have been laid but for the vigour of Mr. Chamberlain. The scheme was more or less coldly looked on at home, until he (as Colonial Secretary) took it in hand as part of a great national and Imperial policy. He recognised its importance as a link for bringing the Empire into direct telegraphic connection for political, commercial, and strategic purposes. In practically annihilating space, the telegraph is one of the strongest links between distant countries, and its importance from a sentimental point of view should not be despised. There is no question that direct and unbroken Imperial telegraphy can do much, not only to stimulate commercial activity between the Mother Country and the Colonies, but also to strengthen that sense of unity and that community of feeling and policy on which the cohesion of the

1 This is a distinct mechanical improvement on the liright and Clark segmental conductor and has nearly an equal electrical efficiency. 
Empire under present conditions depends. In the words of Mr. Rudyard Kipling :

"Here in the womb of the world, here on the tie-ribs of earth,

Words, and the words of men, flicker and tutter and beat-

Warning, sorrow and gain, salutation and mirth-

For a Power troubles the Still that has neither voice nor feet.

"They have wakened the timeless Things; they have killed their father Time:

Joining hands in the gloom, a league from the last of the sun.

Hush! men talk to.day o'er the waste of the ultimate slims,

And a new Word runs between, whispering "Let us be one"!

For purely commercial reasons, if the Pacific cable is to compete successfully with the Eastern system-and in order to provide for possible breakdowns, not to mention ordinary conditions of traffic-it will probably require to be duplicated before long. Strategic reasons point strongly to the same conclusion. It is indeed quite conceivable that, in the event of a European war, the Pacific cable and the Atlantic lines might one day be the only means of communication between the different parts of the Empire, or even between the Empire (including the British Islands) and Europe. Any scheme, therefore, for further reducing the chances of a total breakdown of tele. graphic communication between Great Britain and the Colonies, and between the Colonies themselves, by the provision of an extra string to our bow, can 
scarcely fail in the end to commend itself. If Britannia is to continue to rule the waves she will have to keep a sharp look-out in the Pacific as a probable scene of any future naval warfare; and naval strategists appreciate the fact that the combinations on which naval supremacy will depend require direct communication with the nearest coaling-stations as well as with headquarters.

Thus, it was recently pointed out by the writer, in the course of an address to the London Chamber of Commerce, ${ }^{1}$ that, though the duplicating line of the All-British scheme may well be Anglo-American in character, the original line itself should be strictly All-British to and from head-quarters at London. At present it is insecure because the land line passes through American territory in the State of Maine, while several of the Atlantic cables pass in shoal water dangerously near to the island of St. Pierre-a French possession off the south coast of Newfoundland, where two of the French Atlantic cables land. ${ }^{2}$ Further, if we had trouble with the United States, the Canadian-Pacific telegraph, passing, as it does, close to the American frontier, would be readily open to interruption, the cutting of its wires leaving Canada at the mercy of her powerful southern neighbour. It is clear,

1 London Chamber of Commerce, Special Meeting, December $4^{\text {th, }} 1902$.

2 Mr. P. T. McGrath, of St. John's, Newfoundland, says that the French have already realised the bearing of the above, and that the French cable-ship, Amiral Caubet, was there for strategic purposes at the time of the pro-Boer fever. 
therefore, that in such circumstances the Pacific line would be of little use to Great Britain. Hence, we are bound to recognise the need for an independent Imperial link between the Mother Country and the Pacific cable at Vancouver.

The Pacific cable has set an example which may well be followed. It is high time to grasp the fact that additional lines of communication on a variety of routes are desirable in the interests of the Empire. Although the bridging of the Pacific goes a long way towards meeting Imperial and strategic requirements, it should be regarded as a first step only. On our necessities in this connection, the recommendations of the recent Cable Communications Committee throw an important light, but whether they will ever get beyond the Blue-Book stage-or whether further developments will be only "watched with the greatest interest" -it is difficult to surmise. The Committee commenced its deliberations in February, rgor, and the examination of witnesses was concluded in August of that year, but the report was not drawn up until March, 1902, and was not presented to Parliament till six months later.

Let us now consider the general question of strategic cables on alternative routes. For strategic purposes we require a number of lines in different directions, rendering it practically impossible for an enemy to cut us off, telegraphically speaking, from the rest of the Empire, 
and maintaining telegraphic communication with all our fortified and garrisoned coal-stations. Some would have us rest content with the shipping trade. routes for our avenues of communication with India or the Colonies, on the ground that they can be adequately protected by British ships of war; but it should be remembered that-apart from the folly of putting all our telegraphic eggs into one basket-we have to provide against a "surprise" war, and the possibility that our Imperial communications in European waters might be cut off before the actual declaration of war. This would not be an easy matter to accomplish, but it would be a measure so damaging to us that an enemy would probably do his best to accomplish it. Thus it would be equally well worth our while to make such a coup impossible; and this object can best be attained by increasing the number of our telegraph routes, and by placing future cables further out of the reach of naval Powers. Rapid communication with fleets on foreign stations is an essential indeed for a Power which would retain command of the sea at, and previous to, the outbreak of war.

Some students of the subject have suggested that the cutting of neutral cables is contrary to international law; but Article XV. ${ }^{1}$ (touching the freedom of belligerents) of the Convention that

1 "Il est bien entendu que les stipulations de la présente Convention ne portent aucune atteinte à la liberté d'action des belligérents." (Martens, $2^{\text {me }}$ ser., tome xi., 285.) 
resulted from the International Telegraph Conference of 1884 , seems to dispose of that argument. In any case, we know from experience that cables are cut in time of war, in spite of all conventions or international laws, which would, indeed, be a broken reed for a great commercial nation like ours to rely upon.'

There may yet come a moment when the Mother Country and her children will have things to say to each other which strangers should not overhear. Our cables are indispensable to a properly organised intelligence department; and one of the most important advantages of an All-British system is its privacy, whether in time of peace or of war. This advantage, which exists in no other class of cable, is sufficiently great to counter-balance any other considerations. Moreover, it should be remembered that censorship is not possible with a cable landing on neutral territory. Though the precise scene of any future war in which this country may be engaged cannot be foretold, surely it is well to be forearmed as far as possible all round.

In this connection let us note the views of Col. Sir G. S. Clarke, R.E., K.C.M.G., F.R.S. When discussing a recent paper by Lieut. Carlyon Bellairs, R.N., at the Royal United Service Institution, Sir George said:-"I do not attach very much weight to the point about the nonliability of cables connecting a neutral and belligerent to be cut except in the belligerent's territorial waters. There is no international agreement at all 2 s to the status of cables in war such as will protect them. In the Conven. tion of 1888 we kept entirely clear of all attempts, which other Powers were ready to make, to obtain some recognition of the neutrality for cables." 
That is evidently the conclusion that our Continental neighbours and the United States have already arrived at as regards cable communication. France, in particular, has a complete scheme in view; and her prospective cable from Brest to Dakar (Senegal) and thence to Cayenne forms the most important portion of it.

Strategic lines are more or less invulnerable if laid in deep water, with few landing-places, on out-of-the-way (non-trade) routes, their exact course being kept secret. ${ }^{1}$ The best route for such lines is in the open ocean, where they are admittedly difficult even for a cable-ship to find even when their course is actually known. The general superiority, on the whole, in regard to life, maintenance, and comparative invulnerability, of a deep over a shallow water cable was so clearly recognised by the merchants of Alexandria, even in the year I866, that they appealed for a line from that point direct to Malta, to replace the cable laid in I86I along the north coast of Africa with several intermediate stations. This step was the more remarkable when it is remembered that, from the shareholder's point of view, a shallow water cable possesses the advantage that

1 To meet this end it would be advisable for the Intelligence Departments concerned to abandon the drafting of large-scale charts with the cable course marked thereon. The present custom of reporting home the position of the ship when laying cable and the length paid out should, for similar reasons, be abandoned in the case of a strategic line. The French have laid cables so that the route is unknown except to their Ministry of Marine. 
a breakdown in such a line is repaired at less cost than one in a deep-water cable.

In this connection it may be well to quote some extracts from a paper on "The Influence of Submarine Cables upon Military and Naval Supremacy," by' Licutenant G. O. Squier, U.S.N.'

"The story" of the Spanish.American war is largely" a story of 'coal and cables.' ... The nation with exclusively controlled submarine communications, not possessed by an adversary, has an organised service of surveillance which is not only important during actual war, but which may and will prove a powerful weapon in the diplomatic and preparatory. conflict which always precedes a declaration of war; and these communications are a means of securing a first real victory, even before war has been formally declared. . . It may be said, therefore, that the very foundation of successful naval strategy is efficient and exclusively controlled communications, and the lack of them more serious than inferiority in ships. . .

"It appears that the searching for deep-sea cables in the high seas in time of war, without an accurate chart of the location of the cables, is a difficult and very doubtful operation. . . A ship engaged in such a search must carry a moderate supply of spare cable and machinery for laying and picking up cables, as well as instruments for testing and operating a cable, and the buoys suitable, if necessary, for buoying the cable and operating the ship as a floating cable. station. It is unnecessary to state that her personnel must be specially trained in the highly technical duties required, and, from actual practice in all the operations necessary, be made ready for the performance of their duties efficiently under the conditions of war. . . It may be said at present that no modern fleet is complete without a cable-ship especially adapted for cable operations in the time of war."

' Proceedings of the U.S. Naval Institute, vol. xxvi. 
All-British cables have been seriously opposed on the ground that they may give offence to Europe and the United States. Complaints on this score were loudly made during the South African war; but if we were to listen to such objections we might as well abdicate our Imperial position at once. Other States have the remedy in their own hands, and, as already shown, France and Germany, in addition to our American cousins, are now taking similar precautions themselves.

Until quite recently the only three English Government-owned cables were the Red Sea cable, laid in 1859; the Malta and Alexandria cable of the same year; and the Persian Gulf cable of $1863-4$. The first of these failed, both physically and financially $;^{1}$ the second had only a short useful existence; and the third (laid at the instigation of the Indian Government), though a complete and lasting success from an engineering point of view, gradually proved to be altogether insufficient for the purpose of maintaining efficient telegraphic communication between India and Great Britain, even after the establishment of the Indo-European Telegraph Company's land-line system, with which the Indian Government had entered into a working agreement. Thus, after

1 The interest on the outlay of this line became a charge to the country of $£ 36,000$ per annum, only recently cleared off. 
various companies (afterwards merged into the present Eastern Telegraph Company's system) had been formed for establishing telegraphic communication with India by means of submarine cables, and after these cables had been in operation a few years, it was to the interest of the Indo. European Telegraph Department and the IndoEuropean Telegraph Company to enter into a joint-purse agreement with what afterwards became the Eastern Telegraph Company. These cables to India, which all pass through the Mediterranean, had been strongly recommended in a report of a Select Committee of the House of Commons in 1866 , in view of the serious delays, amounting sometimes to a week, ${ }^{1}$ occurring on the Turkish land lines; and they were carried out entirely by private enterprise, without the aid of public funds.

The same Committee also recommended further extensions; to Australia on the one hand, to China and Japan on the other. These were subsequently effected on an independent basis by what ultimately became the Eastern Extension Telegraph Company, which later on received a substantial subsidy from the Australian Government. About the same time the West Indian Islands were linked together telegraphically, as the result of British enterprise and British capital,

1 "Report on East India Communications," Parliamentary Blue Book, 428 of 1866 , p. viii.; also " Life-story of Sir C. T. Bright." 
though subsidised to some extent by the British and French Governments. On the other hand, in 1878 and subsequent years, the cables to the Cape of Good Hope by the east and west coasts of Africa were laid mainly out of capital raised by the Eastern Associated Companies on the strength of subsidies granted by the interested Governments. These facts are enumerated to show how comparatively little the Government of this country has done for telegraphic enterprise, which perhaps accounts for their having made so little attempt at controlling the administration of ocean telegraphy on behalf of the general public.

We have now to consider whether the Telegraph Companies have treated the public fairly. With regard to this point, views have sometimes been expressed which indicate insufficient acquaintance with the subject. It has, for instance, been argued that, because the consumption of electric energy is practically the same for sending a longdistance message as for a short-distance message, therefore, "the initial outlay being practically the same, the rates should be the same." Such an argument, however, ignores the most important item in initial outlay, i.c., the cable itself, the cost of which varies, for a given speed, not merely in direct proportion to the length, but as the square of the length. Conditions as to the general tariff having seldom been imposed by the Governments concerned, the companies have established whatever tariff rate seemed to have the best 
prospect of "paying." It may, perhaps, be questioned whether the Telegraph Companies have in the past been altogether wise in the general policy they have pursued. However that may be, there is abundant evidence of reform said to be fatal to their interests proving the reverse. Besides waiving the question of subsidies, which had previously been declared to be essential, the companies have, in recent years, lowered some of their rates considerably, without (it may be remarked) incurring the disastrous consequences foretold. On the contrary, the results appear to have been beneficial for them as well as for the public. In 1890 , the year before the tariff to Australia was lowered to 4 s. $9 \mathrm{~d}$., the gross cable business amounted to 827,278 words. In 1897 it had increased to $2,349,901$ words. In 1890 , with high charges, the revenue of the company was $£ 331,468$. In 1897 , with reduced charges, the revenue was $£ 567,852-i . e ., £ 236,384$ in excess of I89o, when the highest rates were exacted.

The writer is persuaded that, as in the case of the penny post, a reduction of tariffs would eventually lead to an increase rather than a diminution of revenue. Had the companies gone in for opening up a country and its trade, and lowered rates in order to increase the demand, they would probably have been even more successful than has actually been the case. Private individuals scarcely ever use the cable except in an emergency, and the same remark applies more 
or less to small business firms who cannot afford costly cablegrams. The Press, too, would use the cable much more if the tariff was not so high. We shall perhaps, some day, get a universal shilling rate on all cables throughout the Empire; meanwhile the adoption of identical rates for all stations on a given system would have many advantages. The Associated Telegraph Companies aver that the volume of telegraphic communications between given points on their lines is practically governed by the amount of trade. This may be so; but it may be suggested that the lowering of rates might before long considerably swell this volume of trade. A company prepared to establish and maintain a submarine cable system connecting the Mother Country with her Colonies on popular lines may fairly claim public support, and should achieve financial success. In this connection we may point to the satisfactory results obtained by the adoption of this policy in the case of the Commercial Cable Company's (Mackay-Bennett) lines, which brought down the rates between Great Britain and America to a shilling per word. The efforts of the promoters of that scheme were warmly encouraged and supported by the public, with the result that to-day the earnings and dividends of the "Commercial" Company stand higher than those of their rivals.

Whilst it is devoutly to be hoped that the existing cables will never come under the control of a 
French, German, or American combination, the writer is deterred by a variety of reasons from suggesting the taking over of existing cables-at any rate, those of an international character-by the State; for, as a rule, a business is best looked after where the administrators are directly interested in its financial success. On the other hand, it is desirable, on both commercial and strategic grounds, that the Government should, so far as lies within its power, encourage and facilitate the establishment of auxiliary lines of communica. tion in various directions, such as would link together all important points of the British Empire, and adequately guard against rupture of commu. nications in any direction. If, however, State purchase becomes eventually desirable, it is to be hoped that the Government will neither be "hood. winked," as they rather appear to have been when taking over the inland telegraphs in 1869 , nor will act unfairly, as when they paid little more than the price of old iron for the Submarine Telegraph Company's Channel cable system in 1889 . 


\section{IMPERIAL CONSOLIDATION BY TELE- GRAPHY. ${ }^{1}$}

If it has accomplished nothing else so far, the fiscal controversy has at any rate set thinking from an Imperial standpoint a large proportion of our people throughout the Empire. ${ }^{2}$ But individual thinking, without interchange of thought, will avail nothing; and interchange of thought effected through the mail is of but little use-it is altogether too slow in these days of rapid movement and rapid action.

The suggested Imperial Intelligence Department should do much towards furthering this highly desirable tendency, but its scope is at present strictly limited for want of the proper machinery for carrying out a really useful programme. It may be doubted, indeed, whether Imperial Unity will advance any further until the entire Empire is brought into closer communication by means of the Press as well as individually - until, indeed, we know and understand each other. In the present day constant misrepre-

1 Monthly Revicw, October, 1905.

2 It is said that the term "Little Englander," although of earlier origin, came first into common use in connection with the South African war controversy. Surely it is equally applicable to all those who approach our present subject merely from a United Kingdom aspect. 
sentations take place in one corner of the Empire or another, owing to a lack of systematic, accurate and full telegraphic reports (condensed afterwards where desirable) of important speeches made in other portions of the Empire. Friendly advances are frequently brought to a standstill owing to misunderstandings due to an indirect, and, at the best, a costly cable service. It is, therefore, on political, as well as on strategic, grounds, of the utmost importance at the present moment, that all the outlying portions of the Empire should be brought into direct telegraphic communication free from the prospects of interruption or "eavesdropping" by outsiders.

Our initial effort in this direction has not, of course, achieved this end; and even so far as its scope allowed, the prevailing state of things in connection with the Imperial Pacific cable can scarcely be termed satisfactory. The cable itself, from Vancouver to Australasia, is certainly "AllBritish," being, indeed, under the joint control of the Home and Colonial Governments concerned; but the connecting links on this side are by means of submarine cables and land-wires, open to interruption or confiscation in the event of war, and the terminal rates in Australia are out of all proportion to what they should be.

It has, however, always been urged by the present writer that the "All-British" Pacific line was mainly justified (a.) as a political and strategic necessity, and (b.) because the cable companies

T.c. 
would not undertake it themselves. Thus, whilst strongly advocating this route being rendered strictly and invulnerably "All-British" the whole way from the home country to Australasia, and whilst also advocating all necessary extensions, such as will produce a complete connecting link betwixt the various important units of the Empire, the writer considers that the entire system should be solely regarded as a political-cum-strategic requirement, whilst always viewing with disfavour any proposal which would involve absorption by the State of the existing English cable properties reaching to foreign territory. Such a measure, indeed, would almost certainly prove to be a false step politically. The cable companies - the nature of whose business is essentially different from that of our inland telegraphs - have to behave highly diplomatically in regard to their cables landing on foreign soil ; and if once our Government took over all the cables belonging to English companies, a deadlock would be likely to ensue in regard to further English cable developments with foreign countries.

Turning to the advantages that might accrue from competition, or expropriation of the cable companies' business, by the State, it may be quite true that no such return would be looked for as that which is expected by shareholders in the form of more or less large dividends; and either step would permit of, or effect, substantial reduction in the rates. It should be remembered, 
however, that the shareholders in the cable com. panies-in bearing the heat and burden of the day, so to speak-risked their capital at a time when submarine telegraphy was a distinctly hazardous business. The protection of rested interests should, indeed, be an accepted principle in this country, for England's pre-eminent greatness-or what is left of it-is largely due to private enterprise. If that were ever to receive a really serious check, it would, assuredly, be an evil day for this country. We have, unfortunately, no bushido here to fall back upon, being a highly individualistic people both by temperament and by tradition.

But while contending that it would be unwise -as well as unfair-for the Government to step in as general traders in the matter of submarine telegraphy, it is greatly hoped that the cable companies will see their way to lowering their tariffs, and that no agreements will be entered into by the State in future without such being provided for on a sliding scale. The writer ventures to think that, in many instances, the reduction of rates would, in the long run, be found advantageous to the cable companies as well as to their customers, the general public. Is it not possible-will not the cable companies endeavour - to establish such a tariff as will popularise the use of the cable, and thus draw more attention to Imperial importance? An inter-Imperial understanding and closer contact 
with our Colonial cousins will be difficult to attain officially unless backed up by personal interest. In the present circumstances no one ever dreams of communicating to another across the high seas on a purely private matter, unless it be of the greatest urgency. On the other hand-for the purposes of Imperial consolidation and colonisation-we ought to achieve that state of things by which one member of a family in England can communicate with another in an outlying portion of the Empire as readily as could be effected if they were both in the Mother Country.

The principal objection to a reduction of rates on the part of the cable companies is-I believe admittedly-that it involves the laying of more cables to meet the increase of traffic that would thereby ensue. But surely that objection can be overcome, even though implying temporary expenditure, where both large reserve funds are at hand and big dividends paid. Moreover, is there not such a thing as meeting a demand a little in advance-sometimes even creating it by means of supply - in order to forestall competition?

To return to the main purpose of this article, though unfavourable to the State taking over the existing cable service as a commercial business, the writer considers there are overwhelming arguments in favour of a single trunk system of cables all connecting up the more important points of the British Empire under direct control of the State, and without touching other countries. The 
All-British Pacific cable was but the first step in this project for girdling the entire Empire. A cable system of this character-owned or controlled by the State-would, inter alia, be free from all possible objections on the score of foreign shareholders, or foreign administration.

A cable system of this character should be regarded as a political and strategic necessity of the age, in the same way that we regard our navy -or, indeed, our army, or any of the necessary services and expenses of the nation for which "safeguard" is our only return in times of peace, but which we could not do without as a provision for war and, therefore, also as a provision for peace. Let us not forget, too, that whereas one first-class battleship eats into about a million sterling, all told, an Atlantic cable only costs about balf a million; and, in certain circumstances, if the battleship cannot be called to the point required for want of telegraphic facilities, the million spent on her might as well be at the bottom of the sea.

If Imperial consolidation is to get beyond the talking stage, further alternative means of communication on different routes between important Imperial centres will become every day more and more essential-to meet the contingency of war, as well as for the purpose of identifying the British and Colonial communities. As the result of the London Traffic Commission's report, we are at present contemplating the question of establishing certain avenues through the heart of London, and 
it is estimated that two of these highly desirable avenues-with their accompanying subways, railways, and tramways - would involve some twentyfour millions sterling. The result would certainly be pleasant from the point of view of personal comfort, for we should thus secure more elbowroom in the greatest city of the Empire-ay, of the world; but surely the Imperial mind should recognise that these costly avenues (with a total length of nine miles) must not interfere with the prospects of completing our Imperial telegraphic chain running into several thousand miles at a tithe of the cost.

To effectively "girdle the Empire" under this scheme would be of immense advantage to the cause of a truly national and Imperial policypartly through the establishment of a sure service of rapid and secret communication between the various Governments concerned, but also through that of a systematic and more or less continuous service of news, freely transmitted under proper restrictions, to every newspaper published in any portion of the British Empire. 


\section{IMPERIAL TELEGRAPHY AT A POPULAR TARIFF."}

PartLy associated with the visit to London of the Canadian Postmaster-General, further attention has recently been drawn to the subject of cable rates, the proposed completion of the AllBritish cable girdle and the question of the British cable systems being taken over by the State. Additional interest was excited in regard to the matter by Mr. Henniker Heaton's paper read at the Royal Colonial Institute, on November Ioth, with the attractive title, "Penny a Word Telegrams Throughout the Empire"; and by a public meeting at the Mansion House, on December I Ith, convened by the Telegraph Committee of the House of Commons "to discuss the policy of State-owned and controlled cables, with a view to bringing about cheapened rates for telegraph messages within the Empire."

We certainly live in an age of minding other people's business rather than - or in addition toour own. In this instance, however, the business is one in which the general public are substantially concerned; and it is proposed here to set forth the principal points for consideration in this absorbing

IFortnightly Review, March, 1909. 
and important topic. It may be stated at the outset that the main question the disinterested and temperate examiner has to ask himself is whether further All-British telegraph lines with the rest of the Empire, are now sufficiently desirable from a political and strategic standpoint to warrant their being made (if necessary) the subject of taxation, on the same principle that prevails with our battleships and other necessary "impedimenta" in which the only anticipated return for expenditure is the security of the Empire. It must not be forgotten that the principle has already been accepted in the less obvious case of subsidies to cable companies, and also in regard to the mail service. The question of tariff is really a secondary matter, though low rates throughout the Empire-especially for Press purposes-can scarcely fail to be attractive to people with Imperialistic instincts, even if a low tariff does not directly benefit themselves.

Familiarity with all the various aspects of the subject leads to the conviction that it is one which requires to be approached with considerable caution and reserve. We are here beset with many different points of view, and if only on account of the vested interests involved, it would be unfair to shut our eyes to any one of them. We have, indeed, constantly to bear in mind the standpoint of those who have risked capital-to their own profit certainly, but also to the immense benefit of the country-for providing a system of 
Imperlal Tzlegraphy at a Popular Tarim. 105

world-wide telegraphy of an eminently efficient, if expensive, order.

It may, perhaps, be said that we have now arrived at a parting of the ways when the interests of cable shareholders and of the community at large are becoming less and less in common, and when the cable companies' views as to what is good for us in cable lines and cable rates are less and less favourably accepted. Be this as it may, the com. panies and the public are obviously on opposite sides of the counter, and therefore likely to regard the questions under discussion from a different point of view. It is, therefore, all the more impera. tive to dofull justice to those on the other side-in a word, to "do to others as we would be done by."

It has frequently been suggested that the profits of the cable companies are of proportions such as suggest their making too good a business at the expense of the public. Anyone versed in the history and technique of submarine telegraphy knows, however, (a.) that those who invested capital in what was at the time a strikingly hazardous venture-perhaps the most hazardous of any industrial (even electrical) undertakinghave naturally looked for a substantial recompense for their money ; (b.) that submarine telegraphy, like all industrial concerns, is still fraught with much risk, and that consequently a comparatively big return is still expected by shareholders-more, for instance, than in the case of indiarubber motor tyres, though the expectation is scarcely 
Iọ6 Imperial Telegraphic Communication.

realised. This being so, it may be questioned whether, as things go, 8 or 9 per cent. on the ordinary share capital is greatly out of the way, even with a concern partially assisted by subsidies. Comparisons are scarcely satisfactory in such matters; and the nearest approach to an argument contrary to the above is that similar enterprises constituted by the railway companies of this country-which, without any subsidies, have also created their own business-do not manage to produce nearly such good returns.

But though the dividends of cable companies may not be anything out of the way, there can be no question that their reserve funds are wont to attain somewhat excessive proportions. As an example of this and of the general financial position of the Associated Cable Companies, it may be noted that at the last (seventy-third) ordinary general meeting of the Eastern Telegraph Company, after providing for the usual interim dividend, no less than $£$ roo,00o was carried to the reserve fund, whilst a balance of $£ 53,700$ was carried forward. We have thus to consider to what extent these large reserves are justified for the renewal and maintenance of cables, and whether they are to any extent warranted for other purposes, such as for dealing with prospective competition. In the former connection it may be observed that the renewal funds have been based on what was in early days considered to be the life of a cable-20 years-rather than on what 
is now found to be nearer its actual life, 40 years. In the latter connection it is certainly a significant fact that practically no successful competition has been experienced by the Associated Cable Companies. In any case, the question as to what is or what is not a fair return in an industrial enterprise can only be one of degree and a matter of opinion depending upon circumstances.

It may, indeed, be admitted as natural that everyone should seek to secure as much as he can for his investment, and that, accordingly, the primary object of telegraph companies is to earn satisfactory dividends for shareholders. In view of this it is conceivable that low rates are inconsistent with a cable worked by a telegraph company, and that if we are to have them it can only be by State absorption. Be that as it may, it would be altogether unfair to arrive at a conclusion unfavourable to a company on the basis of rates charged on State cables worked more or less at a loss. Neither is comparison suitable between land-line and cable rates, the initial cost and upkeep of a land line being but a small fraction of that associated with a cable; besides which the service provided by a cable system is vastly superior in practically every respect-even though the technical conditions are more favourable in an aerial wirc.

Let us now turn to a consideration of $\mathrm{Mr}$. Henniker Heaton's proposals. Notwithstanding 
the title of his paper, these mainly took the form of a suggestion for penny a word telegraphy throughout the entire world, at a time when we are still paying $2 \frac{1}{2} d$. for letters to other European countries which hold out against penny postage. Whilst fully recognising the honourable member's activity and zeal in a good cause, the writer cannot agree with the notion that because Imperial penny postage was once spoken of as impracticable, a fortiori universal penny-a-word telegraphy -by cable, as by land line-will also be ultimately achieved. Though it is, of course, quite possible that Mr. Heaton's ideas may come true in the end, this is more likely to be due to the march of invention-just as we may some day talk to the moon-than to anything else.

Mr. Henniker Heaton thinks, this time, to call to his aid the land wire. He says: "Why should we not hire from the friendly foreign Governments telegraph lines to carry our messages?" That, however, is an old story. The land line has been tried and found wanting as compared with the submarine cable. Even now it is no uncommon experience for a message sent over a Spanish aerial wire to be detained at the receiving office for several hours before it is delivered at its destination; and land lines through foreign countries worked by inefficient native clerks are a constant source of delay, with the result that, in the end, the submarine cable is a far more reliable and speedy message carrier. If we could arrange 
to place expert English clerks on Continental land lines, it would be another matter, but that is practically out of the question. The submarine cable is much more costly from beginning to end; but it can be got under uniform control through. out, and is infinitely better adapted to the exigencies of war-indeed, the land wire may be said practically to cease to exist, for the purposes of outside countries, the moment war is declared.

In the present day, some people seem to think that exaggerated clamour is the surest method of securing attention; and certainly it often appears as though the more impossible an idea, the more notice it gains; but such suggestions as those of Mr. Heaton are calculated to do any cause considerable harm with thinking men, as also with responsible officials. It is astonishing how any proposal sufficiently attractive at first sight "catches on" if emanating from someone who is regarded-by the general public, at any rate-as an expert authority on the subject. Thus, the honourable member has undoubtedly enlisted for his suggestions a remarkable degree of support, though most of the published replies to his appeals consisted merely of pious and vague blessings of cheap telegraphy. It could scarcely be otherwise, seeing that they invariably came from public men -including eminent divines and a great galaxy of peers-rather than from those especially versed in the matter. With that natural desire for reduced 
rates, the newspapers have not perhaps exercised in this instance as much discrimination as they might in regard to the class of arguments given publicity to; and the very expression "Penny a Word Telegraphy" has a sensational ring about it, when associated with costly cables, that has caught many a penny and deceived many a newspaper reader.

The whole of Mr. Heaton's not very illuminating theme appears to centre on the idea that the cable companies are guilty of a wicked conspiracy against the British public. He suggests that they wilfully keep their lines idle by maintaining excessive rates. Whilst undoubtedly a comparatively small volume of traffic at high rates is more remunerative than a large volume at low rates, such a course, if pursued, would be scarcely consistent with the recent laying of new cables across the Atlantic at an individual cost of half a million -though certainly these are mainly provided for efficiently handling the traffic at rush hours. In pressing his point, Mr. Heaton goes on to ask, "What is the question before us? It is thisWas electricity given for the benefit of a small body of shareholders, or for the benefit of humanity at large." As a matter of fact, the question lacks accuracy, for electricity is open to the community. The honourable member can buy it in various shapes, made up by various dealers and inventors into various ingenious forms; or, if he prefers it free, he may, with luck, be accommodated one 
day by our beneficent Creator, during a thunderstorm, at that lowest of all schedules.

Everyone would agree that penny-a-word cablegrams would be very nice-though not so nice as free cablegrams. Theoretically the scheme is magnificent, but its practicability is quite another matter. In point of fact, in speaking of penny a word, Mr. Heaton was presumably oblivious of the rates to be added for the collection and distribution of the message by connecting land lines owned by the Government, or company, at each end. These would be bound to bring the total (inclusive) charge up to at least $2 d$.; but even on that basis Mr. Heaton's proposal can scarcely be considered within the sphere of practical politics. It has, indeed, to be remembered that $\frac{1}{2} d$. a word has not yet been made to pay within an area of 500 densely inhabited British miles-knit together by the closest ties of kinship and commerce. Yet the honourable member proposes to achieve a satisfactory commercial result at a penny tariff throughout the entire world-this, too, in connection with a system of cables whose cost relative to carrying capacity is out of all proportion to that of our insular telegraph system. There are, in fact, cogent reasons (as explained hereafter) why the cost of messages could never-with our present facilities-be reduced to anything approaching Id. a word, unless at a heavy loss to be borne either by the nation (at the expense of the taxpayer), or by those who put their money into what 
must always be a more or less speculative business. In a word, Mr. Heaton's finance seems to rely more on faith than figures; and his "scheme" is suggestive of the Irishwoman who sold apples below cost price, but who always hoped to benefit on the score of the numbers she thus disposed of.

It does not appear that wireless, or radio, telegraphy is in any more favourable position for meeting the honourable member's demands; for, in the course of the discussion on his paper, it transpired that whilst Mr. Marconi was ready to undertake trans-Atlantic messages at $\mathrm{Id}$. a word, this was only "provided the Governments concerned will pay for the working expenses of the stations on both sides of the Atlantic, andalso give a comparatively moderate subsidy." It maybesafely said that the English Atlantic cable companies would be prepared to "do likewise" if insured against loss in this way; and it should be added that, so far, none of these particular companies have received any sort of Government subsidy.

This is, in point of fact, the most likely quarter in which a reduction may shortly take shape; for though the trans-Atlantic cable rate now stands at Is. a word-where it was originally as much as $f \mathrm{I}$-there has been for some time a strong feeling in America, as well as in Canada, that a further reduction should be effected.

Though, indeed, Mr. Heaton deals mainly in generalities and platitudes about an impossible rate, this is not to say that his suggestions will not 
Impzrial Tzlegraphy at a Popular Tarity. 113

bear fruit and develop into something more tangible. He is, however, on quite insecure ground where he suggests that the cable companies are so foolish as not to take advantage of inventions for improving their service. He even goes so far as to propose that the Pollak.Virag apparatus (an admirable system for working land lines) ought to be adopted on cables. Truly, "a little knowledge is a dangerous thing." It should be added, perhaps, that the difficulties of the problem are not so much associated with the receiving instruments - which are surely not much at fault-but inherently in the cable itself, where very considerable distances have to be dealt with.

Individually speaking, it may be doubted whether we are any the better, or happier, for our extensive facilities for rapid intercommunication with almost every quarter of the globe. On the contrary, these facilities certainly add to the worry and wear and tear of life, whilst leaving but little time for reflection-an occupation less indulged in nowadays than of yore. From a national and Imperial standpoint, however, the advantages of telegraphy are obvious; and, in order to keep in time with an increasingly hustling -indeed bustling - age, rapid communication with those at a distance becomes practically imperative for business purposes. The telegraph can alone knit together the scattered units of a far reaching Empire like ours; and there can be little doubt that telegraphy is destined to 
play an increasingly important part in the gradual strengthening of our Imperial bonds. While, in the past, it will scarcely be questioned that lack of mutual knowledge has been the cause of many an Imperial misunderstanding, the cable has already done much in extending that knowledge and avoiding disruptions, whilst serving as a speedy healer where misunderstandings have already arisen.

But we Britons in different corners of the Empire require to know each other better; and cheaper telegraphy would undoubtedly do much for achieving that end, tending towards Imperial co-operation and-as Lord Milner puts it-"ultimately towards Imperial union." There have already been special occasions when a lower tariff would have been an inestimable boon-as, for example, during our misunderstandings and subsequent war with the Boers in South Africa. It is on these premises that the writer has always argued for a reduction of rates where practicable, though unable to support Mr. Heaton's movement for universal $I d$. a word telegraphy.

Cable tariffs to certain outlying portions of the Empire still run as high as $7 s$. a word, and, in the writer's opinion, it is contrary to the spirit of the age that, after half a century of submarine telegraphy, there should be no alternative between waiting three months for an answer to a penny letter from Australia and sending a cablegram at 3s. a word 
Imperlal Telggraphy at a Popular Tarify. IIS

With cheaper Imperial rates, the newspapers might do much in the way of bringing each branch of the Empire into closer touch by general diffusion of information on all topics of common concern. At present cable summaries of important Imperial speeches are so condensed (on account of cost) as often to be misleading, thereby doing incalculable harm. The compression of such matter should be achieved at the receiving end to suit the scope and requirements of the individual journal.

Then, again, cheap cabling would give the man in a comparatively small way a better chance of developing his business; indeed, as the Canadian Postmaster-General (M. Lemieux) has said: "Every reduction in rates would open the door to a class of trader who cannot now afford to use cables." If we only considered one class of the community, and that class were those who at present use the cable most, things might well be left as they are, for a lowering of the rates leads to competition; but the interests of the country are not limited to any particular class. It has been urged that, as only one per cent. of the public use the cable, it is not worth while making any change for the benefit of that small proportion. But this argument omits the increased number of cable users resulting from reduced tariffs.

Turning to the individual or domestic aspect of the question, whilst there may not appear to-day 
il6 Imperial Telegraphic Communication.

to be any great demand for the interchange of social messages with our Colonies, this demand would undoubtedly receive considerable impetus when the facilities rendered anything of the sort reasonably practical. To effect such a result would do much towards establishing a better inter-Imperial understanding and consequently stimulate inter-Imperial trade. It has sometimes been stated that the volume of telegraphic communication between given points is practically determined by the volume of trade, but may it not with equal force be suggested that the volume of trade might be considerably extended by a lowering of telegraph rates? The question practically resolves itself into who is to take the initiative. Railways have done much on their own account towards opening up a country and its trade; and it is conceivable that telegraphy might be made to do more than it has so far in developing the trade of the Empire by a reduction in the tariff.

Let us not forget, too, the humanitarian standpoint. At the present time, as Mr. Heaton reminds us, if a serious accident occurs-say, in a mine-to any of our thousand and one emigrants, often nothing is known by telegraph as to who is alive and who dead. Thus our boasted civilisation is, in this instance, limited to a class; and it would certainly seem that, after half a century of submarine telegraphy, it should be feasible for all grades, in case of emergency, to 
communicate with relatives in other branches of the Empire. It must, however, be added that there is no fundamental difference between the submarine telegraphy of to.day and that originally conceived, such as could, in itself, tend to popularise the cable.

It may be well at this stage to consider the Mansion House meeting of December Irth. As already stated, this was convened by the House of Commons Telegraph Committee, of which Sir Edward Sassoon is chairman. The Lord Mayor presided, and the speeches were of an eminently statesmanlike character, though it is a matter for regret that these were practically limited to the platform. The first resolution passed (on the motion of his Grace the Duke of Argyll, K.T., seconded by Viscount Milner, G.C.B., G.C.M.G.) was: " That this meeting, convinced of the desirability and necessity to manifold Imperial interests of a system of lowpriced, easy and uniform means of telegraphic connections within the Empire, pledges itself to support the efforts of the Telegraph Committee of Members of Parliament with that supreme object in view." The second resolution, also passed with but few dissentients, was worded as follows: "That this meeting, composed of representatives of commercial and industrial interests, respectfully suggests to his Majesty's Government the convening of a conference of postal authorities of the States and Dependencies within the Empire for 
the purpose of concerting measures tending to a wider recognition of the policy of State-owned and controlled cables, subject to respect for private rights." The latter was moved by Sir Albert Spicer, M.P., as President of the London Chamber of Commerce, and seconded by the Earl of Jersey, G.C.B., G.C.M.G. Though the meeting was very properly thrown open to the public, an attempt at stifling discussion occurred; this was unfortunate, the more so as there is indisputable internal evidence that notice was actually given in advance of an amendment to the resolutions. ${ }^{1}$ In the end, however, opportunity was accorded for a full expression of the only discordant note. This came from so high, if interested, an authority, as Mr. G. R. Neilson; but it is to be regretted that we were only favoured with his views "as a tax-payer" and not-for reasons of modesty, no doubt-as Secretary to the Europe and Azores Telegraph Company.

For those who were unable to gather up all that fell from Mr. Neilson, during a rather speedy reading, it may be mentioned that his remarks are apparently reprinted in full by the accredited official organ of the Associated Telegraph Companies -The Electrician ${ }^{2}$ - with which he (Mr. Neilson) is so actively associated. Though somewhat common to his previous speech at the Colonial

1 See The Electrician, December I8th, 1908,-p. 367.

2 Formerly owned by Sir James Anderson (the late distinguished Managing Director of the "Eastern" Companies), and subsequently by his family. 
Institute, dealing mainly with Mr. Heaton's pennya-word fable, there was much force in many of Mr. Neilson's remarks; but, as Lord Jersey argued, the resolutions passed bind no one to any definite scheme. In effect, they mainly express a hope that the various Imperial Governments will come together and consider the subject, without for one moment forgetting the rights of the cable companies, or what they have accomplished for the country and world at large.

With the march of time and events it seems likely, if the public are able to show there is a sufficient call for reasonable reduction in rates, that such will receive all possible attention from the cable companies; for there is already evidence of substantial reductions having been effected, in a number of instances, where formerly it was not -for one reason or another-considered possible. As chairman of the Eastern Telegraph Company, Sir John Wolfe Barry recently spoke of these reductions as "to the great advantage of the public" ; but the most hopeful line for pressing the point is as a return for past favours in the way of subsidies, and on the basis of favours to come. Moreover, the fact of the Associated Companies being on so large 2 financial scale should augur well for their being ready to take the rough with the smooth in the matter of rates. In any case, it is unlikely that

i Seventy-third Ordinary General Mecting, Novem. ber sith, 1908. 
they (the cable companies) will be at all adverse to the full inquiry that has been suggested.

Let us now consider the extent of the difficulties surrounding the objects aimed at. The cheap cablegram should mean, if it means anything, a great number of messages; and it has to be remembered that if the tariff is, say, halved, the number of messages sent must be materially more than doubled to make up for increased overhead charges. Now the message carrying capacity of a cable is confined within circumscribed limits. Thus, if the traffic between two points gets beyond that limit, it becomes necessary to lay a further cable, or cables, in order to deal with the surplus traffic. A cable costs much to make, much to lay, and much to maintain. A large staff of skilled operators are necessary for the mere transmission and reception of messages, besides which technical skill of a high order is involved for tending to the electrical requirements-both as regards the line itself and the instruments employed to work it. In addition to this, considerable administrative ability is necessary for the organisation of a big cable system. All these things have to be paid for, and the only possible means of doing so is by a charge for messages. Then, again, scientific and engineering skill-let alone commercial enterprise - are things which command a certain figure. Indeed, though we have now been enabled for a good many years to defeat space by electrical 
communication with far distant lands, we can still only do so at substantial cost. Thus, the main difficulties in achieving our goal, without loss of revenue, are (a.) that cables are, for fundamental reasons, an expensive medium of communication and $(b$.$) that their carrying capacity, in proportion$ to cost, is closely limited. Then, too, by the contrariness of things, just where a low tariff would be most acceptable-i.e., where, owing to the distance, the mail service takes so long in comparison - the difficulties are at a maximum, for here the additional cables entailed would be an especially serious item in the matter of cost.

The increase in working expenses entailed by a reduction of postal rates is insignificant in comparison with that involved by a drastic reduction in cable tariffs. A steamer, or a train, is able to carry a great increase of mailed matter without materially adding to the cost of so doing. It cannot, therefore, be rightly argued that a reduction in cable rates should be as easy to bring about as a reduction in letter rates. No comparison can, indeed, be suitably made between the postal and telegraph service.

Over 90 per cent. of the messages now transmitted are in code, and by this method the equivalent of an enormous number of words are already sent at what really amounts to comparatively cheap rates. Thus, it is possible to send in two words, at a shilling apiece, a trans-Atlantic message which 
when decoded, works out to 170 words-representing no less than seven words for a penny. Without the code system the cable companies would not be able to handle anything like even the present traffic, except by laying down more cables. Secrecy is one of the principal objects of codes. There is here, however, especially when in cypher, a greater liability to error. Apart from this, codes cannot, from a public standpoint, be recognised as an entirely satisfactory substitute for low rates in plain English, for they involve a great deal of work in " coding " and " decoding."

Whereas on land lines more than half of the messages sent are of a more or less domestic nature, the corresponding proportion on the cables of the world is at present only five per cent. Though, no doubt, this difference is largely accounted for by the inherently different circumstances in each case, it is also probably due, in some measure, to the comparatively high cable rates; for, letters travelling so much more slowly by sea than land, the tendency should be towards the transmission of a greater number of private messages by cables than by land lines. In any case, the small proportion actually sent by cable is a state of things which should be remedied as far as possible, for reasons already set forth. Such messages are, as a rule, of a comparatively non-urgent character; but if the rates for these could be made lower-for great distances, at any rate-a large number would undoubtedly be sent to lands reached only in the 
course of several weeks by letter. In most instances delivery within twenty-four hours would meet all requirements; and the same might be said of many official, business and Press messages. This points to the classification of messages under the head of "urgent" and "non-urgent," such as the writer advocated when giving evidence to the Cable Communications Committee and again subse. quently.'

Reduced rates for "deferred" (non-urgent) messages have since come into partial operation in Canada, as well as India; and it is submitted that a further extension of the principle may now be found within the pale of practical politics, especially as France has for some time had a lower rate for messages sent after business hours. Putting aside the increased number of cables likely to be involved thereby, the circumstances should be favourable to the above reform ; for, as things are now, all public messages being charged at the same rate, each has to be treated as equally urgent. Many would, however, serve their purpose just as well if held over a little. Whilst during the busy " rush" hours, the more important cables are worked to their full capacity, they all lie absolutely idle for at least four or five hours out of the twenty-fourlargely due to the time difference at each end. ${ }^{2}$

- Blue Book. Cd. 958, 1901, Q. 3. 592 ; address to the London Chamber of Commerce, December 4 th, 1902 (The Times, December 5th) : Qwarterly Rrview, April, 1903, P. 38 r. - On this account there are only three to four hours business-bours in common between each side of the Atlantic. 
Thus, for a quarter of the day-and, therefore, a quarter of the year-the capital locked up in submarine telegraphy is at present unproductive; and though it is true that no one-not even an American "hustler"-is going to bestir himself at three or four in the morning to send a telegram, it would seem as though this part of the twenty-four hours might well be employed in dispatching non-urgent (deferred) messages at reduced rates. The cable would thus be more uniformly fed during slack periods as well as mutual business hours. The Cable Communications Committee reported favourably on the subject in the following terms: "By this plan the sender of the message would receive an inferior service for a lower price, and such a plan would be a considerable boon to the public, especially as regards messages which are domestic rather than commercial."

It seems not unlikely that wireless telegraphy may, in due course, be turned to considerable account in this direction for comparatively unimportant, or non-urgent, messages, as well as for the simultaneous transmission of news to different parts of the Empire. In such cases, economy is really more important than celerity or efficiency. On the other hand, for business messages of great urgency and importance, the first essential will always be efficiency, ${ }^{1}$ accompanied as far as may

1 An excellent illustration of this was recently given by Mr. H. Laws Webb, M.I.E.E., in The Times Engineering Supplement. To quote Mr. Webb:-"So vital is speed in 
be by economy-and here the cable is likely to hold its own between two given spots for many a day.

With ever-increasing demands, it is conceivable that some day an all-round Imperial tariff of a comparatively low order-is., or even $6 d$.-may be found feasible by the cable companies working together. Largely on the score of a strong financial position, it is hoped that they might thus be prepared to take the rough with the smooth in this matter. It is, however, necessary to add that in taking such a case on its merits when comparing rates, these cannot rightly be adjudged merely from a point of distance. The cost of working the cable, the cost of maintenance, and the volume of traffic are all variable quantities independent of distance, and the two latter are often just as important items for consideration as the initial cost. Distance provides, however, a considerable inkling into what a rate should be under given conditions. Thus it is not a little remarkable that whereas Frenchmen can send a cablegram to all their distant possessions for no more than $\frac{1}{2} d$. a word, to send a message to Egypt costs twenty-four times as much as the Frenchman pays to send one to Algiers or Toulon. The answer is, of course, that the $\frac{1}{2} d$. French rate is a Government rate, and, therefore, independent of commercial business affairs, that people will often pay 2s. a word to telegraph from England to France by Atlantic cable via New York, merely because that route is quicker than the more direct route." 
profit such as is naturally looked for by private companies. On the score of simplicity, there would be a good deal to be said in favour of a universal tariff if found practicable. Travellers, for instance, would use the telegraph much more if they had a settled idea of what the cost would be. As things are, they have a vague notion that the enterprise is too costly for their purpose, and they accordingly cease to bother themselves any more in the matter. In point of fact, a man who can afford to travel about the world can also afford to send a costly cablegram, but he does not often do so; and the same applies to all sorts of people at home and abroad. Cheapness and simplicity would undoubtedly work wonders in creating a demand-if such were wanted. It may well be asked, however, why should a universal cable tariff throughout the Empire be expected any more than a universal railway fare throughout the United Kingdom-or throughout any one railway company's system ; and from a practical and commercial standpoint, so far as concerns cable companies, this view is incontestable. Yet the political and individual desirability of a universal Imperial rate of a modest order remains the same ; and it is to be hoped-largely from a point of principle-that some day we may see it.

For national reasons already set forth, it is highly desirable that we should bring the separate units of the Empire into closer telegraphic touch 
-politically, socially, commcrcially. Moreover, on strategic grounds, we require to complete the All-British electric girdle so usefully initiated by the Pacific cable. This could be effected by a cable from Ascension to Jamaica via Barbados, and thence to Bermuda and Halifax, where it would meet the Atlantic cable system, thereby providing-amongst other things-the first truly All-British line to the Cape, or between Canada and the Cape via the West Indies. It may be further noted that the element of time would be highiy favourable to a cable system to and from the Cape by the Atlantic route. If this AllBritish system is to be, like the Pacific cable, a Government affair, further lines would require to be laid to render the Imperial chain independent of other systems. There would have to be a cable between Australia and South Africa, and thence to Ascension. Such a plan would be preferable, in many ways, to the Governments concerned buying up existing lines; and if a State Atlantic cable is to be the order of the day, care should be taken to render it absolutely All-British, as well as the land-line system between the Atlantic and Pacific Oceans.

The cable companies have centred their energies on the trade routes, but these are seldom good routes strategically, if -as is often the case - the cable passes through shallow water in close proximity to foreign territory; and, on the other hand, the best strategic routes are liable to be 
financially unprofitable to a cable company. Imperial cables should be regarded as a political and strategic requirement of the age, for forming part of a great Imperial movement-largely for the development of Imperial trade. These should be considered from the same point of view as our navy, army, and other essentials. The difference between being in telegraphic communication with, or being cut off from, the rest of the Empire at the moment when war is upon us is very remarkable; for in the former instance we are enabled to amass our collective resources at the correct spot. Then, too, the stricter privacy of an All-British cable in times of war should not be forgotten; moreover, censorship is not possible with a cable landing on neutral territory. It should be remembered, too, that if such strategic cables are laid, the traffic on the ordinary trade routes would be less likely to become disorganised in time of war by the suppression of code messages. Though lines of this description may not "pay," on their own basis, for some time to come, they would pay indirectly at once in serving as an incentive to Imperial trade. ${ }^{1}$

It is just such cables as these that form a proper subject for Government consideration; and in view of what we expend on postal sea service to the Colonies and how comparatively little has been

1 A point like this should appeal to a State in a way that scarcely applies with a company primarily concerned with satisfactory annual dividends for shareholders. 
spent on Imperial telegraphic communication, it is hoped that these proposals may be adopted. ${ }^{1}$

To meet the main purposes of the case it would be almost essential for these suggested lines to be worked as one system with the already existing All. British Pacific cable. The latter fully justified itself on strategic grounds alone, but was eventually undertaken by the Home and Colonial Governments concerned only when it was found that the cable companies were not prepared to do so; and though from a point of principle many of us would prefer to see these further Imperial lines made a subject of private enterprise under adequate Government subsidies-or preferably guaranteesand a subject of suitable conditions, this would seem now to be out of the question.

If the All-British chain is eventually taken in hand as a State affair-as an extension, maybe, of the great British postal, telegraph, and cable service-it is to be hoped that it will not unduly interfere with the business of the cable companies. It may, however, be pointed out that if the latter have not recognised the propriety of undertaking (on reasonable terms) such lines-being, perhaps, naturally disinclined to expend the necessary capital on cables that they cannot see an immediate return over-it is obviously open to the

1 No less than $£ 240,000$ per annum is still being spent on the conveyance of mails to and from the West Indies alone, although the sum received for the mails only amounts to $£ \$ 0,000$ a year.

T.C. 
Government to do so in the interests of the Empire (as explained), without there being any grounds for complaint. Moreover, on a strategic basis, we have here the most legitimate scope possible for a State line as a proper subject for taxation. France and Germany have expended several millions on their recently instituted cable systems ; but it need scarcely be pointed out that there is no country so much as ours which requires a complete telegraph system to all its possessions on alternative routes.

Though it would seem, however, that, as things have gone, the All-British girdle here referred to must be established and worked, if it is going to be, by Government, it appears to the writer quite clear that no attempt should be made to absorb the admirable international service provided by the cable companies. This service has undoubtedly staved off many a war by avoiding international misunderstandings, and the companies working them have acted somewhat in the position of business diplomats. They have obtained foreign concessions and agreements such as no Government could ever have secured; and if only on account of the strategic value of cables during and immediately preceding war it is extremely unlikely that foreign countries would allow cables landing on their territory to be in the hands of our Government. The abrogation- of landing rights would, indeed, be not unlikely.

Then, again, if the Associated Cable Companies 
are to be pointed to as " monopolists," it must be remembered at the same time that they are commercial pioneers of telegraphy with shores outside the United Kingdom, the Governments concerned having taken but little initiative in the matter; and though, no doubt, these organisations have reaped the full benefit of their enterprise, it should not be forgotten that the country has immensely benefited by a vast network of international tele. graphy, due almost entirely to British private enterprise. In a word, the heat and burden of the day has been borne by these companies; and it would be manifestly unjust for the State to step in and say, "Now that you have established an excellent service we propose to take over that service at the price, say, of old iron." 


\section{COMMUNICATION BY CABLE. ${ }^{1}$}

THE question of cheap and extended telegraphy with the scattered units of our Empire being once more to the fore, it may be well to review the subject dispassionately from the public standpoint.

The writer has for many years urged the importance of increasing our facilities for telegraphic communication with a view to a wider understanding on all subjects of common Imperial concern, and the matter is now being forcibly pressed by some of our leading statesmen of the day.

As The Times remarked only recently:- " Lack of mutual knowledge lies at the root of most of our Imperial difficulties." The cable, in serving as a strong binding force, would be capable of overcoming this objection; and there can be little doubt that telegraphy could be made to perform an important part in the gradual strengthening of our Imperial bonds. The British newspaper press throughout the Empire is at present but a poor instrument for serving such an end. Its performance might, however, be rendered infinitely more effective with wider and cheaper telegraphic facilities. With the prevailing march of

1 Westminstor Review, March, Igog. 
Imperialism, the force of this should be more generally recognised.

It would, indeed, seem to be well worth while, from the national and Imperial standpoint, to expend a certain amount on further All-British cables worked on a basis of comparatively low rates within the Empire. The adoption of such a course would serve to foster trade 'twixt the Mother Country and her Colonies.

We should also remember the strategic value of Imperial lines of communication. Let us not forget that there are still some portions of our international telegraph system which are worked by foreign clerks, whose telegraphic energy and efficiency-at no time of a very high class-is liable to be seriously reduced in the event of mis. understandings abroad. It has been argued that strategic cables could be laid "to order" as required. It is even said that a portion of the large reserve funds set aside by the cable companies are intended for that very purpose. Be that as it may, our cable communication via the Mediterranean Sea would be more likely to be cut off as a precursor to war than actually during war. The harm would be effected, indeed, before we knew where we were, and it would then take several weeks probably before the missing link could be restored. What that might mean it is scarcely necessary to state; and the seizure of a cable station on foreign shores previous to, or during, war, is an operation which might any day occur, 


\section{I34 Imperial Telegraphic Communication.}

whether as a formula for the declaration of war or otherwise. In the event of an outbreak, naval supremacy could only be maintained if accompanied by direct communication with the nearest coaling stations, as well as with headquarters. By means of the cable it is possible to concentrate a navy in a way that would be quite impracticable without. The fleet is, indeed, rendered infinitely more effective with cable under our own immediate control than when in the region of foreign territory - where it is liable to be severed at any moment. The best conditions for a strategic cable are peculiarly at variance with those for ordinary purposes. Thus, as the writer has pointed out, ${ }^{1}$ strategic lines are comparatively invulnerable if laid in deep water, with few landing places, on out-of-the-way (non-trade) routes, their exact course not being divulged. The most favourable route for such lines is in the open ocean. Under these conditions they are a hard task even for a cable ship to recover.

Cables have seldom been laid with a mainly strategic object, for the reason that, if so laid, they run counter to financial profit. They are more costly to maintain, and the traffic derived for them is comparatively small. It is, however, just such lines as these that should be recognised as a necessary adjunct for an Empire with important possessions so widely scattered; and as the cable companies appear to be indisposed to undertake

1 Quarterly Revieu', April, 1903, No. 394 (p. 374). 
these lines even under subsidies ${ }^{2}$ - they can scarcely be called upon to do so-it rests with the State to put them into effect.

We think nothing of spending a million on a battleship as a wise provision of war; but the same amount spent on cables might often be of greater national benefit in even averting war, or at any rate in bringing the battleship into more immediate touch with her base-thereby rendering her effective instead of ineffective.

The All-British Pacific cable is an excellent example of something that has already proved its value to the nation. This line was rendered necessary, and became a subject of Government intervention, as the companies responsible for our telegraphic communication with Australia were not prepared to meet requirements. After twenty years' talk the line actually became an accomplished fact on October 31st, 1902; the alleged "insurmountable difficulties" being overcome in a wonderfully short time. It may, indeed, be said that the speed with which this work was carried out - it was made and laid within a year-was one of the grandest engineering achievements ever accomplished; and it certainly reflected the greatest possible credit on the Telegraph Construction and Maintenance Company, as contractors. Previously, telegraphic communication

1 From a point of principle, these are the main description of cable for which Government subsidies are most warranted. 
between our Australasian Colonies and Canada was not only most costly, but also roundabout. It was, indeed, partly performed through rival countries, or by cables landed on foreign soil. For this reason, it was also comparatively slow. The same applies in the case of communication between the Mother Country and Australia, the message taking upwards of a day where it now takes an hour. Then, again, as soon as the scheme began to be seriously talked about, the rates between England and Australia came towering down from $9 s .4 d$. to $4 s$. $9 d$., a further reduction to 3 s. occurring on the cable being constructed. Is it not, too, of any interest to us here that whereas the New Zealander had to previously pay 4s. a word to "cable" to New York, he can now do so for 2s. 6d.? To the colonial seeking a market this difference is most important. Above all, however, by the Pacific cable, our fleet is rendered infinitely more effective in time of war than could ever have been the case before it was laid, when we were dependent on comparatively shoal-water cables passing near foreign territory. It will thus be seen that the line has served a great national object in a number of directions.

It is true that, financially, this line has, as yet, only been a source of expense to the country ; but, as has been well remarked by Dr. G. R. Parkin, C.M.G.: "A great nation need not always build a cable simply in order to give a dividend any 
more than the Inter-Colonial Railway of Canada was built merely in the hope of it paying. It was, on the contrary, mainly built for a great national purpose." I And so it is with the Pacific cable. Are we not, indeed, fully justified in regarding such expenditure on the same footing with battleships and the like?

The All-British Pacific cable has always laboured under considerable disadvantage owing to the long section between Vancouver and Fanning Island - running into $3,45^{8}$ nautical miles. As the transmitting speed of a cable is inversely as the square of the length, this renders the system a slow working affair. Thus, though still unremunerative-partly owing to the difference in time at the two extremities-the traffic becomes congested at certain hours of the day. The line will therefore have to be augmented by a second string before long if there is to be a considerable development of inter-Imperial telegraphy. This augmentation might, however, be effected by tapping the already existing American Pacific cable, as the writer has more than once suggested. 2 This project could be carried out in a manner at once economical and yet satisfactory by laying the following cables, which would be

'Discussion on Mr. Henniker Heaton's paper on "Penny a Word Telegrams throughout the Empire," November soth, 1908. (Joumal of the Royal Colonial Institute, vol. xl., part x.)

2 The Times, June 3rd, 1898. Ibid., December 20th, 1898. Fortnightly Review, September 1898 . 
of mutual use to the countries concerned, and, therefore, should be paid for jointly, viz. :-

(a.) A cable from Vancouver to San Francisco;

(b.) A cable from Honolulu to Fanning;

(c.) A satisfactory installation of radio-telegraphy from the Philippines to Australia by way of either New Guinea or Borneo.

This scheme would have the advantage of increasing the scope for traffic. Moreover, in view of the immense commercial field of China, added to our important commercial and political relations with Japan, it should surely appeal to all true Imperialists partly for strategic reasons.

We should, however, always keep before us the contingency of a great European war such as would, undoubtedly, entail the cutting of many cables on the eastern route. For this reason, therefore, we should render doubly secure our western route to Australia by providing for a possible breakdown on the existing All-British cable; and though the duplication might suitably be effected as above, we should, at any rate, have one strictly "All-British" line to and from Australia.

In the course of evidence to the Cable Communications Committee ${ }^{1}$ the writer-along with other witnesses-set forth a number of further lines which require to be laid in order to com. plete the All-British chain. In his opinion the general principle should be borne in mind that

1 Blue Book, Cd. $95^{8}$ (1902). 
it is better-as a general rule-to lay new Imperial State wires where required than to attempt to lay hold of those owned and worked by vested interests.

Some of the proposed All-British lines would probably not pay in themselves for some time to come; but they would at once benefit not only the Mother Country, but her outlying possessions. A propos of this, Sir George Doughty, M.P., does well in asking: "Is it always necessary in matters affecting the Empire that we should be certain a thing is going to be a commercial success immediately it is started ?" and, as he goes on to say, "Surely people of the Empire might be willing to contribute, through their respective Governments, certain subsidies for a certain time towards any such development in the interests of the Empire." 1 Both France and Germany have already realised the force of this by establishing for themselves a number of cables mainly associated with their distant possessions-serving political and trade purposes as well as strategic requirements.

The cable companies concerned having declined to undertake lines for which there is political and strategic demand, the Government of the day is clearly justified in setting afoot State cables on the above grounds. Had the cable companies

' Discussion on Mr. Henniker Heaton's paper on "Penny 2 Word Telegrams throughout the Empire," November 10th, 1908. (Jourmal of the Royal Colonial Instituse, vol. xl., part 1.) 
undertaken the first link in the chain they would probably have been willing to complete it; and this line of action would have been rendered unnecessary; but they have all along rigorously refused to enter into the matter under any conditions-even as a return for favours received.

Such a scheme, for further State cables, should however, be closely limited to the Imperial chain, no attempt being made to establish a Government service in regard to strictly international cables. In reference to the latter, the cable companies have, from the first, achieved much that would be quite impossible for any State, especially our own. For many years, indeed, the British cable network has been regarded with intense jealousy on the Continent; and it was largely owing to this that both France and Germany-not to mention Italy - eventually established their own systems.

The arguments against the Government embarking on international cables still more apply in regard to the question of the State absorbing, with a view to controlling, those international lines which are already in existence. In the first place, if such a step were taken it is quite likely-for reasons already set forth-that the other countries concerned would make an early excuse for abrogating their landing rights. Secondly, it is very doubtful whether any such absorption could be reasonably effected, whereby full justice was done to the vested interests concerned. 
Sir Edward Sassoon is undoubtedly correct in stating that the cable systems are a more proper subject for State nationalisation than railways, from one point of view, i.e., that the former have been, to some extent, supported by Government subsidies. It should be borne in mind, on the other hand, that our vast network of submarine telegraphs is due almost entirely to the cable companies. The Atlantic cable would never have been embarked on to this day but for the enterprise of a few far-seeing individuals who were ready to risk much. (The British and American Governments lent-ships; but no further assistance was forthcoming from that quarter.) The cable business has since been gradually built up, until a certain state of completeness and perfection has been ultimately reached. Thus the goodwill would necessarily be high. Indeed, the purchase money required for buying the cable companies would represent an enormous figure if on an equitable basis; and the question as to how the piper should be paid for the new tunes to be played would be more readily asked than answered.

Apart from this financial objection, there are reasons of principle against State absorptionexcept under special circumstances-such as will appeal to most outside the purely Socialistic circle. No doubt the latter would like to see industry after industry absorbed by the State until each of them is worked by the State "for the benefit of the Community." It is, however, recognised by most 
thinking people that England's greatness is largely due to private enterprise, to kill which would be highly injurious to the country's welfare; and perhaps the hardest and most inconsistent thing about State trading is that once it is established in any sphere it becomes a criminal offence to compete with it.

Life is, however, made up of inconsistencies, and we have a Conservative M.P. (Mr. John Henniker Heaton, member for Canterbury and probably also of the Industrial Freedom League) loudly expounding the cause of State nationalisation of cables. This appears to be in his usual picturesque concern for "the British people"; for, whilst he never tires of referring to the late Sir John Pender as a "huge octopus," he (Mr. Heaton) recently spoke of the cable monopolists as having " seized the God-given gift of electricity and devoted it to the sole use of the millionaires to the exclusion of the millions." 1 Mr. Heaton suggests that "God's given gift of electricity" should be free. Perhaps this is because he has nothing to do with the harnessing of it. Except above us, from the skies, that which we can get for nothing is difficult to find nowadays; and when found is generally discovered to be scarcely worthy of possession. In the case in point, however, it must be remembered that the

1 "The World's Cables and the Cable Ring," by J. Henniker Heaton, M.P. (Financial Review of Reviews, May and June, 1908.) 
expenditure and labour entailed is of a peculiarly high order. In a long cable, the copper conductor costs much, the gutta-percha insulator costs more, and the necessary cable sheathing also means a heavy expenditure, let alone the subsequent submergence on the required route. Adequate provision has also to be made for depreciation and maintenance.

Whilst not taking Mr. Heaton too seriously in regard to his minimum, free, tariff, he has quite lately told the world that he considers a "UniversalPenny-a-Word" rate should be the order of the day. That sounds very well from the public standpoint; and few message senders would, in that capacity, be found to object to it. Under present conditions, however, a business conducted on those lines would have a brief and unhappy existence. Moreover, if this were to form a part of the proposed scheme for the State nationalisation of cables, the work would be carried out at a heavier loss than the country would be disposed to put up with. Those unencumbered with full and direct knowledge of a special subject and its difficulties are sometimes prone to make irresponsible suggestions in a light-hearted fashion; indeed, as we all know, "Fools rush in where angels fear to tread." And in this matter it would be well, perhaps, to "walk before running."

Then, again, Mr. Heaton brings into prominence that the country at present spends something like a quarter of a million per annum on cabling 
official Government despatches, and that this sum would go a long way towards meeting the interest on the purchase-money for buying out the cable companies. This, however, can scarcely be accredited as an argument-such as can properly be weighed in the balance-for the general principle of the said State purchase.

In addition to the objections already named to Government absorption of the existing international cable systems, there is also the question as to whether-if such absorption were feasible, and, if other countries made noobjection in the matter - the change would prove sufficiently satisfactory. From the commercial standpoint, the British Postal Telegraph Service is scarcely one to be pointed to as an example in favour of State absorption. Though, if excluding the telephone, the service leaves little to be desired-and is as efficient as the cable service-it is one that does not pay. It is quite doubtful, indeed, whether the country has done better by the State purchase of the inland telegraphs in substitution for healthy competition between responsible companies. All that is certain is that the companies did not work the telegraphs of the United Kingdom at a loss; and that, in those days, there was no taxation under this head. The present loss is largely due to the Government having to take the telegraph to obscure, outlying villages, and establish offices which are not remunerative. It is also probably attributable to the development of the telephone service. Certain 
people in the country have, undoubtedly, benefited by having the telegraph brought more or less to their doors where the companies were unwilling to incur the expense; but from the general public standpoint, the disadvantages above set forth, or implied, must be borne in mind as well as the advantages.

It is true that having no shareholders to consider, a Government starts with a definite advantage in working any such industry on behalf of the public; but most people would expect that working to be performed at a profit rather than a loss, except under special circumstances. Indeed, a point to be decided in this important question is whether in getting cheaper messages, under the State, we should have to pay more for them in other ways-whether we sent the messages or not.

But even if the answer to this question were unfavourable to the Government purchase, it would not be sufficient to entirely dispose of the scheme in every direction, provided the arguments in its favour on national grounds were sufficiently strong. Mr. G. R. Neilson, an enthusiastic yet interested authority in opposing State absorption, asks: "Would the working of the cables be more rapid, more accurate or more efficient in the hands of Government employees?"I It may, however, be pointed out that if other advantages are with Government control, then the question is not so

2The Electrician, December isth, igos.

T.c. 
i46 Imperial Telegrapuic Communication.

much whether the working would be " more rapid, more accurate or more efficient," but rather whether it would be equally so.

Though the balance of argument may be against State absorption-even if it were feasible-so far as concerns international lines, there can be little doubt that the Governments would be better advised if, on behalf of the public, they were to exercise a more complete supervision over our cable system. That they have not done so in the past to any material extent is, probably, due to the small part played by Governments in the initiation of the world's cable system. Those subsidies which have been obtained by the companies from our Government are solely concerned with British colonies or dependencies. But even landing rights may be made the lever for negotiations - and in a variety of directions. For example, when a company seeks landing rights for some particular cable, conditions should more often be made, not only in regard to that particular line, but also for reducing the rate on another belonging to the same company. It is doubtful whether, in any case, exclusive landing rights should, in future, be granted to any one company, and certainly not without suitable terms being imposed in the interest of the public. Failing this, every reasonable opportunity should be taken to encourage fair competition; and several modifications in regard to our present cable system might be found feasible where further 
favours are sought from the Governments concerned. It may be here suggested, too, that guarantees of some sort-whether of traffic or revenue-are a more suitable form of Government aid than actual subsidies. Such guarantees, or indemnities, are also infinitely preferable, in principle, to Government competition, if the required results can be achieved without the latter being necessary in the interests of the nation. There is but little to guide one in definitely arriving at what is, or what is not, a fair and proper cable rate. On the other hand, the consideration of a standard revenue and of a Government guarantee for that revenue associated with a limited tariff has many attractions from a point of principle. The Associated Telegraph Companies maintain that the volume of telegraphic communication between given points is practically determined by the volume of trade. Even so, may it not be suggested that the lowering of rates would tend, in time, to substantially augment the volume of trade? But the most popular step would be the classification of messages, whereby the tariff after business hours was reduced to meet the demand for relatively unimportant and non-urgent cablegrams. This would also serve to increase the earning power of cables at moments when-partly owing to time differences-they are but little used at present. The fact is we need a service intermediate between that provided by the mail and that associated with comparatively costly telegrams. 


\section{$14^{8}$ Imperial Telegraphic Communication.}

In many instances the cable would be freely adopted instead of the mail for long distances if there was such a thing as "easy" rates for nonurgent messages to be transmitted, say, within twenty-four hours.

Some of the criticisms which have been made from time to time as to rates charged by cable companies have apparently been based on insufficient information. Sometimes even the length and cost of the cable involved appears to have been lost sight of. Apart from this, however, when capital is raised for a new line, the traffic that is likely to be derived is the main consideration; and the rates have to be adjusted in accordance with the probabilities of traffic volume. It should, however, always be remembered that no reduction in tariff can justify itself for some years, even though it may do so in time.

It may be remarked incidentally that previous to the recent agitation, the Commonwealth of Australia - who since the Commonwealth Government came into being have been in full control of the entire Australian telegraph system-had decided not to renew the exclusive right, nor the $£ 4,200$ per annum subsidy, to the Eastern Extension Telegraph Company for telegraphic com. munication with Tasmania. This, therefore, now lapses, and the Commonwealth Goverrment proposes to establish a cable system of its own. As has been previously shown, Government lines of 
this character are fully justified under such circumstances, where they would be altogether unsuitable, even if practicable, to foreign shores.

Those who object to competition of any sort should bear in mind that the more lines there are the more familiar becomes the idea of a cablegram, and that increased facilities always tend to increase the demand. Thus, healthy rivalry need not necessarily mean detriment to vested interests; and, from the public standpoint, the general principle should be accepted that the greater the number of independent cables the more likely is continuous communication between any two points of the Empire to be assured. Then again, Is it after all such great nonsense to try to do something practical towards more firmly knitting together the British Empire? and should purely personal considerations, when opposed to national interests, be allowed to unduly stand in the way?

The forthcoming Imperial Conference not being due till IgIr, it is to be hoped that the suggested inquiry into the whole subject will take effect, and there can be little doubt that the cable companies will be ready to meet all reasonable suggestions, even if in a good fighting spirit. It is to be feared, however, that the talking will always be in excess of the doing; for, as has already been remarked, though the Pacific cable took but a year to make and lay, this followed on twenty years' desultory talk, carried on at wide and disjointed intervals. 


\section{IMPERIAL TELEGRAPHS. ${ }^{1}$}

THE forthcoming Imperial Conference serves to revive in many people's minds the need for more direct and, at the same time, less costly telegraphic communication between the different sections of the British Empire.

That we are already provided with a highly efficient, if expensive, international cable service no one can reasonably deny. It should also be recognised that the telegraphic facilities available for a large proportion of the British Empire are of a substantial order. These facilities are, however, open to disturbance in several quarters, and, for obvious economic reasons, they are not availed of to the extent that would be desirable from an Imperial standpoint.

There is a growing feeling amongst people of diverse political creeds that the mother country and her oversea dominions should be in closer and more easy commune with one another, partly with a view to increasing the scope of inter-imperial trade. So far, however, we have not really got much beyond the idea: we have, indeed, merely scratched at the surface. How this comes about, why it is so, and what should be done with a view to altering that position I shall endeavour to bring

1 Paper read, in part, to the Royal Colonial Institute, April 25th, 1911. 
home to you in the latter part of my paper. I shall also ask you to recognise that just as in order to ensure peace we must, in the matter of arma. ments, be abundantly prepared for war, so equally it is essential that we should be telegraphically equipped in such a way that we can at all times rely upon talking freely, yet secretly, with the rest of the Empire. The one condition without the other is, I maintain, of little use. This paper will have achieved much of its object if a resolution to that effect be passed this afternoon.

Having sketched out the main burden of my remarks, it may be well to give a brief reference to what has gone before in regard to telegraphy with distant lands. It should first be noted that for our cable service, as it stands, we are mainly indebted to private enterprise. You will observe on the wall statistics of the approximate mileage of cable in operation to-day. Out of this total less than a sixth belongs to any Government. The latter is, however, a distinctly rising proportion; for, as I shall be showing later, foreign Governments, recognising the need for independent strategic lines of their own, are rapidly adopting a policy of State-owned and State-administered cables to their outlying possessions. Thus there are now two submarine cable factories in France, one in Germany, and one in Italy, all of these having been established within the last twentythree years. 
A fair number of the cables laid by private companies have been entirely provided for by capital raised by themselves. On the other hand, large subsidies have been obtained from the Home and Colonial Governments for several important lines to the British dominions.

Thus, in the course of correspondence between Lord Tweeddale (then Chairman of the Eastern and Eastern Extension Telegraph Companies) and the Home Government in 1899, regarding the proposed Pacific cable (now laid) it was pointed out that:

"By the time the existing subsidies to the 'Eastern Extension' Company expire it will have received in direct payments from the Governments of Australia a sum of nearly one million sterling, which must be sufficient to have covered a large part of the capital outlay incurred in opening communication with this country, so that it can have little cause for complaint if it is now exposed to competition." 1

It would seem, on the face of it, that where private companies seek, and avail themselves of, subsidies from the State they cannot rightly object to either Government supervision or Government competition, or, alternatively, the subsidising of some rival enterprise such as they have not been willing to undertake themselves on satisfactory terms.

1 Blue Book, Cd. 46. 
It would, in fact, be unreasonable to expect the State to refrain, under any circumstances, from interference with private enterprise, for very often the results of private enterprise run counter to public interests, owing, maybe, to the business being primarily conducted for the benefit of the shareholders rather than that of the public.

It so happens that the Government of this country has in the past exercised scarcely any control of the British cable system, and has hardly imposed any restrictions on behalf of the public This is, no doubt, partly accounted for by the fact already alluded to-i.e., that our cable system is nearly entirely the result of private enterprise, and was completely so in the first instance.

But even where a cable is not subsidised, the granting of landing rights should always have been made a subject for conditions in the interest of the people; nevertheless, this opportunity has practically never been availed of, whilst, on the other hand, interminable exclusive rights have been granted where they would never have been.

Restrictions as to the tariff would be an obvious condition for Government to make when granting subsidies or even landing rights. I have frequently urged that the companies working our cable systems might, if approached, be prepared to take the rough with the smooth in this matter.

It has always seemed to me that a great advance would be made in our inter-imperial com. munications if an all-round Imperial cable tariff, 


\section{I54 Imperial Telegraphic Communication.}

say of Is., $9 d$., or even $6 d$., could be put into operation. The actual figure for this common rate throughout the Empire might be suitably made a subject for full investigation in the course of a Government inquiry with representatives of all branches of the Empire and of the companies concerned. Whatever might be the figure decided on, I feel that the principle is sound Imperially, just as on a much smaller scale we have a uniform inland rate throughout the United Kingdom. It was in the year I90I that I first ventured to make the proposal, but I am afraid I cannot report much solid progress since then.

My suggestion was based on the fact that the cable companies are given to entering into pooling arrangements and joint purses, and are, as a matter of fact, very largely a single organisation -at any rate for the purposes of staving off com. petition; and this being so, it seemed to me advantage might be taken of the circumstance for the benefit of the public in the matter of tariff.

Before condemning a proposal of this character it is well to remember the various reforms that have ultimately taken place in the face of repeated derision. We know now what the effect has been of a uniform penny postal rate throughout this country-notwithstanding the loss predicted, with figures to prove the loss! ${ }^{1}$ We know that this

1 It was once said that penny postage throughout the United Kingdom would bring the Post Office to bankruptcy, and that different charges must be made according to the distance a letter was taken! 
satisfactory outcome is solely due to the impetus given to an enormous increase in correspondence such as was never contemplated by permanent officials in the department concerned. History reveals the fact that no great reform was ever achieved without having been ridiculed as an outrageous proposal, and so forth. Thus, those who aim at fundamental changes gain encouragement from the study of history in matters of a similar character. After I had already prepared this paper it occurred to me to refer to Mr. Henniker Heaton's first (1888) paper to this Institute on "Postal and Telegraphic Communication of the Empire." I In the discussion a well-known and distinguished official assured Mr. Heaton he would have to wait a very considerable time for Australian penny postage to be realised. He, indeed, said it was altogether out of the question. Yet we have it to-day, and why? The answer is because we have men like Mr. Heaton whohappily for themselves and for us-see no obstacles in the way of their high ideals some day to be realised. Mr. Henniker Heaton can undoubtedly claim to have done much towards the cheapening of postal rates to the Colonies; and, whether we ayree with him or not in some of his views, I feel sure that all those present will wish him a complete and speedy recovery from his serious illness. That there are difficulties in carrying out my

I Proc. Roy. Col. Inst., vol. xix., p. 170. 


\section{I56 Imperial Triegraphic Communication.}

uniform Imperial rate I would not for a moment deny; but it appears to me that really useful work would be accomplished by any Government that took steps towards its realisation on a basis equally fair to all parties concerned.

The companies themselves are, in the main, in a very strong financial position. Their reserve funds are largely based on what was once the accredited life of a cable-twenty years-rather than double that period, such as is now known to be nearer the mark. In these circumstances, I imagine they would be prepared to meet Government suggestions in the matter, if negotiations were pursued on right lines and in a suitable spirit.

Where substantial reduction of rates in any direction carries with it an increase of traffic, a corresponding increase in establishment charges is necessarily entailed. Furthermore, a point would be reached in some cases where the existing cable, or cables, would be insufficient satisfactorily to cope with the increased traffic at certain hours of the day, thereby involving an additional line-a distinctly costly article in itself. All these things require to be taken into account in order fully to appreciate the expense incurred by a private company when reducing the rates to meet a public demand. Then, again, before criticising a company for high rates in certain instances, it should be borne in mind that owing to wide time differences and to the limited business hours in common at each end many cables are only earning revenue 
during a portion of the day, and in some cases a comparatively small portion.

Thus, for this reason, amongst others, some of the comparisons that have been made with railway tariffs are altogether beside the mark; though, on the other hand, there appears to be quite as strong reasons for imperial cable tariffs being regulated by the State as for the $\mathrm{Id}$. a mile Parliamentary fare in force on the railways of this country.

I would here remark that, in the absence of a standard, the term "high" as applied to cable rates is, of course, a purely arbitrary one, and should only be used in the general sense of what we get in return for our money.

It should also be added that the Companies have reduced their rates very considerably from time to time in various directions, though without incurring the disastrous results that have sometimes been feared. Thanks, perhaps, to Sir Edward Sassoon's activities, the tariff to India has, in recent years, come down to the 25 . a word for which he so strenuously worked, whilst with the laying of the All-British Pacific Cable a 35. a word rate to Australia and New Zealand took the place of what was originally $9 s .4 d$. a word. Similar reductions have taken place in the tariff to the Cape and other quarters of the Empire.

From the general public point of view, however, these reductions serve only to remind us that telegraphing to other parts of the Empire was once an even costlier business than it is to-day. It is 
conceivable, of course, that further reductions may not be possible at the hands of the companies. It has, however, always been admitted that if the Government took over our Imperial cables the rates could be substantially reduced. ${ }^{1}$

Whilst increased overhead charges and additional cables constitute a real objection to tariff reductions even with companies possessed of immense reserve funds, this difficulty has of late been met to a great extent by a recent invention-the cable relay; for this permits of a cheaper type of cable for a given volume of traffic, and, correspondingly, by its adoption at intervening points the same type of cable has a greater earning capacity.

Hitherto, when once long continuous spans of cable had been satisfactorily dealt with, the elimination of intermediate stations - unless of a remunerative nature-was always aimed at in order to dispense with manual retransmission. Now, however, this retransmission being effected far more efficiently and economically by machinery, it is usually considered good policy to take the line to as many intermediate points as are reasonable on the route.

1 Thus Sir James Anderson (the late distinguished Managing Director of the Eastern Associated Telegraph Companies) once remarked that " the Government in taking over the telegraphs (meaning apparently the British cable system) could reduce the tariff one half and still make a profit. Private companies," he added, "could not do that." Proc. Roy. Col. Inst., vol. xix., p. 212. 
The question of reduced rates for messages to be held back for any time up to twenty-four hours has, for very nearly a year, been once more under "close consideration." An innovation of this character would, in a great measure, satisfy prevailing needs in supplying an alternative service intermediate between the sometimes unnecessarily speedy yet costly cablegram and the despatch of a letter by mail occupying several weeks in transit.

The cable companies, perhaps naturally, cater almost exclusively for business messages, which form at present 96 per cent. of the whole. In this way seventeen Atlantic cables are kept well employed during the four or five business hours in common on each side of the ocean. By the introduction of lower rates for deferred messages, the remaining hours could be turned to more profitable account by the cable-in the same way that certain railway companies fill their trains with ladies in the middle of the day. It is understood that the Eastern Associated Companies are now favourable to the reform, though certainly not so when I, for one, advocated it to the Cable Communications Committee in the year 1900.'

In that occasion, the companies proposed as a substi. tute that treble rates should be adopted for " preferential " messages marked " urgent " which were to be given priority. In other words, no reduction on the ordinary messages was agreed to under any pretext, but an increased tariff suggested instead for messages of an extra-urgent character. The answer given to Question 578 at the Cable Communications Committec Inquiry (Blue Book, Cd. 958) shows 
My suggestion was made mainly with a view to developing private messages, but also for obviating the necessity of coding and decoding in the case of many business cablegrams of a non-urgent character.

The "Western Union" and "Postal Telegraph" Companies of America recently introduced what is known there as the "night letter" system, under which telegrams are accepted at very low rates for transmission during the night. This is said to have resulted in an enormous increase of business. The innovation is, indeed, stated by the general manager of the "Western Union" Company to have also greatly increased the number of full-rate messages, the recipients of night letters often replying at once by wire. One man is said to have despatched no fewer than 500 night letters in a single evening. A Chicago business house sent I, rog letters at once, and two New York firms 8,600 letters in the course of a week. ${ }^{1}$

Following up their night-letter innovation, the Western Union Company have now introduced what they call a "day-letter" service. By it, the company accepts a message of fifty words or less, to be sent at its convenience at a rate one-half

pretty clearly that the companies as a whole were at that time unwilling to adopt deferred rates; whilst an absolute proof of the desirability of the plan from the public stand. point is to be found in the answer to Question 578 .

1 There would be little point in introducing a corresponding system for our inland telegrams in this country where the delivery of letters is so much more expeditious, on account of the comparatively small area to be dealt with. 
more than the existing night-letter rate. To put the matter in another way, a fifty-word day message will cost half as much again as a tenword day message. (Under existing tariffs for telegrams and cablegrams a fifty-word message would cost five times as much as a ten-word message.) This last reform is practically on the same lines as what has been constantly pressed for over here under the name of deferred messages for cablegrams.

Our present Postmaster-General appears to favour the deferred rate proposal, recognising that "too heavy a burden falls on individuals desiring to send messages by cable." An official conference is still considering this subject at disjointed intervals. Various suggestions have been made as to the exact form the deferred rate system should take, and no definite decision has yet been arrived at. The most generally approved form appears to be on a plain English, non-code, basis, the message being sent within twenty-four hours, and the tariff charged being half that by the ordinary rate. Both the German and French Governments are in favour of the reform being universally adopted; and we now really seem to be within measurable distance of cheap "deferred rates" for plain words being available wherever ocean telegraphy exists.

Yet, for the present, the actual introduction of deferred rates may be said to be "still deferred"!

r.c. 
Apart from instigating the use of the cable by those who have hitherto been unable to use it, the introduction of deferred rates should also achieve much for the Press by diffusing intelligence of an Imperial character on a larger scale. ${ }^{1}$

At the annual conference of the Institute of Journalists, which took place in London last September, special attention was drawn to the needs of an unbiassed and full Imperial news service on an economic basis, free from the possible influence of a foreign, neighbouring country, in times of peace as well as war.

We seem to need something in the nature of an Imperial Press agency for the dissemination of news of Imperial interest throughout the Empire. Such an agency should be under the direct control of a Board representative of the different Imperial domains.

This need would apply equally whether the existing and required Imperial cables are made a State affair or not. If the cables at present serving the Colonies are left in the hands of private enterprise either fresh cables must be laid for the purposes of a cheaper news service, or Government should endeavour to secure a more favourable tariff.

1 In the course of discussion on Captain Muirhead Collins' recent highly.informing Soricty of Arts paper concerning "The Commonwealth of Australia," Sir Francis Hopwood did well in laying stress on the value of reciprocity in knowledge betwixt our widely scattered domains and to the importance of "cheap cabling" for meeting this end. 
Having dealt with the present position in cable telegraphy and with the need for lower rates throughout the Empire, let us now turn to the strategic aspect of cables. This is, after all, a more important feature than any that we have to consider. To a country like ours, with far-reaching possessions in every corner of the globe, the necessity of being in constant communication with our outlying tributaries can scarcely be overestimated.

As previously indicated, France as well as Germany have already realised this importancethough obviously of far less moment to them. Further, an agreement has recently been entered into between the French and German Governments the object of which is to render these countries independent of British cables-more especially for communication with Africa. The agreement provides for the common use of their respective submarine telegraph lines at any time that "accidents of a technical or other nature" interfere with the normal working of the services. But, immediately, perhaps, the most striking feature of this agreement is the laying of a Franco. German State cable between Brest and Emden, with German extension to Monrovia (West Coast of Africa) and Pernambuco (South America). ${ }^{2}$

I On the other hand, representations bave recently been made to the Birmingham Chamber of Commerce that there is need for a British.owned and controlled cable all round South America, "in order to counteract the great efforts now being made by the United States to advance their trade and binder that of other countries." 
196 Imperial Telegraphic Communication.

This brings us to the general question of Stateowned cables.

If telegraphic communication with the Colonies were only needed for individual purposes, there would, I consider, be no justification for the Government embarking on the expenditure of public money for State-owned cables. But such communication is highly necessary for the nation -(1) strategically, (2) politically, and (3) for developing inter-imperial trade.

There is, in my opinion, an unwholesome tendency at the present time towards State enterprise and State expenditure in entirely wrong directions. Instead of being focussed on National and Imperial objects they are devoted to individual and class interests. Old age pensions are a case in point.

Whilst, on general principles, there are many objections to State trading, there are more sound reasons in favour of Government-owned strategic cables to our distant possessions than would apply in the instance of State railways or the Government land telegraph svstem of this country. Both of these may be said to serve individual interests rather than the nation as a nation-or, at any rate, rather than the Empire as an empire; and may it not be contended that we have arrived at a stage when it behoves us to consider things from an Imperial instead of a purely National standpoint.

I would venture to urge that there is every justification for State-owned and worked lines 
of communication between the various corners of the Empire where such are needed for strategic as well as other high State reasons. The fact is that in an emergency, a battleship, or an army, away from the required spot-for want of telegraphic communication-might as well be at the bottom of the sea.

Then, again, with the present food supply of this country so seriously out of proportion to the population, absolutely secret and invulnerable communicating links with the wheat growing areas in our oversea Dominions become every day more vital to the nation if we are to guard against the chances of being starved out by foreign Powers, bearing in mind that we import four loaves out of every five we eat.

Some people urge that cables could be laid to order to meet emergencies.' Whilst this could often be successfully accomplished, it is an opera. tion that takes time, during which many serious things may happen for want of telegraphic communication with some corner or another of our scattered domains.

Others may argue that the cutting of cables is no easy matter. Whilst this is true of deep water cables, those at comparatively slight depths could be readily disposed of. It is not, however, only the cutting of cables that we require to provide for: we have also to remember the possible control of them

- The cable companies have lengths of cables stored in tanks at some of their stations for this very purpose. 
by an enemy for censorship purposes. That is an equally popular plan which was exercised by the Americans during their recent war with Spain.

I trust, therefore, I have set forth sufficient grounds for a liberal expenditure in State-owned or State-subsidised and controlled cables to the various points in the Empire on a variety of routes, so that where one cable is out of operation another is available at any moment. As you will gather from the small map I have had distributed, there is already a fair network of cables throughout the world. There are, however, several Imperial points that require additional provision on a fresh route, right away from the ordinary hunting ground of foreign battleships. ${ }^{1}$ These are indicated in red.

That cables to foreign countries are, for more than one cogent reason, best left in the hands of private enterprise there can, in my opinion, be no gainsaying. ${ }^{2}$ Whether, however, the same applies

1 This branch of the subject is dealt with more fully in some lectures I gave recently to the Royal Naval War College, Portsmouth, as well as to the Royal United Service Institution (R. U.S. I. Journal, vol. lii., 1908).

${ }^{2}$ As a matter of fact, no other course is open; for just as no foreign country would grant landing rights for a British Government cable on their shores, so, similarly, the moment a private-owned cable was taken over by Government the landing rights would be abrogated. Foreign nations have, in the past, granted landing rights to private companies of this country because they can at any moment put an end to the privilege. Moreover-for a variety of reasons-a cable connecting different countries is most effectively worked by a private company at each end-under uniform direction-rather than by different nationalities. 
in the case of Imperial lines is another question, depending upon conditions; and, in any event, I am convinced that Government control on behalf of the entire Empire should be brought into effect.

There would, I consider, be less reason for several important State lines if the companies had been prepared to reasonably undertake these. The Imperial Pacific cable is a case in point.

After twenty years' talk and much opposition this project, thanks to the persistent efforts of the Colonial Governments concerned and to Mr. Chamberlain's business capacity and Imperial instincts, was eventually effected in 1902. The scheme had waned many a time, but when that distinguished statesman became Colonial Secretary some life was thrown into it and prompt action was the order of the day. If Imperial telegraphs generally could be dealt with on the same broad principle that Mr. Chamberlain adopted in this matter much good might accrue. The vital importance of the All-British Pacific cable may abundantly prove itself any day, if only on account of developments going on in the waters in which it is situated. ${ }^{2}$

1 Before the line became an accomplished fact, Australia's means of communication with the mother country were a constant source of anxiety. Here are the words of Sir Samuel Griffith, late Premier of Queensland:- "These (Eastern and Eastern Extension Co.s') cables run from England through foreign countries or through seas which are continually full of the ships of foreign countries. During the war scare about two years ago there was the greatest anxiety in Australia. ... We know perfectly 
As was mentioned the other day by Lord Selborne, as chairman of the company that was responsible for the entire carrying out of the project, the Imperial Pacific cable has never had a single interruption since the day it was laid, notwithstanding many unfavourable suggestions and prophecies to the contrary.

This line will, of course, require in time to be duplicated, but a reserve fund amounting to a quarter million has already been put aside towards that object.

Arising out of a suggestion I recently made to the Festival of Empire, a demonstration of the Pacific cable's useful operations will be given at the forthcoming Imperial Exhibition at the Crystal Palace. Here you will be able to see certain recent developments in cable signalling which increase the carrying capacity of the longest section by 20 per cent. at each end.

Let us now turn from the Pacific to the Atlantic Ocean. From the very commencement "pooling" and uniformity of tariff between the different Atlantic cable companies have obtained. The Commercial Cable Company has certainly always stood outside the pool, but it has agreed with the other companies as to the tariff.

well that at any moment the cable might be cut, that we should have no means of communication, and that we might have hostile cruisers at our doors. The risk was thought to be so great that in some of the Colonies it had been resolved that the moment cable communication was interrupted it should be assumed that war had broken out." 
A fresh and-from an Imperial standpoint - rather a serious light has been thrown on the situation quite recently, which points ominously to the future possibilities of an enormous American trust in our Atlantic cable service. Let me now particularise. It is something like a year ago since the Western Union Telegraph Company, controlling well over a million miles of land wire, was united with a huge financial trust in the person of the American Telephone and Telegraph Company, with a capital of over 100 millions sterling.' Each of these concerns had, with the exception of the Postal Telegraph Company, practically held the field as regards the land lines of the United States and Canada; and it will easily be understood that an Atlantic cable without a land line connection is of no value whatever. The Commercial Cable Company have an exclusive agreement with the Postal Telegraph Company and with the Canadian Pacific Railway, but the other Atlantic cable servicesnotably that of the Anglo-American Telegraph Company - have always been dependent upon the "Western Union" company and its ally, the Great North.Western Telegraph Company of Canada, for reaching the heart of the latter country and the United States. With the aforesaid amalga. mation, however, the American Telephone and Telegraph Company come into an exclusive agreement with the Western Union Company.

- This colossal concern had formerly acquired the American Bell Telephone Company. 
i70 Imperial Telegraphic Communication.

It was, therefore, not surprising to find that the "Anglo-American" Company was, a little later, in active negotiation with the "Western Union" Company in regard to important changes, practically amounting to the "Anglo" company's four cables being controlled by the "Western Union" Company. These negotiations are still pending, but there seems little doubt as to what form their conclusion will eventually take.

The Commercial Cable Company, with five cables, is, as is generally known, like the "Western Union," an American concern, and there only remains one other Atlantic cable serving these shores-i.e., the single line of the Direct United States Cable Company, laid as far back as I874. The "Direct United States" Company have as yet withstood persuasive American overtures. But, whilst it can more easily stand out against practical absorption or extinction than would be possible for the "Anglo" Company, its prospects are bound to be somewhat crippled by so doing unless it achieves some entirely new telegraphic connection, such as might result from special working arrangements with the Imperial Pacific Cable.

To get a further insight into the seriousness of the position in an Imperial and strategic sense we must now turn to the "Western Union" Company's own cables. These amount to three at present, two of them the original Jay-Gould lines, hitherto-for some deep reason no doubt-leased to a company known as the American Telegraph 
Cable Company. The third was laid during last August and September and yet another is shortly to follow.

Thus, we have the prospect before us of our Atlantic cables-originally a British rather than American enterprise-being more or less in the hands of two American camps, namely, the Western Union (amalgamated with the American Telephone and Telegraph Company) on the one hand-controlling perhaps nine trans-Atlantic cables-and the Commercial Cable Company with its five, these two concerns being between them practically masters of the situation as regards land line connections in Canada as well as the United States.

Things have moved rather quickly in this matter since preparing my paper; for Mr. Theodore Vail, President of the American Telephone and Telegraph Company" and of the "Western Union" Company has arrived in London within the last few days. I think I saw it stated that he had come for a holiday and to rid himself of a cold; but he appears to have found some other way of occupying his time whilst over here. Thus, it is expected that a definite working agreement will be reached within a few days now, including the

1 Possibly because in conservative England we still put the Telegraph before the Telephone, most of the Press in referring to this company have reversed the correct order in its title-finding it difficult, I suppose, to realise that the Telephone could possibly take precedence over the Telegraph. 
172 Imperial Telegraphic Communication.

"Direct United States" Company. I notice that Mr. Vail assures the Press, on a rather liberal scale, that the agreement "will not mean an amalgamation of the rival concerns, but rather a community of interests." This is a distinction that I should not like to rely upon; and as regards his promise of deferred rates, I will only say that the Government of this country should, in my opinion, be in a position to secure that end for us in other ways.

I need scarcely say I have nothing but admiration for American enterprise; and my objection to the outlook is only on national and Imperial grounds, together with the fact that any huge trust is more likely-if securing a complete monopoly - to raise the rates than to lower themnotwithstanding what Mr. Vail says to the contrary. In this connection it may be useful to mention that, up to the present, all the Atlantic cable companies having so far stood out of the International Telegraph Convention, are free to charge whatever tariff they think proper. ${ }^{1}$

It might be thought that in view of the aforesaid amalgamations the Government of this country would take the opportunity of exacting favourable conditions on behalf of the public when appealed to for landing rights. That, however, does not

1 It is not suggested here that $1 s$. a word is anything out of the way for a trans-Atlantic rate. On the contraryresulting no doubt from competition-it is fairly reasonable as compared with other existing cable tariffs. 
seem to have been thought necessary or desirable ; for, though something like six months elapsed before landing rights were actually granted in the case of the new Western Union cable, the neces. sary leave was given by the State (after it had already been taken !) without any conditions being stipulated for. It may be interesting to note that the laying of the main section of this cable was actually completed ready for working on August 15th, 1910, and that of the section between Newfoundland and New York on September 25th, 1910. Yet for want of landing rights the cable was not open for public working till February 17 th, 19II. Hence the cable was lying idle without earning a penny for some six months, while if it had not been made so unnecessarily early (as it proved) its cost would have been far less, owing to the difference in the price of raw materials and to the fact that only one contractor had, at the earlier period, the necessary stock of gutta-percha available.

As an instance of how much Atlantic cable traffic is dependent on the land line connections to the States and Canada, it may be mentioned that the two German lines-which are worked in close co-operation with the "Commercial " system -carry considerable traffic; and, on the other hand, the two French cables-which similarly enjoy a subsidy - are associated with a very small portion of the total trans-Atlantic traffic, being 
allied to neither of the great land telegraph companies in America.

The All-British Pacific cable system has laboured, so far, under just such disadvantages on this side, in that it has no collecting office of its own in London, and is, moreover, entirely dependent on the Atlantic cable companies for the transmission of messages between the mother country and Canada.

Thus, it will be seen, from what has been said generally, that inter-Imperial news to or from the United Kingdom is at the moment subject to the control of American interests and party politics. Further, those interested in American trade would be naturally inclined to keep the cable rates up between Canada and Great Britain.

At present, thanks to the Pacific cable, the Dominion of Canada is better supplied with news from Australia and New Zealand than with news from the mother country - and this notwithstanding the numerous cables spanning the Atlantic Ocean. Incidentally, too, not a single one of these Atlantic cables-though affording a highly efficient service-could at any time be relied upon as a genuinely All-British strategic connection in the event of trouble with the United States or with other countries interested in disturbing our Imperial communications. This defect is now accentuated by the aforesaid amalgamations, whereby all our Atlantic cables pass into American hands and become subject to the American flag. 
Thus, for the various reasons here set forth, there should be an end to delay in establishing an independent and more or less invulnerable connecting link - free from American influence between the mother country and Canada. This points to a new Atlantic cable either worked by the State-including all branches of the Empire concerned - or under definite State control.

Moreover, by way of still further increasing the utility of the All-British Pacific Cable as an Imperial asset, the new Atlantic cable should be supplemented by a really satisfactory land line connection across Canada-taken throughout at some distance from the American frontier. By this means the whole telegraphic system between London on the one hand, and, say, Melbourne on the other would, for the first time, become one. It should not be forgotten that on the occasion of a Conference at the Treasury on July $4^{\text {th }}, \mathbf{1 8 9 9}$, it was specifically laid down by Mr. Chamberlain "as a provision upon which the Home Government must insist that the route the whole way between this country and Australia should be absolutely 'All-British.' This would apply to the lines across the Atlantic and America, as well as to the Pacific cable. This stipulation was agreed to." 1

1 This understanding was later confirmed in a Colonial Office minute of July 14 th, 1899 (Blue Book, Cd. 46 of 1900, pages 25 and 30 ). 
i76 Imperial Telegraphic Communication.

The proposal for a State Atlantic cable in consort with the State Pacific cable has lately been brought forward in a somewhat new form, fully described in The Times of November 26th, 19ro, and November 3oth, rgro. In this proposal the "AllBritish" idea is sunk on technical and commercial grounds, and the route for the line is from Scotland via Orkney, Shetland and the Faröe Islands to Iceland; hence to the Southern point of Greenland (Cape Farewell) and from there to Hamilton Inlet, Labrador. This route is practically the same as that which was, in $r 860-I$ under lengthy consideration-and a considerable survey made for what would have been the second Atlantic cable. ${ }^{1}$ The idea was to avoid the difficulties-which seemed so formidable then-associated with the laying of a long continuous length of cable. In the present instance the object for this particular route is entirely different. The idea is that by

1 The following papers deal with this project:-

(I) "Communication with America via the Faröes, Ice. land and Greenland," by Colonel T. P. Shaffner, read before the Royal Geographical Society, May I 4 th, 1860 (vide Proc. R. G. S., vol. iv., p. IIo).

(2) "Surveys of H.M.S. Bulldog," by Sir F. L. McClintock.

(3) "Synopsis of the Surveys of the Fox under the command of Sir Allen Young," by Sir C. T. Bright.

(4) "Exploration of the Faröes and Iceland, etc.," by D. J. Rae.

(5) "Fiords of South Greenland," by J. W. Tayler.

The last four papers were all read at a meeting of the Royal Geographical Society on January 21 st, 1861, the dis. cussion thereon taking place on February inth, 186I (Proc. R. G. S., vol. v., pp. 62 et seq.). 
breaking up the line into sections, with intermediate landing stages for the insertion of automatic cable relays, a higher working speed could be achieved with the same type of cable as that used on the ordinary trans-Atlantic spans. In this case a lower tariff could be charged-possibly $6 d$. a word ordinary rate instead of is.

It is sometimes said that a trans-Atlantic cable on this extreme northern route would be especially prone to disturbance by earth currents, on account of the aurora borealis, \&c. On the other hand, in breaking the line into a number of sections with intervening stations, the unfavourable effects of earth currents could be successfully overcome by a complete metallic loop in each section, instead of using the earth as a "return." This is not practicable on the ordinary trans-Atlantic sections owing to the great length of cable involved being unfavourable to high-speed working. Another advantage in this northern route is the freedom from trawlers, so common a cause of trouble on the usual North Atlantic cable routes. An objection to it, however, is the heavy initial and maintenance cost in what would seem likely to prove more or less unprofitable intermediate stations.

I have on several occasions pointed to this northern route, more especially for meeting the objections to long ranges in the case of wireless telegraphy. I am, however, opposed to Hamilton Inlet as a terminus for the cable, if only because there is no prospect of a railway being taken there; 
178 Imperial Telegraphic Communication.

and without a supervised railway line to protect it a land wire connecting up to such a point would be likely to have a brief and unhappy existence-or would, at any rate, be a constant source of trouble and expense.

Turning to the scheme as a whole, from the point of view of a connecting link with the Imperial Pacific cable, it would seem that so considerable a departure from the "All-British" condition would require substantial justification. ${ }^{1}$ In other words, the only grounds which warrant the various proposed foreign (possibly unprofitable, and certainly costly) intermediate stations, are on the basis of the line being jointly undertaken by the other countries concerned; and then the Imperial object is more or less defeated.

The technical and commercial object of the scheme could, to a great extent, be met by a single intermediate station at Cape Farewell, Greenland, such as would effect a considerable break in the ordinary long stretch across the Atlantic. In my view, there are also technical and administrative advantages in taking the cable from the west coast of Ireland rather than from Scotland, though near the mouth of the Clyde (where Glasgow is situated) would probably prove an excellent terminus.

${ }^{1}$ It must be remembered that the raison d'étre of the proposed connection-as originally laid down by $\mathrm{Mr}$. Chamberlain and the rest of the Committee dealing with the Pacific cable scheme-was to establish a complete All-British chain. 
Apart from Greenland, the intermediate relay stations-for increasing the output of the cablewould be more suitably situated on British North American soil, where an Imperial, strategic, or commercial object would also be served. You will observe on the large map here-as well as on those you have by you-certain alternative routes that would meet these conditions. The most obvious terminus at the other side for an Imperial Atlantic cable would certainly be up the Gulf and River St. Lawrence, as near Montreal as possible - say at Tadoussac, with an intermediate station at Cape Bauld, on the extreme north point of Newfoundland, ${ }^{1}$ and another at Cape Whittle. Halifax would be a further highly suitable terminus, especially as it is also the northern terminus of the West Indian cable system, with possible extension to the Cape-besides being a calling point of the proposed "All-Red " steamship route. Halifax could be brought into the scheme by a branch line to it from Cape Whittle, and a connection with Montreal by land line alongside the Inter-Colonial (State) Railway to Rimouski, hence by cable up the River St. Lawrence to Tadoussac, where it would meet the land line connection with Montreal.

The River St. Lawrence has hitherto been severely left alone in such projects, on account of

- Up till recently the Anglo-American Telegraph Com. pany held exclusive landing rights at Newfoundland, but these ran out in 1904 . 
i8o Imperial Telegraphic Communication.

the prevalence of ice during a great part of the year. This objection is, however, more or less met by special types of cable, which have proved highly effective in such ice-bound regions as Iceland.

The route I have just sketched out would form an absolutely All-British and more or less invulnerable connecting link with the Pacific cable terminus at Bamfield (Vancouver), viâ one of the Canadian Pacific Railway's land lines now leased to that system and worked by their own clerks. It has to be remembered, however, that the route of thisland line is still-in part at any rate-somewhat near the American border and, in the event of trouble with America, would be open to ready interruption. For this reason, I would urge that an entirely independent-more or less State-line should be erected further into Canadian territory, forming a satisfactory link between the proposed Imperial Atlantic cable and the existing Imperial Pacific cable. Failing this, the Grand Trunk Pacific Railway route might meet the purpose, and that line will, I understand, be completed within two years' time. In any case a similar route may be commended, going further north, avoiding the Rocky Mountains, and including a branch to Prince Rupert-another " All-Red " point of callwith a further cable from there to Vancouver.

As you all, I expect, know, the Hudson Bay Railway and Steamship route is now being 
favourably considered for the carriage of grain. It would have the advantage of saving (in cost and time) about 1,000 miles of railway transit from the great grain-growing area of Western Canada to Fort Churchill (or, alternatively, Port Nelson) in the Hudson Bay, in place of Montreal.' Thus, a highly useful purpose would be served by establishing a branch telegraph system between Cape Bauld (Newfoundland) and Fort Churchill (or Port Nelson) with intermediate stations-for technical reasons only - at Cape Chidley (Labrador) and Cape Wolstenholme (Labrador). Wireless telegraphy could be well turned to account for this branch telegraph system. Further, to meet the contingency of breakdown at any time, a land line might be usefully erected sometimein the event of a railway being constructedbetween Fort Churchill (or Port Nelson) and Montreal (or Tadoussac). On the other hand, to meet the case of a breakdown on the main Imperial cable to Tadoussac (River St. Lawrence) on the one hand and Halifax on the other, very satisfactory connection with the Pacific Cable could be established by erecting a railway land line from either Fort Churchill or Port Nelson-probably the former, unless the railway is, after all, ultimately taken to the latter. This line would be some 750 miles less than is involved from

- For further information regarding this ronte, reference may be made to a series of articles in The Times of Septem. ber $2+$ th, September $29 t h$, October ist, October 3 rd and and October 4 th. 
182 Imperial Telegraphic Communication.

Montreal, besides being far removed from the American frontier-passing, indeed, through the heart of Canada.

An objection to all extreme northern routes is that they are subject to ice during eight months in the year. Thus, on this account alone, wireless telegraphy would have actual points of advantage over a cable which could only be readily repaired at seasons of the year more or less free from ice. For this reason, too, a wireless station should certainly be established at Cape Farewell (Greenland) whether as an auxiliary to the cable or as a substitute for the cable being taken there at all.

As a matter of fact, the Hudson Bay Railway and Steamship route would, in any case, be only entirely open during three or four months in the year; but it is now widely thought that more might usefully be done-by the extended use of ice breakers, \&c.-in the other months than has hitherto been realised.

Having in mind the fact that one of the projected All-Red Steamship routes has Blacksod Bay (on the north-west coast of Ireland) for its mother country terminus and headquarters, a useful purpose would be served if the end of the proposed Imperial Atlantic cable was taken here, where, moreover, the harbour is recognised as having special strategic features. ${ }^{1}$ By taking the main

${ }^{1}$ It is sincerely to be hoped that the All-Red Steamship project will shortly be given a real start as the result of consideration at the forthcoming Imperial Conference. Our communication with Canada by steamer at present 
cable from Blacksod Bay, the ordinary route of existing Atlantic cables would be avoided. The most satisfactory connecting link for this main cable with the headquarters of the Empire (London) would be by cable to some point slightly to the west of Brighton-free from anchorage grounds and trawlers-with an intermediate station at Cape Clear, the extreme south. west point of Ireland. From Brighton an underground land line could be run to London along the London, Brighton and South Coast Railway. This would be reducing the length of land line to the lowest possible limits, and, if underground, atmospheric and other disturbances to which an aerial wire is prone could be overcome. ${ }^{1}$

Some fortification should be erected in the vicinity of this cable end-similar to that at Dover. In other respects, the route suggested here for the proposed Imperial Atlantic cable would be more or less under naval protection at most of the landing places suggested; but further protection should be provided if deemed advisable.

occupies eight days, the route being via New York. On the other hand, twenty-five.knot steamers go direct to the United States, the capital for which service was lent by the Imperial Government at a low rate of interest. Surely this comparison in regard to prevailing conditions suggests something contrary to the right order of things ! So far as concerns the actual movement of persons and merchandise, the All-Red shipping scheme should do much to further our trade and otber relations with the rest of the Empire.

Up to the present only one of the existing Allantic cable systems has an underground land-line connection with London. 
184 Imperial Telegraphic Communication.

Possibly on account of its increasing trade relations with the United States and the increasing hold America is gaining on our Atlantic cables, Canada-though at one time setting the example - appears to be rather holding back in regard to Imperial cables. ${ }^{1} \quad$ But Canada above all countries should support the Atlantic-cum-Pacific cable scheme-if only for strategic reasons.

The relative facilities for travel and exploration between Canada and the mother country on the one hand, and between Canada and the United States of America on the other, may account in some measure for the recent reciprocity agreement between Canada and the States. Such reciprocity treaties are, perhaps, a natural result of close contiguity in cases where distance renders business relations with other countries-even a mother country-so comparatively difficult.

This indicates the absolute necessity for a country like ours to obliterate as far as possible what it loses in distance; and the only practical way of achieving this space annihilation is by rapid and constant communication with its outlying dominions.

Let us now turn to the requirements of other parts of the Empire in regard to fuller and more direct telegraphic communication.

I would first call your attention to the fact that

1 Another possible explanation is the reduced activity of that Imperial Telegraph veteran, Sir Sandford Fleming, K.C.M.G. 
our present means of telegraphic communication with South Africa is by cables landing on foreign territory in more than one instance. Moreover, all these various lines are subject to ready interruption by foreign fleets in the event of a European war. This points to the desirability of a cable between Gibraltar and Bathurst, thereby filling a gap in the All-British chain.

Another useful link would be effected by a cable between Bathurst and Barbados, with an extension to Jamaica. Here it would meet the existing cable to Halifax, via Bermuda, being thus brought into direct touch with the proposed Imperial Atlantic cable.

By filling up these gaps we should achieve a complete All-British chain between the mother country, Canada, Bermuda, the British West Indies and South Africa, and back by St. Helena, Ascension, Sierra Leone, Bathurst and Gibraltar.

Thus, the proposed All-British Atlantic cable would serve an additional purpose beyond that of forming a satisfactory connecting link with the Imperial Pacific line to Australia; and I venture to suggest that any project for bringing the important sections of the British Empire that I have named into direct communication with one another is a matter worthy of serious consideration at the present moment when it is so desirable to foster trade betwixt all of them.

In this regard it will be suitable to refer to the unsatisfactory position of cable telegraphy in the 
West Indies, full particulars of which may be found in the recently published report of the Royal Commission on "Trade Relations between Canada and the West Indies." 1 Whilst the rates are high-standing at 3 s. a word in the case of Jamaica and $7 s$. a word in the instance of British Guiana ${ }^{2}$ - the traffic is naturally very small. By placing the West Indian cable system (worked by different companies) under Government control, steps could be taken to improve the service by a process of unification, whilst the tariff could be brought down to a more favourable figure. In recommending expropriation of the West Indian cables, the Commission I have just referred to (with Lord Balfour of Burleigh as Chairman) said in their recent report :-

"We think it may fairly be deduced that if the property of the companies were obtained for anything near the price suggested, the Government could at a cost little, if at all, exceeding the amount of the subsidies now paid by the Imperial and West Indian Governments, give to the West Indies an incomparably better telegraphic equip-

3 Blue Book, Cd. 5369 .

2 This latter is the highest tariff now in existence. Yet the service appears to be of a very superior order, for only a short time back the inhabitants of the colony were informed by cablegram that Mr. Austen Chamberlain's Tariff Reform Amendment to the Address resulted in a majority of only two for the Government instead of one hundred and two! I give this instance on the authority of the "West India Committee Circular," but it does not stand altogether alone. 
ment, and probably at the same time considerably reduce rates."

I do not know whether it is necessary for me to remark that no definite steps have yet been taken by the Government to follow up the recommendations of this Commission.

An additional cable might well be laid between British Guiana and Bermuda-touching at Barbados, if not at Trinidad-as recommended by the aforesaid Commissioners. From Barbados this line should also, in course of time, be extended to Ascension.

In view of the bad behaviour of cables in these coral-ridden vicinities, and the high rates that appear to be involved on the cable system, the West Indian Islands would seem to be an especially suitable quarter for the adoption of wireless telegraphy between the minor points, or for the purposes of an auxiliary service. Wireless telegraphy would also be peculiarly well adapted for a news service between the various islands-for bringing them into more intimate and friendly touch with one another.

If the proposed Imperial Atlantic cable is to be undertaken as a State affair for connecting up with the All-British Pacific cable, and if the Canada-British West Indian cable service is to be expropriated by the State, it would be probably desirable additionally to bring the further cables that I have suggested-possibly also other 
is8 Imperial Telegraphic Communication.

existing Imperial lines-under the same single control.

The aforementioned additional means of telegraphic communication are such as I should especially advocate as forming a suitable basis for earnest consideration. There are also other lines which would undoubtedly serve a useful Imperial end, such as a cable from Cocos-Keeling to Ceylon. Further, a "wireless" system between Port Darwin (North Australia) and Labuan (North Borneo) would form a useful connecting link with the Eastern route. (The prevailing conditions as to bottom would scarcely favour a cable.) Again, the strengthening of our telegraphic bonds with Egypt and India would be desirable; but no cables to effect this on the ordinary routes could be relied upon strategically. Thus, this again is an obvious field for wireless telegraphy - if only for emergencies.

Wireless telegraphy has now sufficiently proved the utility of its application to be recommended both as an auxiliary or reserve means of communication to the different parts of the Empire, and for establishing communication where, owing to prevailing conditions, communication by cable is impossible or difficult to maintain. Wireless telegraphy should further be established on all the trade shipping routes throughout the Empire.

It is satisfactory to note here that the cable companies have now begun to recognise the 
useful part to be played by wireless telegraphy as an auxiliary and "feeding " string to their cable service. Thus, quite recently, a wireless station has been opened at Cocos-Kecling Island to be worked by the Eastern Extension Telegraph Company in conjunction with the Marconi Company. In this particular case, it is obvious that the station will be of considerable value for vessels trading on the eastern routes to Australia, \&.c. By its means, ships will be enabled to keep in constant touch, at considerable distances, with the cable network of the world, and similar "wireless" stations are to be established for the same purpose elsewhere.

Notwithstanding the progress made in wireless telegraphy, it would be a matter for regret if the Government of the day, of whatever party, evadeay, excuse itself for-following up the All-British cable project further on the plea of waiting for the development of wireless telegraphy! That would, indeed, be a regrettable development of the admonition "Wait and see!"; and mere pro. miscuous flirtations with wireless telegraphy, though cheap, are not good business for the public or anyone concerned.

The All-Red route should do much to improve on the comparative lack of inter-imperial communications so far as shipping goes; but in my opinion if the effect of distance is to be satisfactorily overcome we must commune a great deal more than we do through wires that bring us into 
speedy touch with our several sisters of the Empire. The facilities at present available do not permit of this, partly owing to cost, but also on account of an actual insufficiency of cables to bear any considerable increase of traffic.

In the ordinarily accepted sense there are, it may be granted, an enormous network of cables throughout the entire world; and, certainly, if you look at the map, this network appears very formidable! Indeed it almost seems as though there could scarcely be comfortable room for more cables in certain directions. But things are very different in reality at the sea-bottom from what they appear on a map; and, as a matter of fact, many a cable must feel cold and draughty for want of companionship.

At one time I remember there was an idea that cables must not cross each other, but that notion has since had to be departed from, and we now know that it can be without any very serious results.

What we want is many more cables, in a variety of directions, for accommodating an increase of traffic such as would undoubtedly result from a considerable reduction of tariff. I am not wishing to say that a considerable reduction of tariff would be feasible with things as they are; but it would be more likely to go with the increase of traffic that should, in my opinion, be developed in the interests of inter-imperial politics and trade. 
If someone were to invent a cheaper and yet more efficient type of cable the problem would at once be solved. Meanwhile, we also have wireless telegraphy to look to for helping us in meeting the problem.

The object of my paper has not been to present technical business or financial particulars. These the consulting engineer usually prefers to reserve for other occasions!- and I am no exception to this rule! Moreover, the present meeting would be scarcely suitable for a close technical discussion. This being so, I trust you will not misunderstand the sketchy character of my suggestions.

I mention this because the question uppermost in some people's minds will be, no doubt, what is it all going to cost if put into effect? That I do not propose to go into here. I would, however, in returning to one of my leading passages, ask you to concede generally that extended and cheaper Imperial telegraphy is highly desirable in the present time for developing inter-imperial relations, socially and politically, as well as for increasing the trade of all branches of our widespread Empire. That we should have many more connecting links on a diversity of routes is also highly desirable-if not essential-for the purpose of Imperial defence. 
Many people talk patriotism and Imperialismthey often shout them indeed. If some of these would take steps towards realising their vague, general, ideas by practical steps such as I have here called attention to, their activities would, in my opinion, be more usefully applied. Again, it is rather the fashion for some of our great journals with patriotic and Imperial instincts to raise funds for presenting airships to the nations. Why not devote some of their abundant resources towards improved Imperial telegraphy, thereby assisting in a cause that must be near to the heart of British journalism-i.e., the rapid and cheap dissemination of news throughout the Empire.

In conclusion, let me urge for a subject of so much importance to the Empire at large being entirely freed from party political considerations and from our variable political machinery.

Apart from the fact that there are no votes in Imperial cables, the reason that so little progress is made in the matter is largely due to the nebulous character of our Government administration. Centralisation by a single, yet knowledged and efficient, Board of Control representing all departments and interests concerned-not forgetting our Imperial dominions - would do much to improve matters here.

Even so, organisations like the Royal Colonial Institute have yet to overcome a certain amount 
of individual, as well as Governmental, apathy in regard to the subject. This may be suitably accomplished in connection with the forthcoming Imperial Conference, especially as the All-Red cable is one of the topics for discussion.

On the table here you will find specimens of the Early Atlantic cables, the first line to India the Imperial Pacific cable laid in 1902, and other modern lines of interest. 



\section{APPENDIX $\cdot^{*}$}

\section{TABLE OF CHARGES FOR FOREIGN AND COLONIAL TELEGRAMS.}

FRON ANY PART OF THE UNITED KINGDOM.

EUROPEAN SYSTEM.†

(In no onse le a lower sum than lod, aooopted for a tolodram or reply.)

\begin{tabular}{|c|c|c|c|c|}
\hline & $\begin{array}{l}\text { Fos each } \\
\text { Word. }\end{array}$ & & - & Fou ench \\
\hline 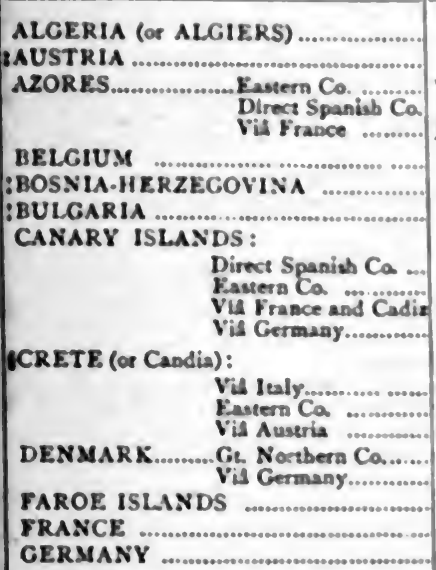 & 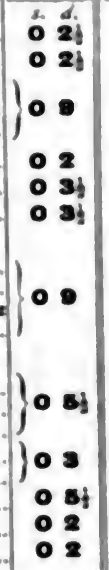 & 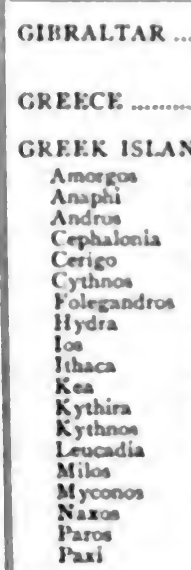 & 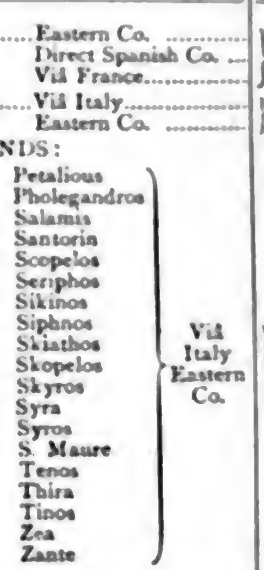 & $\left\{\begin{array}{l}40 \\
00 \\
0\end{array}\right.$ \\
\hline
\end{tabular}

- Eatracted from the Poat Oesce Culbe, Jamasy-March, rest.

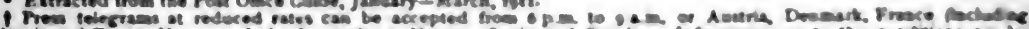

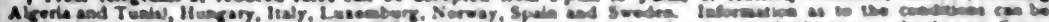

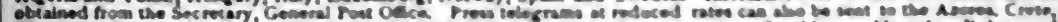

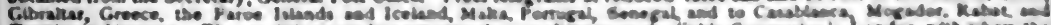

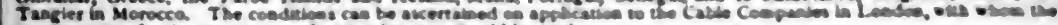

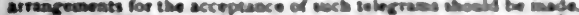

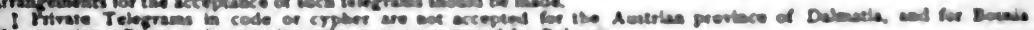

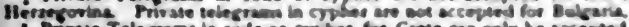

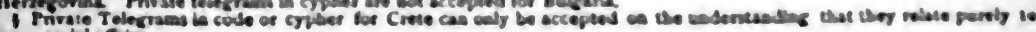
commenclal aftair. 


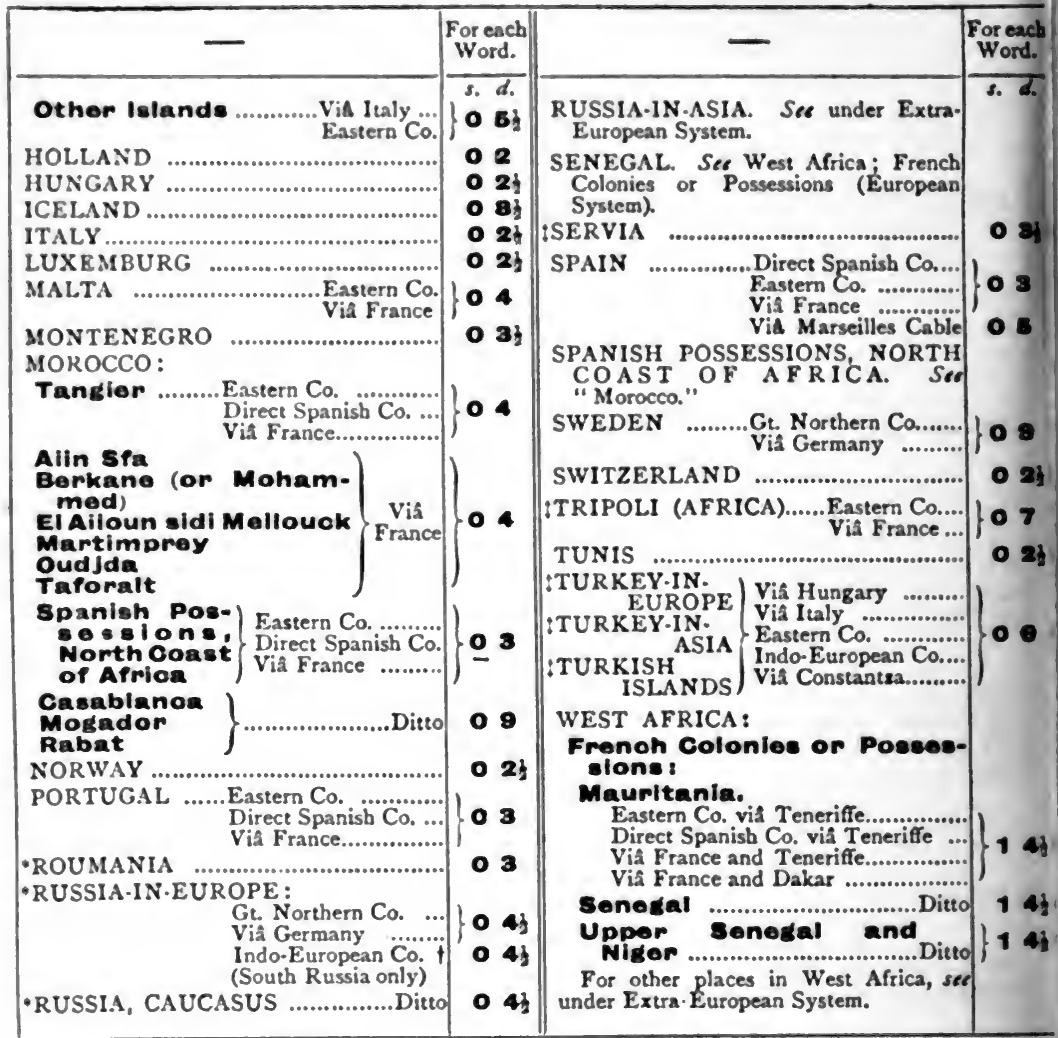

- The addressees of private telegrams in code are liable to be called upon to produce their codes. Telegrams la cyphe reprohiblted.

Telegrams for Russia can only be accepted by the route of the Indo-European Telegraph Co. for places south of thu h degree of atitude.

Private Telegrams la code or cypher are not accepted for Servia. P rivate Telegrams in cypher are aot accepted 6 Tripoll, Turkey and the Turklsh Islands. 


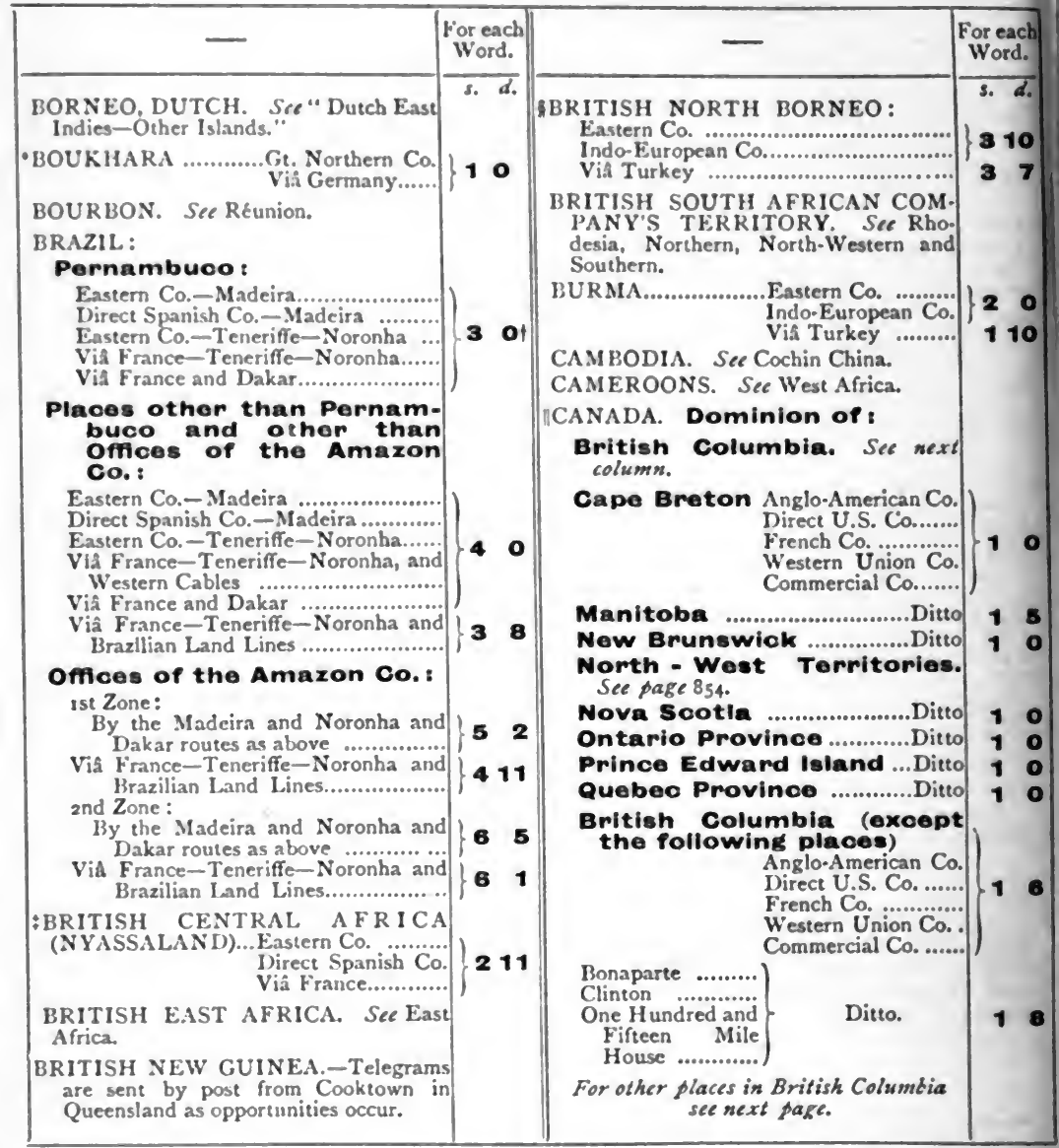

- Private telegrams in cypher cannot be accepted for any place in Boukhara, and private telegrams in code can only be

accepted on the understanding that they relate purely to commercial affairs. The rate for all other places ta the province of Pernambuco is $4^{\text {s. }}$. per word.

Telegrams for Nyassaland can only be accepted at sender's risk as regards reimbursement in cases of delay.

Trlecrams for Sandakan can only be arcepied at sender's risk.

The Telegraph and Postal services in Canada are quite distinct, and it is desirable that telegrams addressed to - Post Jifice" or "Poste Restante" should be registered. 


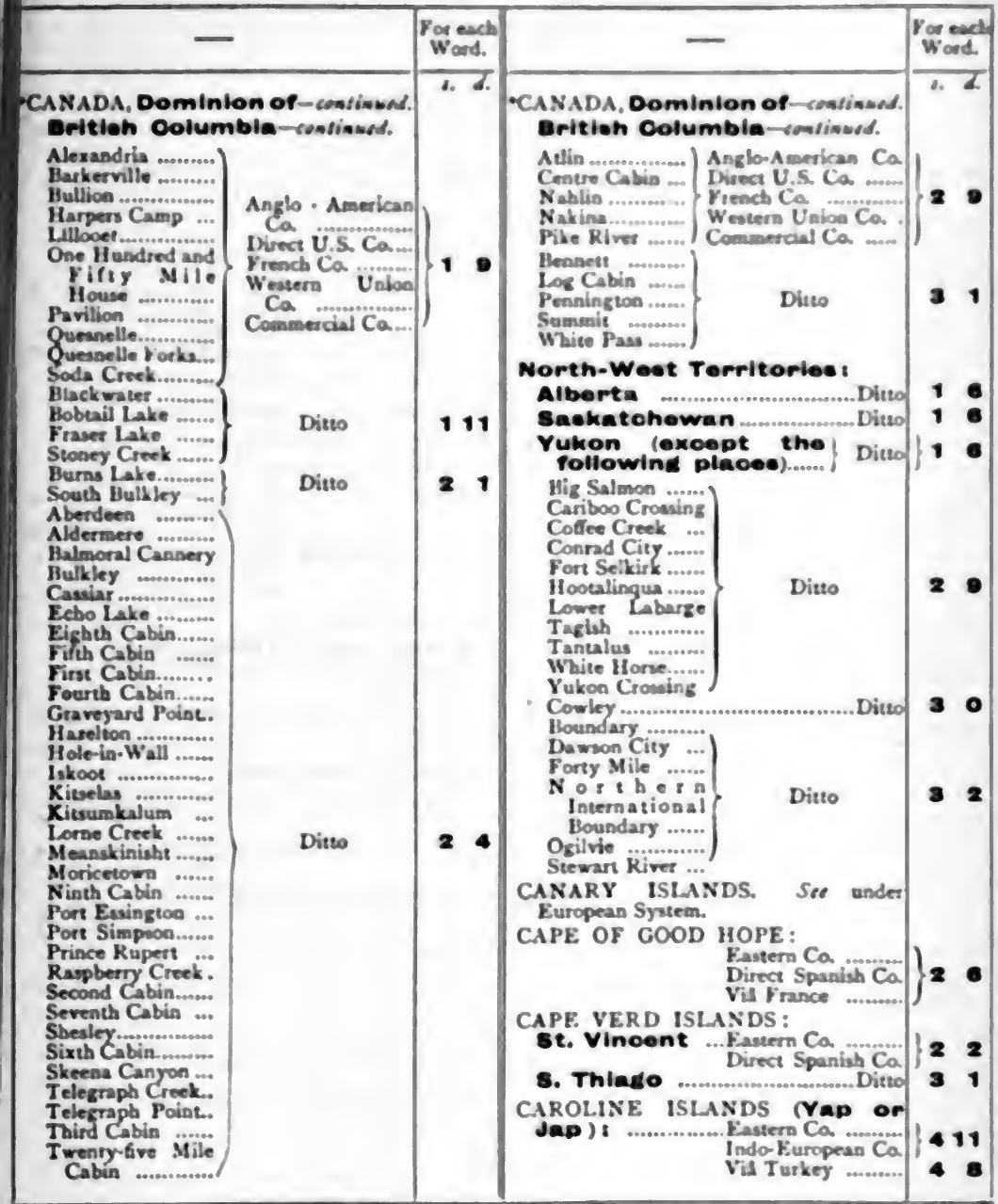

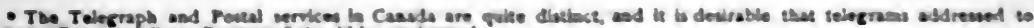

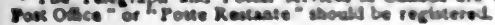




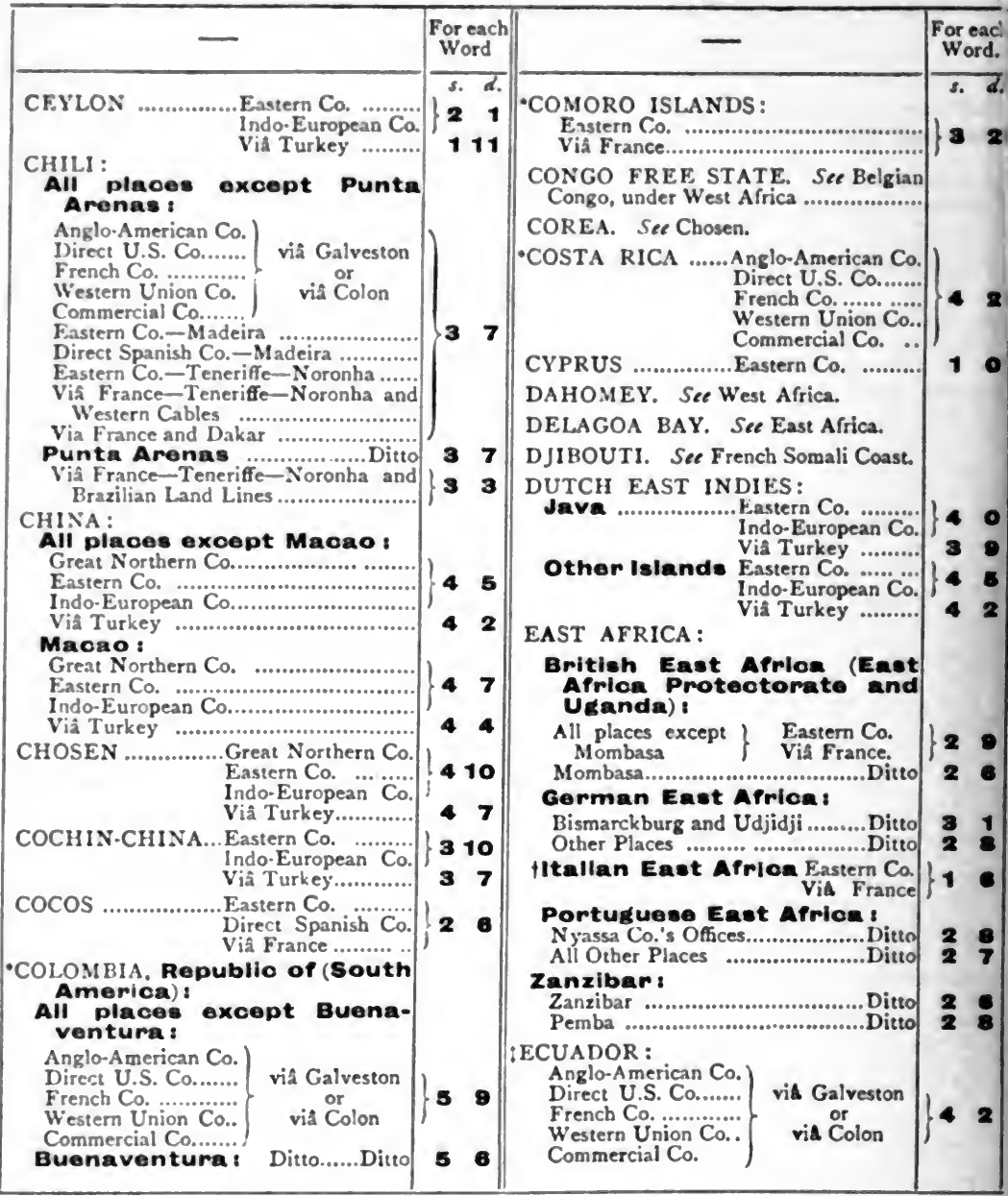

Telegrams for any place in Colombla except Buenaventura, for any place in the Comoro Islands, and for any place in Costa kica can be forvarded only ol sender's isk.

+ Private telegrams in co de or cypher for places in Ital'an East Africa can be accepted at sender's risk, but they will not be delivered without the production by the addressees of the code used by the senders.

: Telegrams for any place tn Ecuador, except Guayaquil and Sta. Elena, and for Honduras (Independent), can be for warded only at sender's risk 


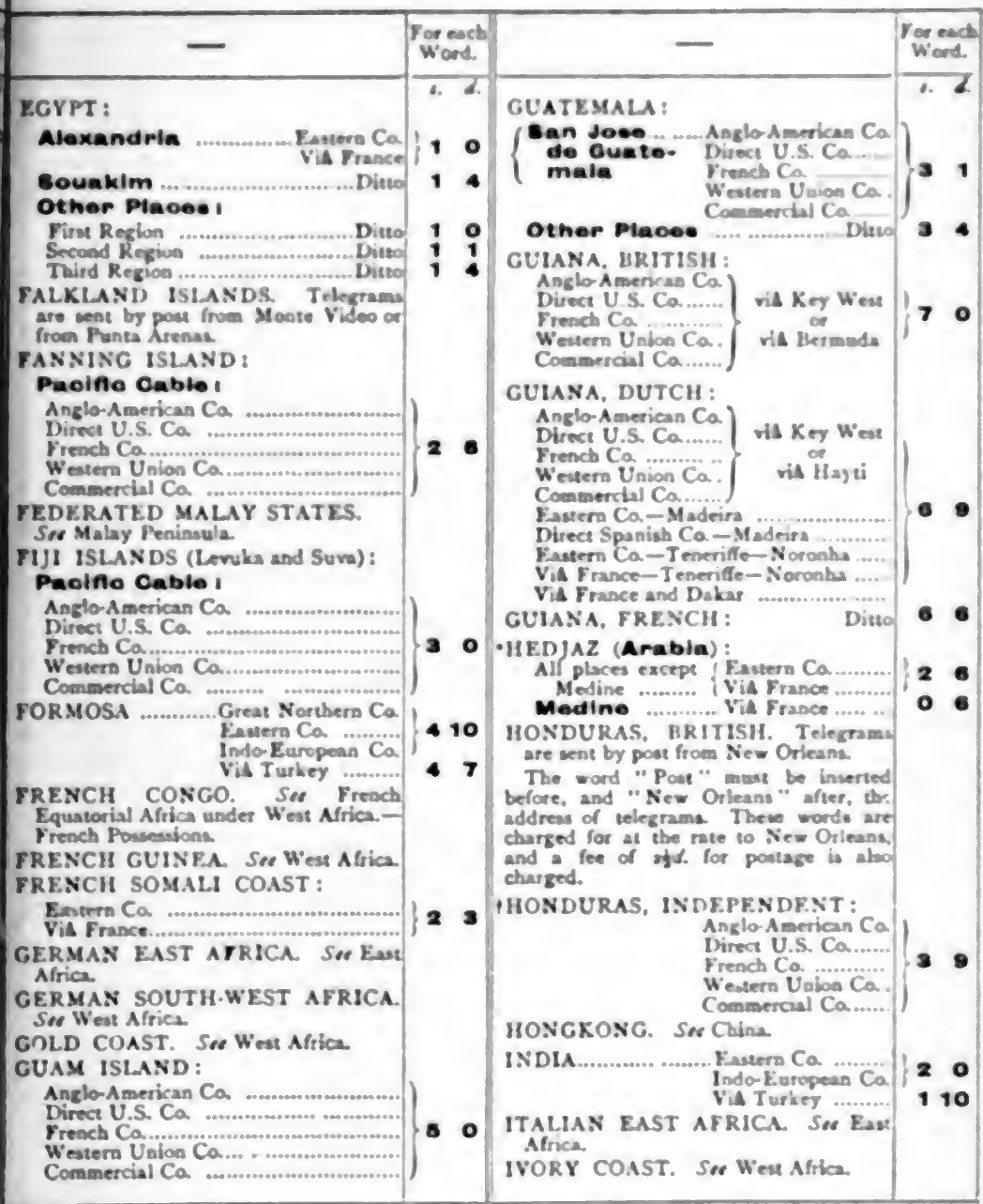

- Mvate tolecrama la cyroes are not accopeed for Meijas.

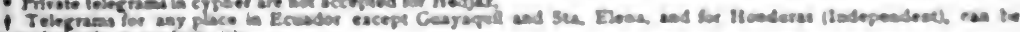
horveriled enly of seeder s riak. 


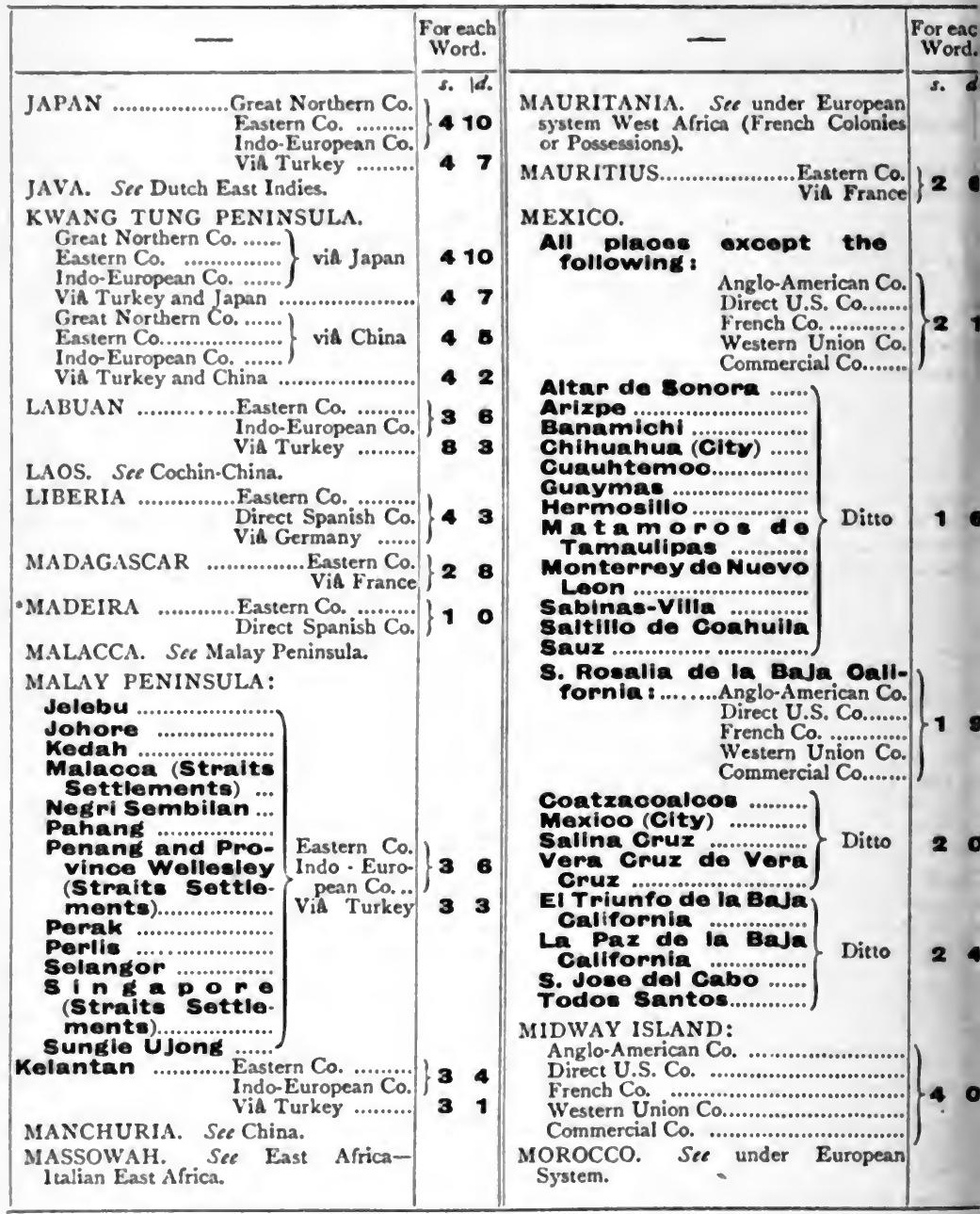

- Telegrams for the Island of Madeira should be addressed to Funchal or one of the other Tolegraph Offices ia th Island. If addressed simply to Madeira telegrams can only be accepted at sender's risk. 


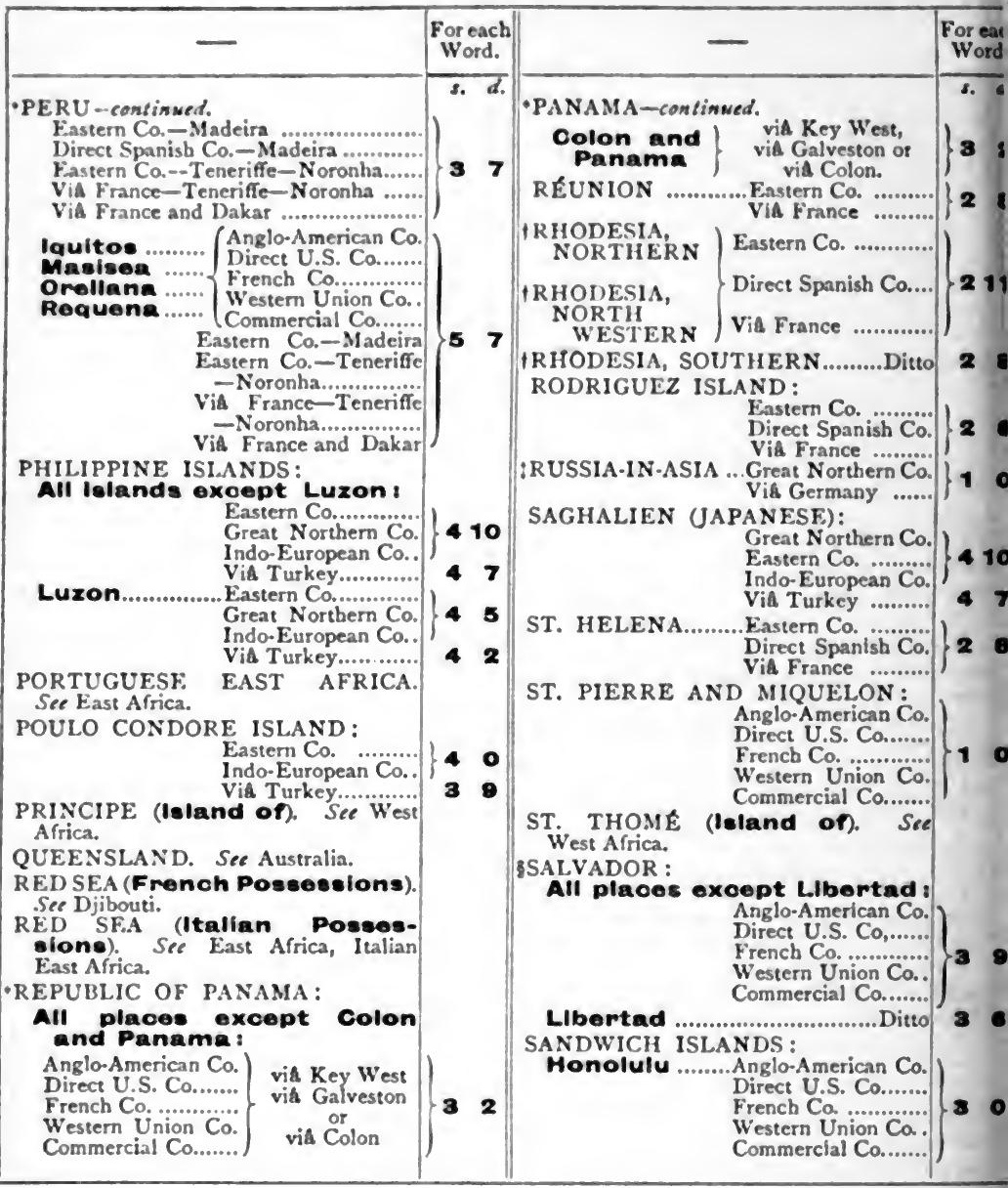

- Telegrams for Iquitos, Masisea, Orellana and Requena In Peru, and for any place in the Republic of $P$ anama, excep Colon and the town of Panama, can be forwarded only at sender's risik

t T-legiams fir Rhodesia can only be accepted at sender's risk as regards reimbursement in cases of delay

The addressees of private telegrams in code are liable to be called upon to produce their codes, Telegrams in cyphe are prohibised.

f Telegrams for any place in Salvador can be forwarded only at sender's risk. 
SENEGAI. Seu under Luropean Syreen-West Alrica (Frend Colonies or Posecalonal.

SEYCHELLES ISLANDS:

S1.AM :

Pisutern Ca

Fiatern Ca.

Vis Prance

Indo-Europeas Ca $\}$ vis Suiguo

Vis Turkey and Moulanein.

Vis Tukey and Salgon .........000000000000

SIERRA I.EONE So West Africa. SINGAPORE Ser Malay Peninsula. SOCIETY ISIANDS:-Telestams are sent by pose from San Francisca.

SOMALILAND (BRITISH):

Derbera

Fistern $\mathrm{Ca}$ Via France SOUDAN. See keypt (Thind Region) SOUTH AUSTRALIA. Sn dustratia. STRAITS SETTLEMENTS, Ser Malay Perinsula.

SUMATRA. Sre Dutch Fast Indies

TASMANIA. Se Autralia.

TOGOLAND. See West Africa.

TONQU1N

Fasern Ca .......... Indo- European Ca ViA Turkey

TRANSVAAL .......Fasern Ca ........ ViA birance ..........

TRIPOLI (Afrion). Sre under Luro pean System.

TUNIS. See under $\mathbf{i}$ uropean Syotem. TURREY.IN.ASIA..... Sre under TURKISH ISIANDS $\}$ European UGANDA. See Fas Africa. UNITED STATES:

Mabama ........ Apelo-Americas Co Wirect U.S. Ca..... French Ca ............ Western Union Ca. Commercial Ca.....

Alaske Disto

Arizona Dited

Arkanea Disto 1

Callfornie Ditto 1

Carollina.

Dituo | 13

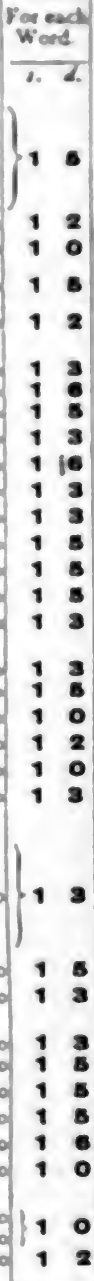




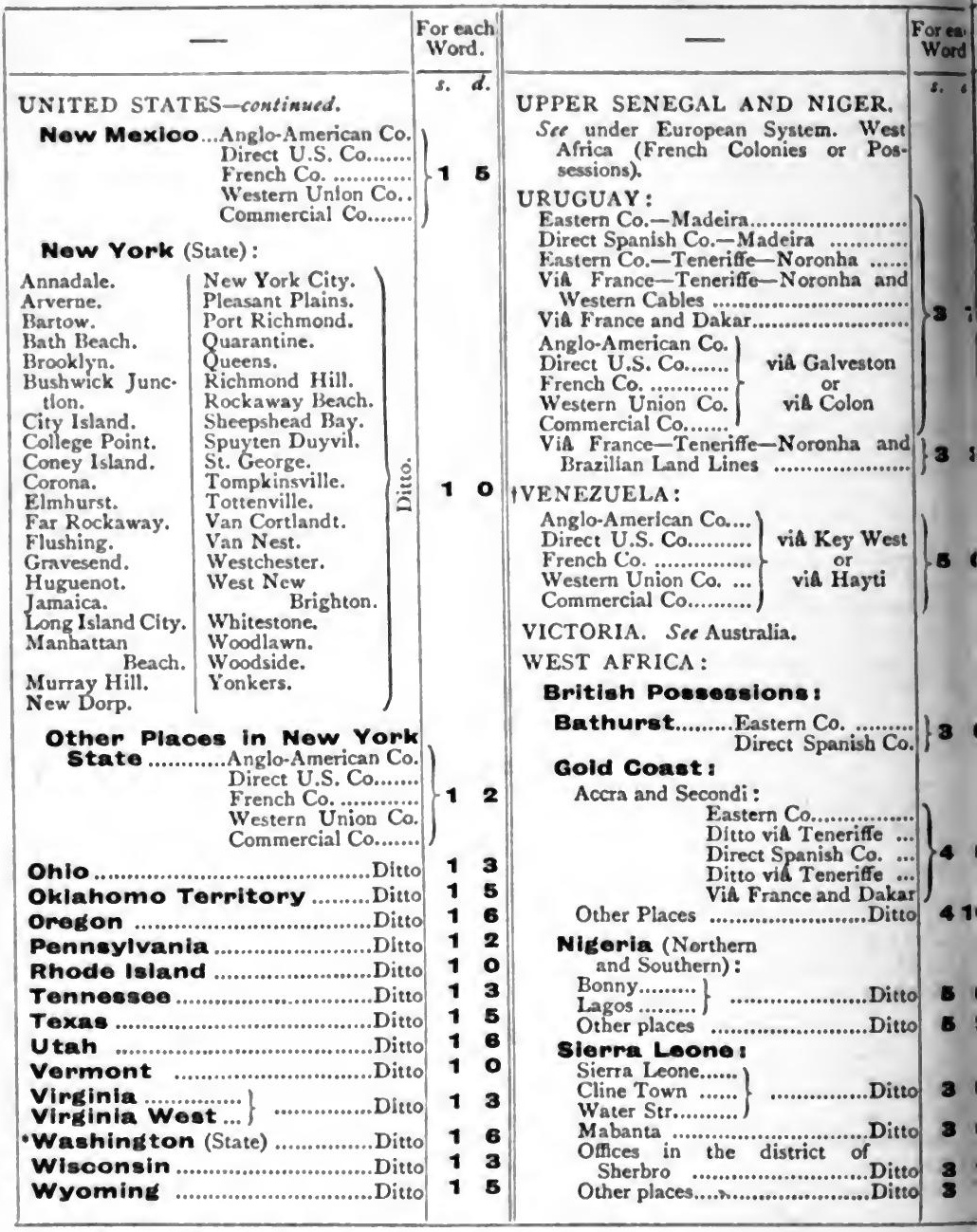

- For the rates to Washington City, see "Columbia District."

t Telegrams for any place in Venezuela, except Caracas and La Guayra, can be forwarded only at sender's risk. 


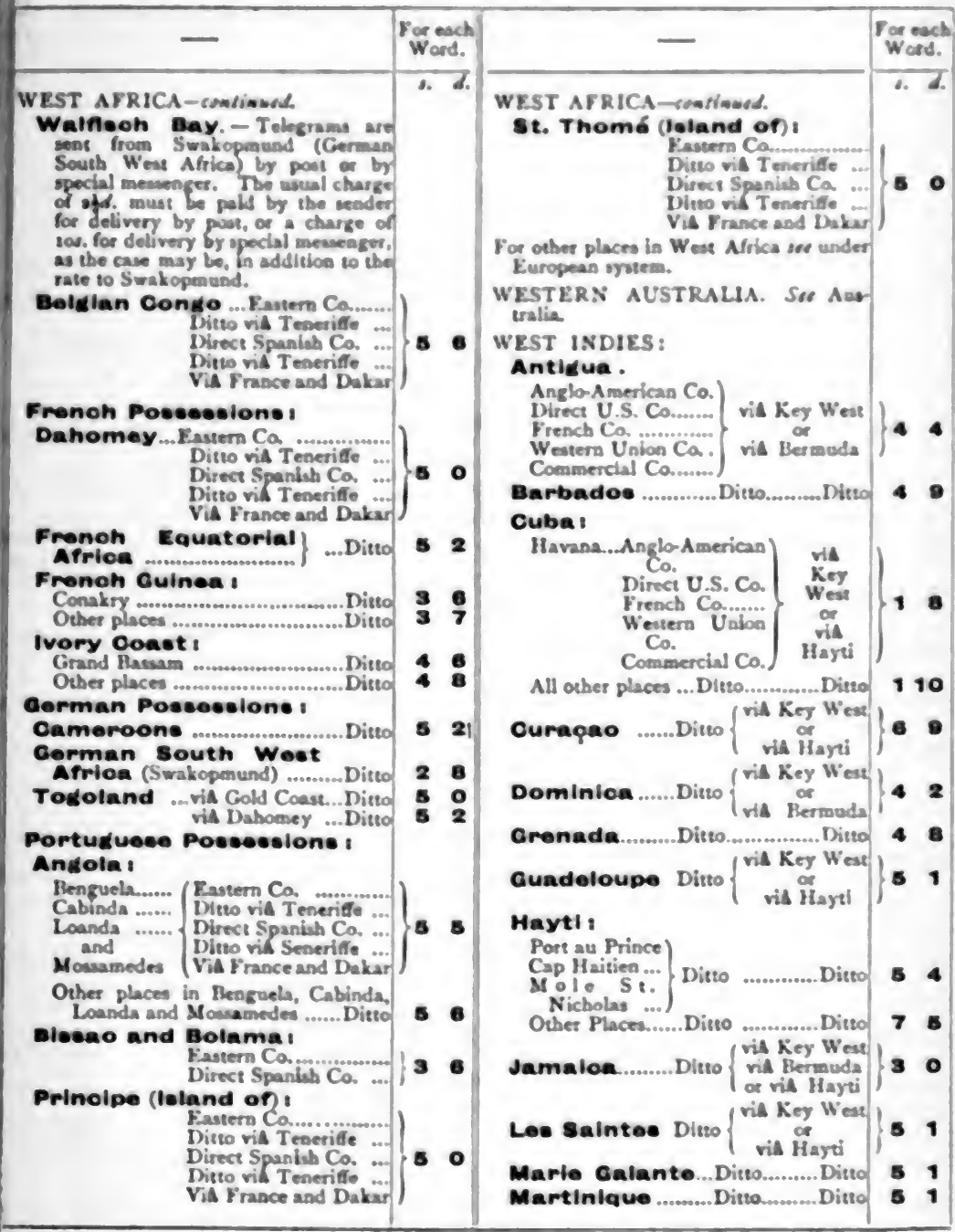




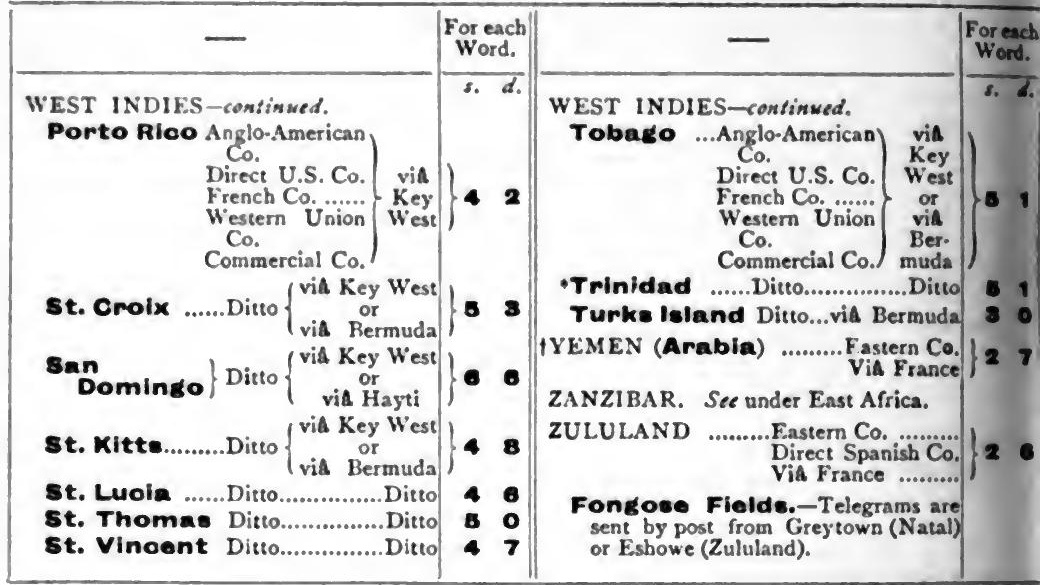

- This entry does not relate to the office named "Irinidad" In the Island of Cubs, but to the Island of Triaida Telegrams for places in the island must be addressed to the telegraph office of destination and aot to Irinidad. $\downarrow$ Private telegrams in cypher are not accepted for Yemen. 


\section{INDEX.}

Admiralty Opposition to an All-British Llne, 5

African Direct Telegraph Com. pany, Subsidies granted to, 68

All. British Pacific Cable:

Admiraliy Opposition. 5

Advastages of, 10, 12, 34. 35. $60,127,135$

- Blocking" Rates, abo. lishing, 50

Codes and Cyphers, In. security of, 57. 58, 128

Cost Considerations, 13. 39

Dopth of Water, Objec. tions considered, 18

Electrical Working. 23

Deferred Messages. 123. 147, 16I

Duplicatios Considerations, 36, 40

Government Control, 41, $42,47,62,97,101,829$, 139, 140,144

Independence of, 36

Land Lines through Canada, 84. 37, 175

Landing Rights, $4^{8}$ note, 50, 866 nole, 172

Laying, Considerations for, 21

Objections, 57, 90

Privacy, 128

Rates, 43

Repairing, 22

Routes, 53.127, 176, 180

Sliding Scale Tarif, 45

Strategic Arguments. 56, $59,60,88,187,134,163$

Surveys, 19

Type of Cable required, 19

Wars causing Change of Route, 55
American Pacific Cable, 36,137

Anderson, Sir James, 46, 128 mole, 158 note

Anglo-American Telegraph Company, 23, 170

Arbitration Movement, 16

Argyll. Duke of : 117

Associated Cable Companies. 92, 106, 247

Atlantic Cable, 33. 75 mote. $176 \mathrm{seq}$.

Australia and British Columbia Cable Scheme, 4

Australia and India. Cable Routes, 6

Barky. Sir John Wolle, 119

Bellairs, Lieut. Carlyon, 87 nose

"Blocking" Rates, suggested abolishing. 50

Board of Control, 78

Bonfires, Cables interrupted by, 8

Bowell, Sir Mackenzie, 77

Brassey, Rt. Hon. Lord, 29, 67

Brassey. Thomas, 33

Break-down of Cables, 8

Bright and Clark. Messrs., 24

Bright, Charles, 29, 66

Bright, Sir Charles Tilston, 30. 43 note, 93 mose, 176 note

Buchanan, President, 65

Cable Communications Com. mittee, 1901-02, 61, 85, 124

Cablegrams:

Number conveyed yearly, $7:$

Rate of Transit. 72

Capital Value of Cables laid, 67,68

Chamberlain. Rt. Hon. Joseph, 5. $77,82,167,875$

T.c. 
Charts of Cable Courses, suggested abandonment, 88

Clarke, Hon. Sir Andrew, 78

Clarke, Sir G. S., 87 note

Classification of Messages, 49, 123,147

Codes and Cyphers, Insecurity of, $57,58,121$

Collins, Capt. Muirhead, 162 note

Colonial Conference, 1887,4 , 32, 77

Colonial Conference, 1894, 4

Colonies, Effects of Cable Communications with, 15

Commercial Advantages of Cable Telegraphy, $60,65,83$

Commercial Cable Company, 37,44 note, 168,170

Competition-no detriment to Vested Interests, 149

Consolidation-Imperial Con. solidation by Cable, 96, ror

Copeland, Hon. Henry, 78

Coral Patches on Bed of Pacific, 32, 79

Cost of Cables, 69, 70, 79, 120, I 2 I

Cutting Cables, 6, 54, 66, 138 , 165

DAy Letter Service, I60

Deferred Messages at Special Rates, 49, 123, 147, 161

Depth, Greatest Known, 73

Direct West India Cable Company, Subsidy to, 69

Direct United States Cable Company, I 70, 172

Dividends of Cable Companies, I05, 106

Doughty, Sir George, I 39

EARTH currents, Disturbances by, 177

Eastern and South African Telegraph Company, 68

Eastern Associated Telegraph Companies, 92, 106, 147, 159
Eastern Extension Telegraph Company, II, 36, 46 note, 68, 91, I06, I19, 148, 152

"Electrician," I 8

Engineering Statistics, 73

Europe and Azores Telegraph Company, II 8, II

Field, Cyrus, 4

Fiji Islands, 19, 20

Finch-Hatton, Hon. Harold, 77

Fleming, Sir S., 34, 76, 185

French Atlantic Cable, 8I, 173

French Government Rates. $\mathbf{2 5}$

Germas Atlantic Cable, 8I note, I 73

Gleadowe, G. E. Yorke, 78

Globigeriana, 80

Gold Coast, Effect of High Rates, 45 note

Government Control, 4I, 42, $47,62,97$, I01, I29, 139, 140, I 44

Gray, M. H., 67

Great Britain and Ireland Coast Cables, Advantages of, 63

Great Northern Telegraph Company, 54, 74 note

Griffith, Sir Samuel, 167 note

Guarantees by Government, 147

Heaton, Henniker, 45 note, 77 , $103,107,108,109$, IIO, III, II 4, II6, IIg, 137 note, I 39 note, I42, I43, 155

Heaviside, Oliver, 27

Hopwood, Sir Francis, I62 note

Hours - Lower Rates after Business Hours, 123

IMPERIAL Pacific Cablo, 97

Imperial Tariff, Suggested, 125 India and Australia Cable Routes, 6 
Indiarubber as an Insulator, 73 Indo-European Telegraph Company. so, $\infty$

International Telegraph Con. ference, $: 88_{4}, 87$

Interruptions of Cables, 8

Investmeats, Value of Cables as, 78

Ireland and Great Britain Cosst Cables, Advastages of. 63

Jayzson Raid. Cable Inter. ruptions during. 8

Japan-American Cable, inclu. sion in All-British Scheme. 14

Jersey, Lord, 5, :18

Kiplivg, Rudyard, 83

Lavd Lines through Canada for All.British Cables, 14.37 . 175

Land Wires, unreliability of ros

Landing Rights, 48 nose, so, 166 mets. 172

Lang. Alexander, $7^{5}$

Laying of Cable, 21, 69

"Leak" Circuits, 27

Lemieux, M., 203.815

Length :

Greatest Length laid and worked, 73

Total Longth so far laid, 67

Life of a Cable, 70

London Chamber of Com. merce, 29, 84

London Traffic Commission, 108

MeClintocx, Sir F. L., 276 note

Macdonald, Sir John, 77

McGrath, P. T., 84 note

Maintenance of Cables, 120

Malta-Alexandria Cable, 90

Mance, Sir H. C., 66

Mansion House Meeting, 187
Marconi. 112

Mercer, W. Hepworth, 78

Milner, Lord, :24, : 17

Muirbead's Duplex Syatem, 23

Mulock, Sir William, 77

Netlsow, G. R., 888, 345

Neutral Cables in Time of Was, 56 nobe, 86

Night Letter Service, :60

"Novoe Vremya," 7

Orrawa Conference, 3884,32 , 34 nobe

Pacizic Cablo Act, 3908,78

Pacific Cable:

American, 837

Cost and Contributions, 79

Origin of, 76

Rates, 2, 26, :36

Routes suggested, 4

Sections of Line, 80

Soutb Australia, Opposi. tion by, II note

Pan-Britannic Customs Lnion, 16, 35

Parkin, Dr. G. R., 336

Peace, Cable Telegraphy in Time of, 64. 65

"Penny-a-word" Telegrams. 103-180, 143

Persian Gulf Cable, 24, 78, $\infty$

Pollak-Virag Apparatus, 113

"Pool "Companies, Rates of. 44 note, 154

Postal Telegraph Company, i69

Press Telegrams. 162, 174

Profits of Cable Companies, Ios

RADIO-TELEGRAPUY. Sn Wircless.

Rates :

Code Messages, 121

Determination of. 43

Freach Governmen : Rates, $: 25$

Hours - Lower Rates after Business Hours, 123 
Rates-continued.

Increased Revenue with Reduced Rates, 46, 92

Imperial Tariff suggested, 124,154

Minimum Rates, 74 note

Pacific Cable, 2, 26, 1 36

"Penny-a-Word" Telegrams, 103-110, 143

Popular Tariff, 103 et seq.

Reduction, Arguments against, 26, 46, 100, 156

"Urgent" and "Nonurgent" Messages, 49. 123, 147, 159, 16 I

Universal Tariff, 126

Variability of, 74

Red Sea Cable, 9o

Reeves, W. Pember, 77, 78

Repairs, Greatest Depth permitting, 73

Revenue from Cables compared with Charges, 46, 92

Rogers, G. Innes, 64

Routes, Consideration of, 53 , 127, 176, 180

Russia. War with, Position of Cables, 7, 54

Sassoon, Sir Edward, 47, II7, I4I, 157

Selborne, Lord, 5, 78, 168

Self-induction, 27

Shaffner, Col. T. P., I 76 note

Siemens Brothers, 24

Signalling upon Cable Lines, Improvements in, 27

Silvertown Company, 77

Smith, Willoughby, 82

Spanish-American War, 6, 56 note, 89

Specific Gravity of Cable, 20

Speeches-Cable Summaries Inaccurate through Compression, II5

Speed, Working, of Cables, 72

Spicer, Sir A., 118

Squier, Lieut. G. O., 89

State Cables, 42, 62, 97, 129, $139,140,144,15$ I

Strathcona, Lord, 77
Strategic Reasons for Cables, $56,59,60,88,117,134,163$

Submarine Telegraph Company, 95

Subsidies. $46,68,104,129,146$, 152

"Surprise War," 3, 9, 53, 86

Survey of Pacific Cable Route, 79

TARIFF. See Rates.

Tayler, J. W., I76 note

Taxation, Subjecting Cables to, 104

Telegraph Committee of House of Commons, 103, 117

Telegraph Committee, 1866 (Eastern Communications), 91

Telegraph Construction and Maintenance Company, 34 , 135

Telegrams, Foreign and Colonial, Table of Charges, 195

Temperature, Minimum, at Sea Bottom, 73

Thomson, Captain Anthony, 65

Tozer, Sir Horace, 77

Tupper, Sir Charles, 77,79 note

Tweeddale, Lord, 152

Type of Cable required, 19

UNIVERSAL Tariff, I 26

Urgent and Non-urgent Messages, Classification and Rates, 49, 123, 147, 16r

VAIL, Theodore, 171, 172

Vogel, Sir Julius, 76

Walpole, Sir Spencer, 78

War, Cutting Cables in, 6, 54, $66,138,165$

Webb, H. Laws, 124 note

West India and Panama Telegraph Company, Subsidies paid to, 68

Western Union Telegraph Company, 70 note, 169, 171 Wireless Telegraphy, $6_{3}, 6_{4}$, $124,138,187,188$

Wolseley, Lord, 7 



$$
-
$$


Rustrallan Rate. 3/. word.

\section{New Zealand Rate. 3/0 a werd.}

No Charge for the words "Via Pacifice"

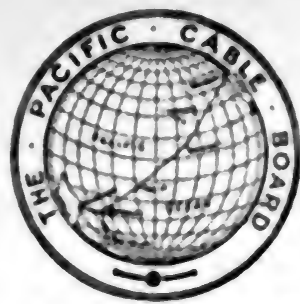

PIII Rate, 3/a word.

Norfolk Islands

Rate, 3. a word.

Panning Istands

Rate, 26 a word.

\section{IONDON OFFICE OF THE BOAKD: \\ QUEEN ANME'S CHAMBERS, WESTUINSTER.}

Telegrama "Vis Pacific" (all-flitiab) Cable will be scopped at any Pontal Telecraph

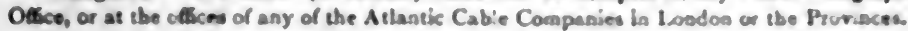

\section{LONDON OFFICES OF ATLANTIC CABLE COMPANIES:}

ANGLOAMERICAN TELEGRAPH CO. 6. Old Hroad Sirret, E.C

The Haltic, Bury Street, St. Mary Axe, i.C. $s 09$, Fenchurch Sereet, E. C.

46, Mark Lane, E.C

- Northamber land A renese, Charing Cross, W.C : 4 , Tooley Street, S. E.

\section{COMMERCIAL CABLE CO.}

a). Royal Exchange, E.C.

3. Shorter's Court, Throgmonon Stret, E.C.

14. Mark Lane, E.C. .

3. Nortbumberland Avenue, W.C.

13, Duke Street, London Bridge, S. $\dot{E}$

East India A renue, E.C.

The Baltic, St. Mary Axe, EC

Sa, Bishopagaie, E.C.

34. Victoria Street, S.W.

\section{DIRECT U.S. CABLF. CO.}

39. Mark Lane, E C

34. Throgmorton Street, E.C.

34/35. Southampton Street, Strand, W.C.

Fast India Avenue, Leadenhall Sireet, L.C.

The Baltic Mercantile and Shipping Exchange, St. Mary Axe, EC.

14m, Winchester House, Oid Broad Street, E.C.

$$
\text { P. Q. CABLE CO. }
$$

24, Royal Exchange, EC.

2, Miscing I ane, EC

5. New Bridge Street, EC

24 and as, Si Mary Axe, E. .

24. Hop Excbange, S. E. .

WESTERN UNION TELEGRAPH CO.

21, Rogal Exchange, E.C.

10. Mark Lane, EC.

The Italtic, St. Mary Axe, EC.

1. Drapers Cardens, L.C.

Fast India Avenue, k.C.

Efforgham House, Arundei Stret, w.C.

100 Fenchurch Sereet, F.C.

5. Koyal Opera Arcade, Pall Mill, S.W. .

a, Northumberland Areave, W.C.

48, Tooley Street, S. E.
TrLa monx Nicmeras. 3316 I undon Wail (a heea)

697. Central. 1050 Avenue. 1070 Arroue. 3 se lienard. Q4. Hop.

38,6 and 12,7 A venese.

1845 and 1847 A reaue.

$1+5$ Arenue.

sits liesrand.

Bj 3 liog.

346 and 347 A venue.

7436 Central.

rog London Wal

4153 Victuria.

238 A renue.

ijos I London Wiall.

iss Cierrand.

6:4 Arenue.

or London Wiall

i yos Londoe Wa!L.

645 Arenue.

46 Avenue.

sosa Central.

7315 Central.

oco7 Ceneral

3ro: I ondon Wall.

$3 r a$ london Wall

$9 \cdot 6$ Londoe Wall.

18 Ceniral.

370) Loadon Hall.

17is Cerrant.

loso Areaue.

oo7 Central

ssol Cerrard.

c. Ilop 


\section{TELEGRAMS for}

\section{Australasia, China, Japan, Africa, India,}

Spain, Portugal, the Mediterranean, and

\section{South America.}

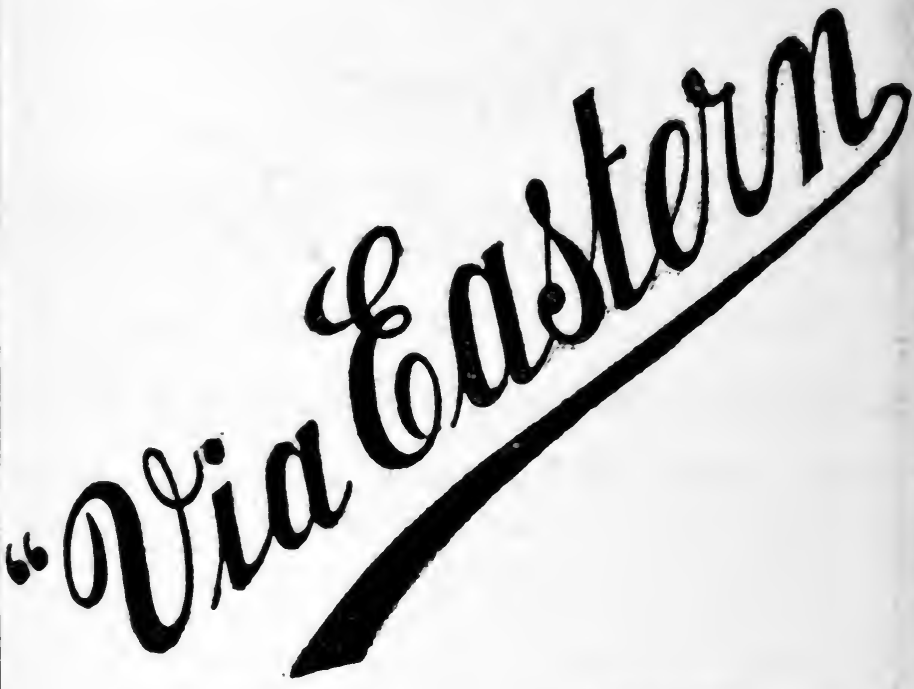

STATIONS.

Liverpool:

K23, Exchange Buildings.

The New Cotton Exchange.

Manchester:

44, Spring Gardens.

Glasgow:

5. Royal Bank Place.

Newcastle-on-Tyne:

Cardifi:

K. Exchange Buildings, Quayside.

13. Merchants' Exchange, Bute Dock.

AND FROM ALL POSTAL TELEGRAPH OFFICES.

\section{STATIONS.}

\section{LONDON :}

28. Old Broad Street, E.C.

8, Leadenhall Street, E.C.

Market Buildings, 29 , Mincing Lane, E.C. 37. Holborn Viaduct, E.C.

4. Electra House, Finsbury Pavement, E.C. The Ba tic Exchange, St. Mary Axe, E.C. 12, Parliament Street, S.W.

Foreign Auction Hall, Covent Garden, W.C. 449, West Sirand, W.C.

6. Denman Street, S.E.

Birmingham: 228 , Colmore Row. AGENCY.

Bradford: 21, Forster Square.

The Eastern Telegraph Company, Ltd. 


\section{INDO-EUROPEAN}

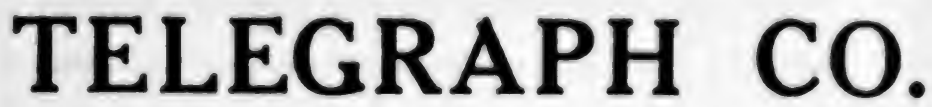

(Limited).

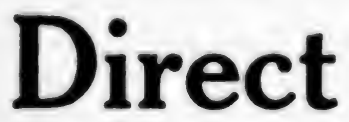

Overland Route

Connecting the UNITED KINGDOM with

South Russia, Turkey (in Europe and Asia), Persia, India (Ceylon and Burmah), and the Far East.

NO RE.TRANSMISSION between LONDON and KARACHI.

Direct Wheatstone Working over all Circuits.

Mark your Telegrams
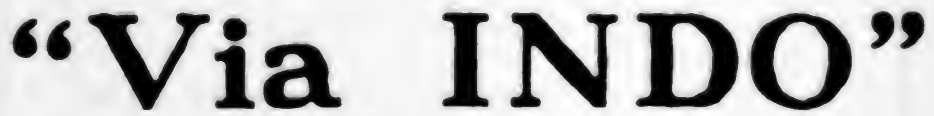

Telegrams are accepted at'the Company's Offices in LONDON, MANCHESTER and LIVERPOOL, and at all POSTAL TELEGRAPH STATIONS in the UNITED KINGDOM. 


\section{THE DIRECT UNITED STATES CABLE GOMPANY, LTD.}

\section{Direct Cable Route for Telegrams}

TO ALL PLACES IN THE

UNITED STATES OF AMERICA, CANADA, WEST INDIES, CENTRAL and SOUTH AMERICA, AUSTRALIA and NEW ZEALAND.

\section{Tapiff to many of the principal Tele- graph Stations in the United States of America and Canada \\ , to Australia and New Zealand $\mathbf{3} \mathbf{s}$. \\ 1. PER \\ 1}

For further particulars, Books of Forms, Tariffs, etc., apply at the General Offices of the Company or any of its Head Stations.

The Name of the place from which Messages originate is Transmitted Free of Charge.

Head Stations (Always Open):

LONDON-39, MARK LANE, E.C.

LIVERPOOL-D 6, EXCHANGE BUILDINGS.

NEW YORK - 60, NEW STREET.

HALIFAX (Nova Scotia)-48, BEDFORD ROW.

BOSTON (Mass.)-3I, DEVONSHIRE STREET (Devonshire Building).

Branch Stations in LONDON:

34-35, SOUTHAMPTON STREET, STRAND, W.C.

EAST INDIA AVENUE, LEADENHALL STREET, E.C.

142A, WINCHESTER HOUSE, OLD BROAD STREET, E.C.

BALTIC EXCHANGE CHAMBERS, ST. MARY AXE, E.C.

34. THROGMORTON STREET, E.C.

Provincial Stations:

BRISTOL-BACK HALL CHAMBERS, BALDWIN STREET. GLASGOW-4. WATERLOO STREET.

To save time the Public in London, Liverpool, Bristol, Glasgow and New York are recommended to hand in their Telegrams at the Company's Stations as above, where receipts are given for the amounts charged.

Telegrams for this Company's Cables handed in at Postal Telegraph Offices must be marked "Via DIRECT CABLE." This instruction is signalled Free of Charge.

General Offices: WINCHESTER HOUSE, 50, Old Broad Street, London, E.C. 


\section{THE WESTERN UNION TELEGRAPH COMPANY.}

The largest Telegraph \& Cable 8ystem in existence.

25,000 ofllee." 1,400,000 Milles of Wire.

THEO. N. VAIL, Presldent. B. BROOKS, General Manager.

Oinet Communleation to all Parts of

NORTH and SOUTH AMERICA, CENTRAL AMERICA, WEST INDIES, *

AUSTRALIA, NEW ZEALAND, \&C.

Rtlantle Cables direct to NEWPOUNDLAND, to CaNada, and to NEW YORK CITY.

DIAECT WIAES TO ALL THE PAINCIPAL CITIES.

Erelusine Conaction with she Groat Norih Wostern Tolegraph Co. of Canada.

\section{REOEIVING OFFICES:-}

London, Bradford, Glasgow, Neweastle, Liverpool, Jundee, Seith, and Bristol, Edinburgh, Manchester, Paris.

CONTINENTAL AGENCIES:-

$\begin{array}{lll}\text { Antwerp, } & \text { Madrid, } & \text { Vienna, } \\ \text { Ximsterdam, Naples, } & \text { Zurich, } \\ \text { Christiania, } & \text { Paris, } & \text { etc., etc. }\end{array}$

Every Post Offce Tolegraph Station accepts Cablegrams "VIA WESTERN UNION."

PROMPT. RELIABLE. POPULAR SERVICE. 

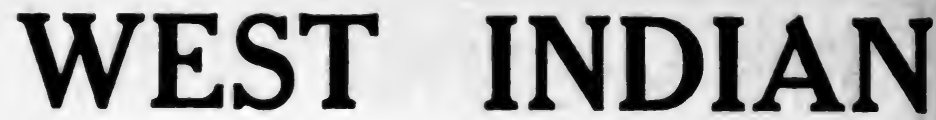

\section{CABLE SERVICE.}

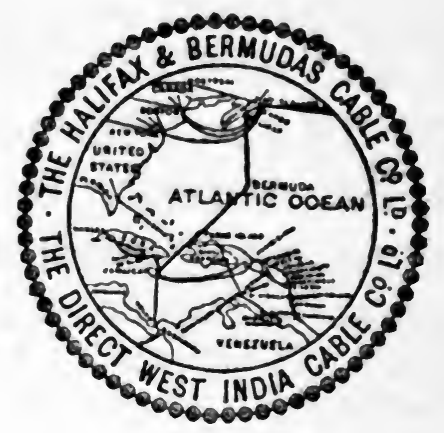

Telegrams for the West Indies should be marked with the free indication

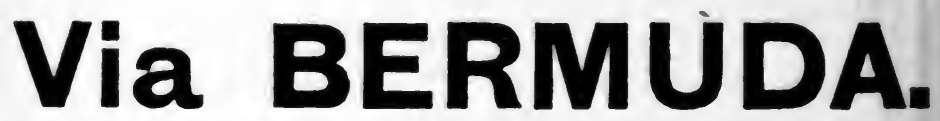




\title{
SIEMENS BROTHERS \& CO.,
}

\author{
I.2.0.
}

Caxton House, Westminster, London, S.W. Works... Woolwich and Dalston.

\section{CONTRACTORS}

for tho Mauufacture, Layiag. and Maiatenance of

\section{SUBMARINE CABLES}

of which the following is a llst of some of the more Important:-

Matino-Brazileira Telegraph Co. Brasilian Cabls ... $\quad . .81373$

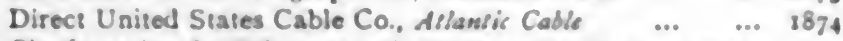

Cie. frangaiso du Telegraphe de Paris 1 New York. Ablansic

Cano

Westera Union Telegraph Co. N. Cable, Aslansic Cable ... I58:

Western Union Telegraph Co. S. Cable, Ashansis Cable _.. iss

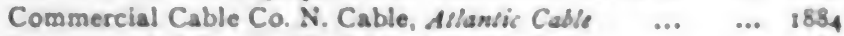

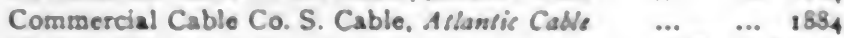

Mexican Telegraph Co., Couss Casie ... ... I8s9 and 1905

Commercial Cable Co., Ailansic Cable ... ... ... . . . IS-

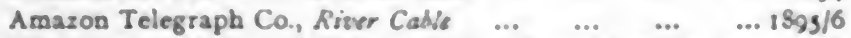

West India and Panama Telegraph Co., Inser-Island Cass ... I8gs

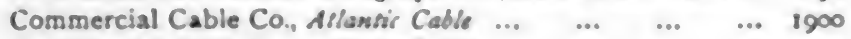

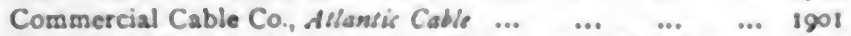

Central and S. American Tel. Co., Valpansiso so Chorilies ... 1906

Commercial Pacific Cable Co., Guam Bowis ... . ... ... 1906

Australian Commonwealih, Bass' Spraiss Cables _... ... 1909

Post Otfice Telephone Cable, Dorr.Calsis. With inductance

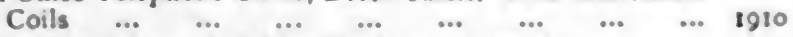

Post Otsce Telegraph Cable, Aindigcin-Arenchsl ... ... 1910

Contractors for the Erection and Maintenance of Land Telephone and Telegraph LInea.

MANUTRETURERS of, and Dealers Ia, all deacriptions of Telegraph and Telephone Rpparatus, Poles, Insulators, and all Materlals for Land Lines, Dry and Fluld Batterles, Wires and Cables, etc., etc. 


\section{HENLEY'S}

SUBMARINE

GABLES

Were first made and laid more than 55 years ago.

Q Since then many thousands of miles of these and of other types of cables have been manufactured and laid by Henley's.

Q Contracts for the supplying and laying of electric cables of any type or size undertaken in any part of the World.

W. T, Henley's Telegraph Works Co., Ltd., BLOMFIELD STREET,

Telegrams:

"Henletel," London and all Branches.
LONDON,

E.C.
Telephones: 4940 Wall ( 3 lines). 3596 Central. 


\section{W. T. GLOVER\& Co., Ltd.,}

HIGH-GRADE

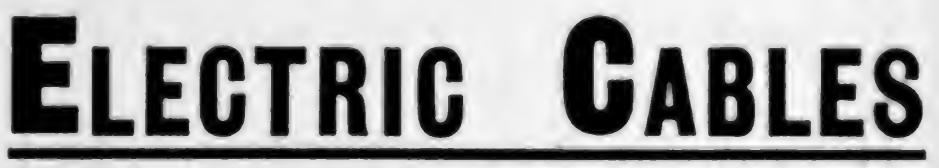

OF ALL

DESGRIPTIONS.

WORKS :

TRAFFORD PARK, MANCHESTER,

ENGLAND. 


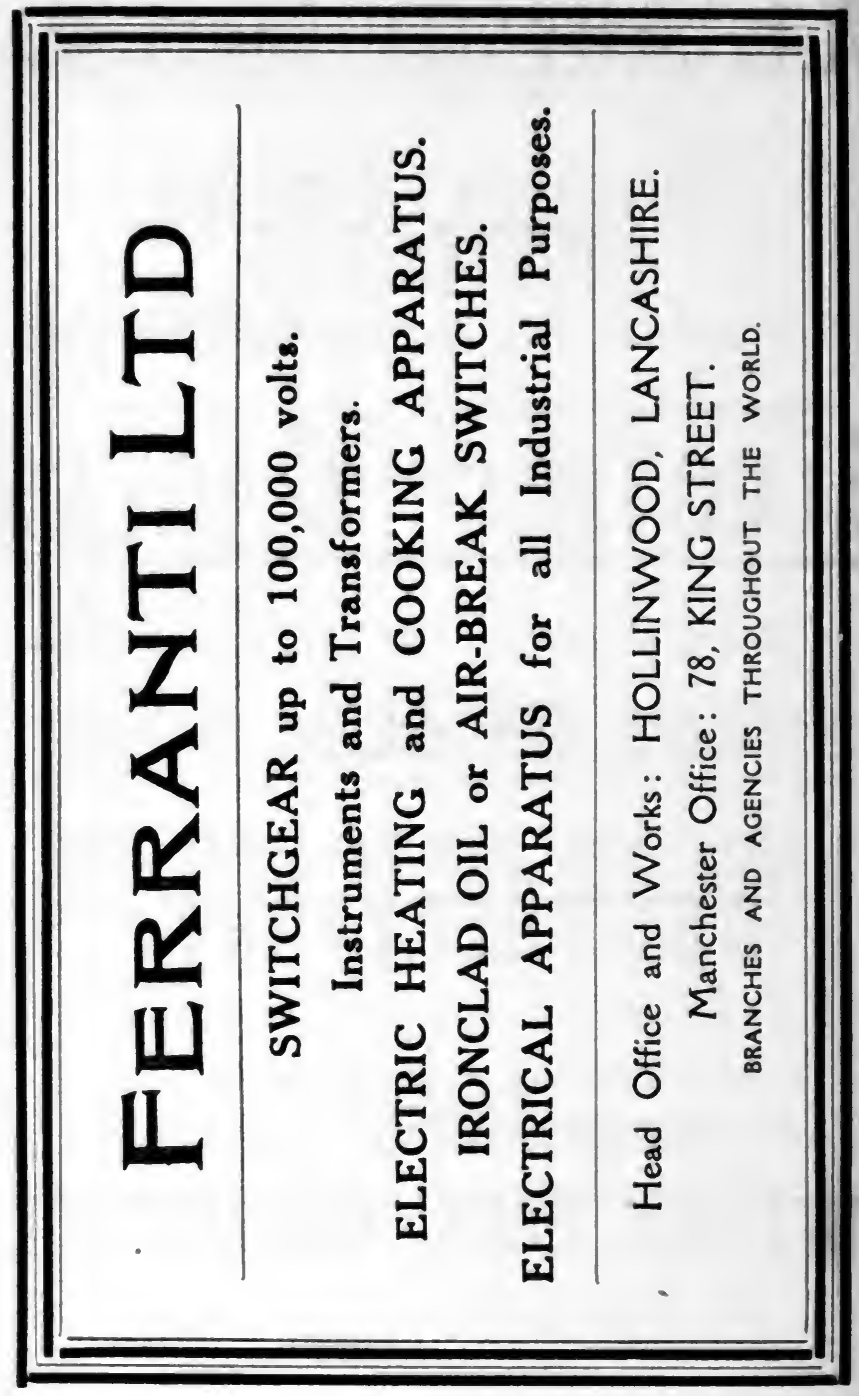




\section{The Telegraph Condenser}

\section{Company, Limited,}

Vauxhall St., Kennington Oval, London, S.E.

Telophane: MOP 1307.

Manufacturers of all Types of

\section{ELECTRICAL CONDENSERS, ARTIFICIAL}

\section{GABLE AND DUPLEX APPARATUS,}

etc., eto.

Sole Licensees for the manufacture of "DEARLOVE'S" PATENT ARTIFICIAL LINE with negligible temperature co-efficient for Duplexing Submarine Cables. 


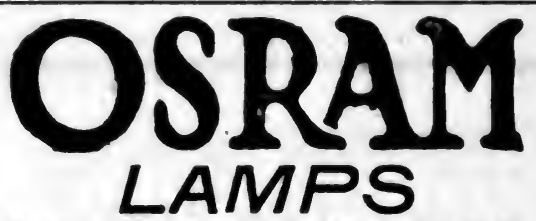

MAKE ELECTRICITY CHEAPER THAN GAS.

The UNRIVALLED ILLUMINANT for all situations. All voltages: 2 to 260 . All candlepower: I to I,000. Average life over 2,000 hours.

THE GENERAL ELECTRIC CO., LTO, Head Office: 67, Queen Victoria St., London, E.c.

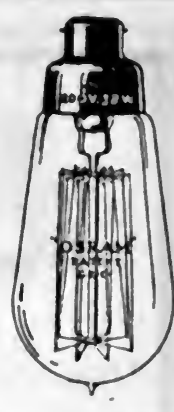

\section{G.E.G. ELEGTRIGAL PLANT and MACHINERY.}

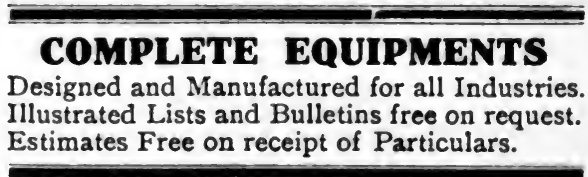

THE GENERAL ELECTRIO CO., LTD., Head Office: 67, Queen Viotorla st., London, E.Q. Engineering Works: WUitton, near Birmingham.

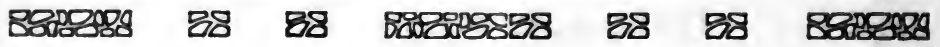
品 Peel-Conner Telephone Works, Ltd., 吠 Manufacturers and Installers of the $:$ HIGHEST GRADE OF ::

Telephone Apparatus. Battery system and subscribers' Instruments.

Df Head Office and Works: PEEL WORK8. ADELPHI, BALFORD, LANC8. LONdON OffCE: MIDLAND BANK CHAMBERB, QUERN VICTORIA ET., E.C. 


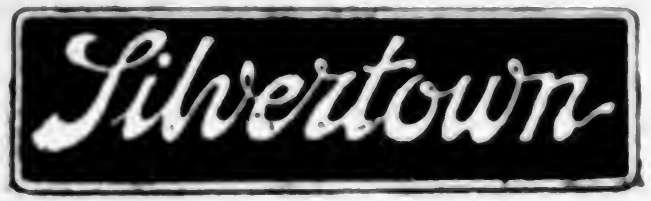

\section{CABLES :}

Electric Light, Telegraph,

Telephone, Submarine.

\section{DYNAMOS :}

Compound Wound, Strunt or Series for Eloctric Light and Power.

\section{INSTRUMENTS :}

For Telegraph and Testing purposes.

\section{WIRES :}

Insulated Iadia Rubber or Gutta Percha. Cotton and Silk Covered.

\section{MOTORS :}

Belt or Direct Drive for all classes of service.

\section{BATTERIES :}

1 All classes of Leelancbe. Dasiell's, Bunsen, etc.

\section{INSULATORS \\ of every description: \\ Porcelaia, Ebonite, etc.}

\section{PRICE LISTS ON APPLICATION.}

The India Rubber, Gutta Percha and Telegraph Works Co., Ltd. HeAs ORnCE:

106. CANNON STREET, LONDON. E.C.

\section{Wors:}

SILVERTOWN, LONDON. E.

\section{BRANCHES :}

HOXE - Belfast, Birmiagham, Bradford, Bristol, Cardit. Dublin, Glasgow, Liverpool, Manchester, Newcastle-oa.

Tyrac, Portsmouth, Shet5eld.

ABROAD-Adelaide, Brisbane, Buenos Ayres, Bulawayo, Calcutta, Christchurch (N.Z.). Durban, Jobanzesburg. Melbourne, Pertb (W.A.), Sydney. 


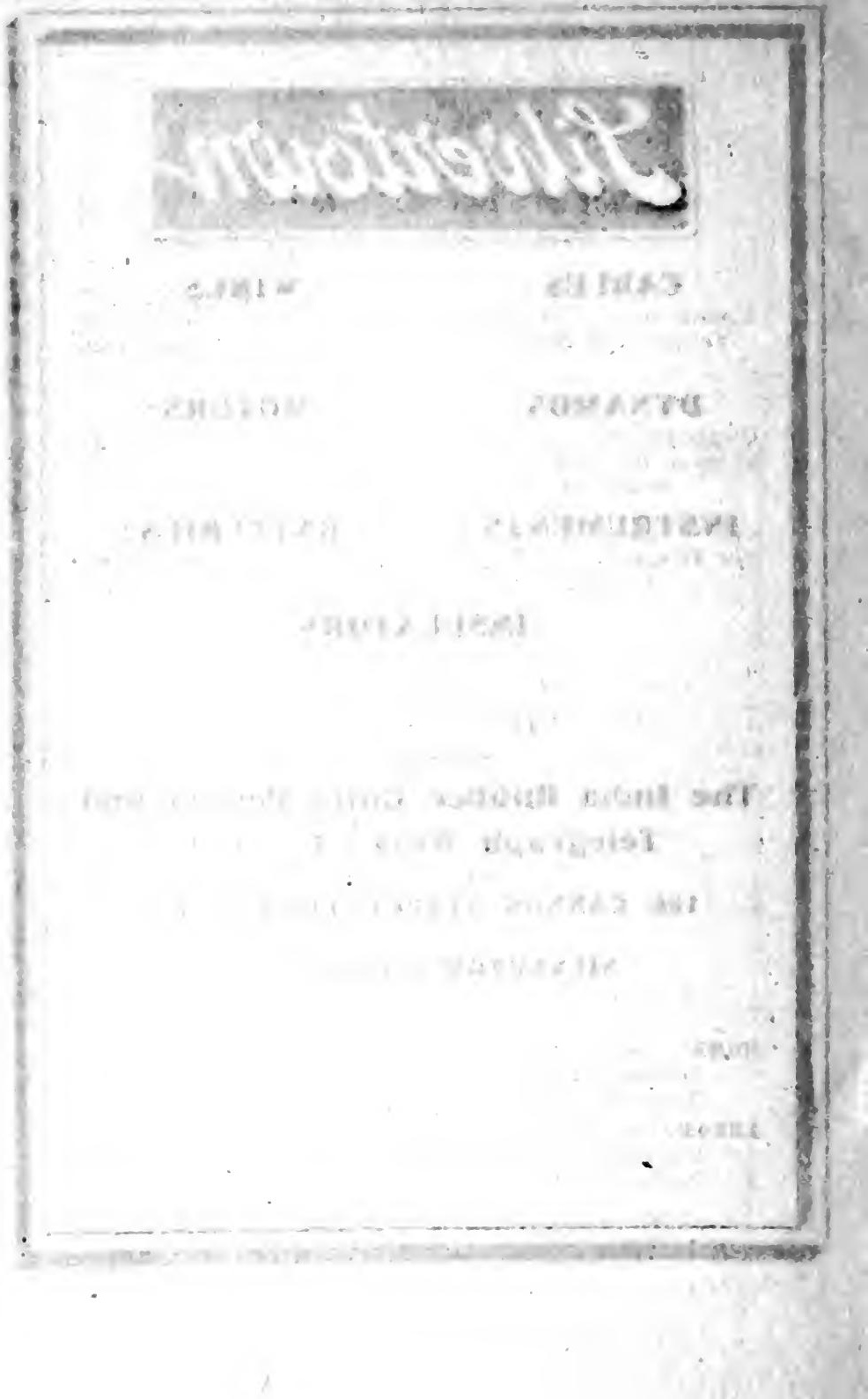



3 


\section{PLEASE DO nOt Remove CAROS OA ELPS FROM THIS POCKET \\ UNIVERSITY OF TOAONTO LIBRARY}




\section{4}

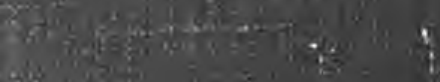

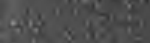

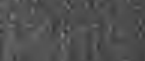

d.

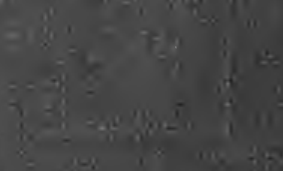

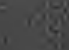

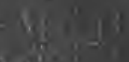

3.

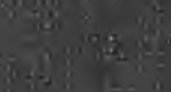

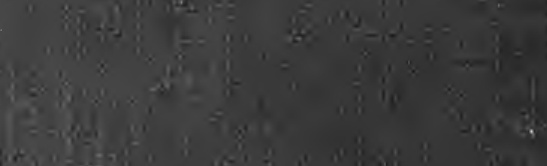

Mand

40

$4 \operatorname{lin}^{2}=3$

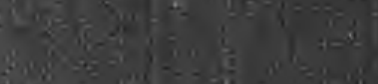

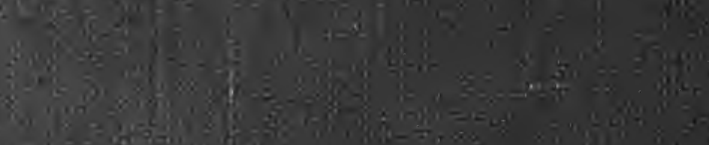

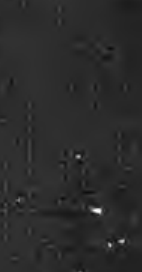

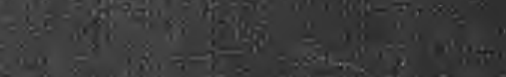

(15. 34

ind

$\therefore$

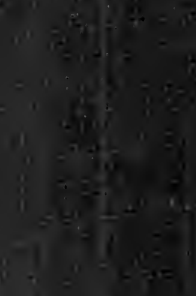

(2)

(2)

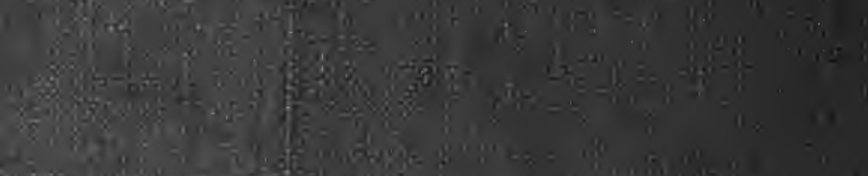

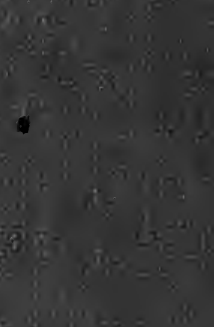

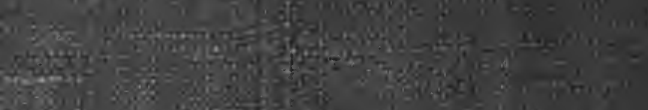

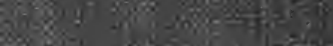

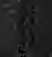

